\title{
NOTICE SUR LES TRAVAUX SCIENTIFIQUES
}

présentés par M. Charles JANET

à l'Académie des Sciences

AU CONCOURS DE 1896 POUR LE PRIX THORE 



\section{NOTICE}

SUR

\section{LES TRAVAUX SCIENTIFIQUES}

PRÉSENTÉS

PAR

M. CHARLES JANET

à l'Académie des Sciences

$\Delta \mathrm{U}$

CONCOURS DE 1896 POUR LE PRIX THORE 



\title{
LISTE DES TRAVAUX SCIENTIFIQUES
}

\author{
Publiés par M. Charles JANET.
}

1. Le Tunnel sons-marin du Pas-de-Calais. Société Académique de l'Oise. Beauvais. I 882.

2. Excursions géologiques aux environs de Beaupais. Mém. Soc. Acad. Oise. Beauvais. I883 (en collaboration avec M. J. Bergeron).

3. Note sur un Echinocorys présentant neuf pores génitaux.

Bull. Soc. Géol. de France. S 3. T 18. p r58. Paris. I 890 .

4. Note sur les Orifices génitaux multiples, sur l'Extension des Pores madréporiques hors du Madréporite et sur la Terminologie de l'Appareil apical chez les Oursins. Bull. Soc. Géol. de France. S 3. T 19. p 295. Paris. I89I (en collaboration avec M. Cuénot).

5. Note sur trois nouvelles Bélemnites sénoniennes. Bull. Soc.

Géol. de France. S 3. T I9. p 7 I6. Paris. I89ז.

6. Note sur les Conditions dans lesquelles s'est effectué le dépôt de la Craie dans le Bassin Anglo-Parisien. Bull. Soc. Géol. de France. S 3. T I9. p 9o3. Paris. I89I.

7. Thermo-régulateur de construction très simplifiée pour

les Etuves à température constante. Bull. Soc. Zool. de France. T 18. p 83. Paris. 1893.

8. Etudes sur les Fourmis. Note $\boldsymbol{x}$. Sur la production des 
Sons chez les Fourmis. Ann. Soc. Ent. de France. T 62. p i59. Paris. 1893 .

9. Etudes sur les Fourmis. Note 2. Appareil pour l'élesage et l'obsercation des Fourmis. Ann. Soc. Ent. de France. T 62. p 467. Paris. 1893.

10. Etudes sur les Fourmis. Note 3. Nids artificiels en platre. Bull. Soc. Zool. de France. T i8. p i68. Paris. 1893.

11. Sur les Nématodes des glandes pharyngiennes des Fourmis (Pelodera sp.). Comptes rendus hebd. des séances de l'Acad. des Sciences. T I17. p joo. Paris. 1893.

12. Etudes sur les Fourmis. Note 4. Pelodera des glandes pharyngiennes de Formica rufa. Mém. Soc. Zool. de France. T 7. p 45. Paris. 1894.

13. Etudes sur les Fourmis. Note 5. Sur la Morphologie du squelette des segments post-thoraciques. Mém. Soc. Acad. de l'Oise. T r5. p 59r. Beauvais. 1894.

14. Etudes sur les Fourmis. Note 6. Sur l'appareil de Stridulation de Myrmica rubra. Ann. Soc. Ent. de France. T 63. p iog. Paris. 1894.

15. Sur les Nerfs de l'Antenne et les Organes chordotonaux chez les Fourmis. Comptes rendus hebd. des séances de l'Acad. des Sciences. T II8. p 8I4. Paris. 1894 .

16. Transformation artificielle en Gypse du Calcaire friable des fossiles des Sables de Bracheux. Comptes rendus de la Soc. Géol. de France. S 3. T 22. p 83. Paris. I894.

17. Etudes sur les Fourmis. Note 7. Sur l'Anatomie du Pétiole de Myrmica rubra. Mém. de la Soc. Zool. de France. T 7. p 185. Paris. 1894.

18. Sur le système glandulaire des Fourmis. Comptes rendus 
hebd. des séances de l’Acad. des Sciences. T r r8. p 989 . Paris. I894.

19. Etudes sur les Fourmis. Note 8. Sur l'Organe de nettoyage tibio-tarsien de Mrmica rubra. Ann. Soc. Entom. de France. T 63. p 693: Paris. I895.

20. Etudes sur les Fourmis, les Guêpes et les Abeilles. Note 9. Sur Vespa crabro. Histoire d'un Nid depuis son origine. Mém. Soc. Zool. de France. T 8. p I. Paris. 1895.

21. Sur les Nids de la Vespa crabro; Ordre d'apparition des alvéoles. Comptes rendus hebdom. des séances de l'Acad. des Sciences. T ir9. p 1282. Paris. 1894.

22. Etudes sur les Fourmis, les Guêpes et les Abeilles. Note I o. Sur Vespa media, V. silvestris et V. saxonica. Mém. Soc. Acad. de l'Oise. T I6. p 28. Beauvais. 1895 .

23. Sur la Vespa crabro. Ponte. Conservation de la chaleur dans le nid. Comptes rendus hebd. des séances de l'Acad, des Sciences. T 120. p 384. Paris. I895.

24. Etudes sur les Fourmis, les Guêpes et les Abeilles Note II. Sur Vespa germanica et $V$. oulgaris. Limoges. I 895 .

25. Observations sur les Frelons. Comptes rendus hebd. des séances de l'Acad. des Sciences. T i20. p 940. Paris. I 895.

26. Sur les Muscles des Fourmis, des Guêpes et des Abeilles. Comptes rendus hebdom. des séances de l'Acad. des Sciences. T г2 I. p 6ro. Paris. 1895.

27. Etudes sur les Fourmis, les Guêpes et les Abeilles. Note I 2. Structure des Membranes articulaires, des Tendons et des Muscles (Mrrmica, Camponotus, Vespa, Apis). Limoges. 1895 . 
28. Les Fourmis. Conférence faite le 28 féorier 1896 , ̀̀ l'occasion de la Réunion générale annuelle de la Société Zoologique de France. Mém. Soc. Zool. de France. T 2r. p 6o. Paris. 1896.

29. Sur les Rapports des Lépismides myrmécophiles avec les Fourmis. Comptes rendus hebdom. des séances de l'Acad. des Sciences. T ז22. p 799. Paris. I896.

30. Sur le Lepismina polypoda et sur ses rapports avec les Fourmis. Bull. Soc. Ent. de France. T 65. p r3r. Paris. 1896.

31. Sur les Fillets arqués des Antennes des Xylodiplosis (Diptères). Bull. Soc. Ent. de France. T 65. p 183. Paris. 1896 .

32. Remarque relative à l'emploi de la classification décimale. Bull. Soc. Zool. de France. T 21. p r93. Paris. 1896. 


\section{Le Tunnel sous-marin du Pas-de-Calais.}

2

Excursions géologiques aux environs de Beauvais.

Cette Note, écrite en collaboration avec M. J. Bergeron, donne la description géologique des Environs de Beauvais, étudiés dans une excursion de quatre jours, faite sous la direction de M. Munier-Chalmas.

3

Note sur un Echinocorys carinatus présentant neuf pores génitaux.

La multiplicité des pores génitaux, chez des individus anormaux du genre Echinocorys de la Craie, ayant été mise en doute parce que les orifices supplémentaires ne sont, le plus souvent, que des perforations faites par des Spongiaires du groupe des Cliona, j'ai décrit un échantillon qui, par son état de conservation tout à fait exceptionnel et par la netteté de ses pores supplémentaires, m'a permis de démontrer qu'il peut réellement y* avoir plusieurs pores génitaux parfaitement nets et distincts sur chaque plaque génitale.

La figure qui, dans ce travail, représente cette monstruosité, 
étant un peu trop petite, je donne, ci-dessous, une figure agrandie faite d'après une photographie.

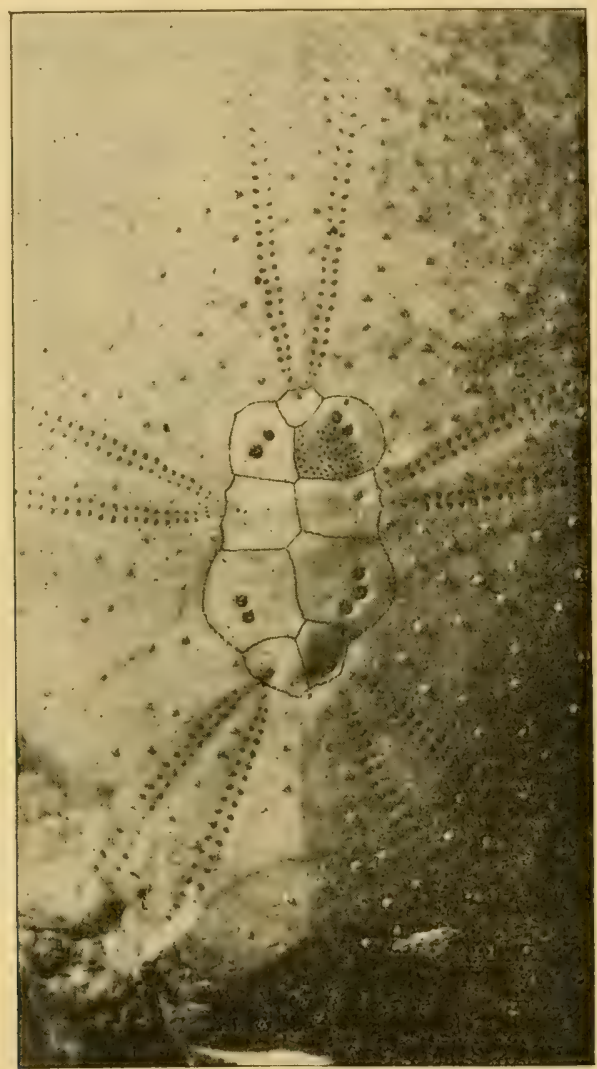

Fig. 1. - Echinocorys çrinatus Desol. Appareil apical présentant neuf pores génitaux.

\section{4}

Note sur les Orifices génitaux multiples, sur l'extension des Pores madréporiques hors du Madréporite et sur la Terminologie de l'Appareil apical chez les Oursins.

Cette Note, publiée en collaboration avec M. Cuénot, fait 


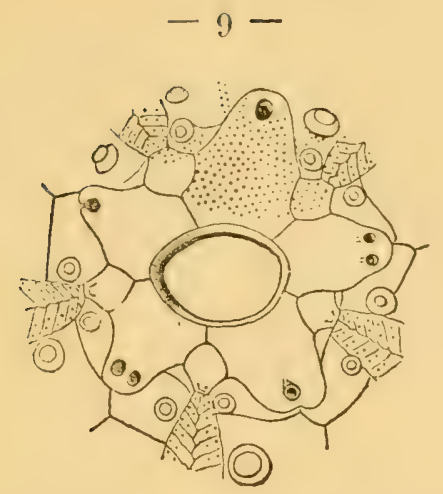

Fig. 2. - Arbacir punctulata Des Moulins (Collection Ch. Jinet). Exemplaire présentant denx hasales avec prores génitaux doubles. Les pores madréporigues se trouvent non seulement sur le Ihadréporite, mais eacore sur les deux ocellaires vols'nes el sur sept plaques de linterradius correspondant. Appareil apical va par la face externe.

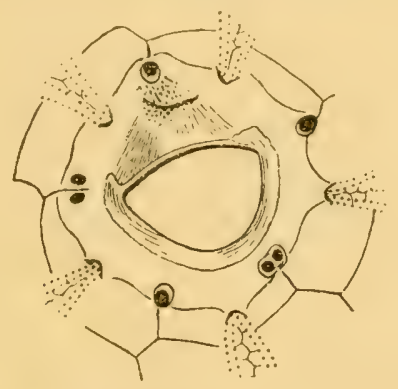

Fig. 3. - Méme individu. Appareil apical vu par la face interne.

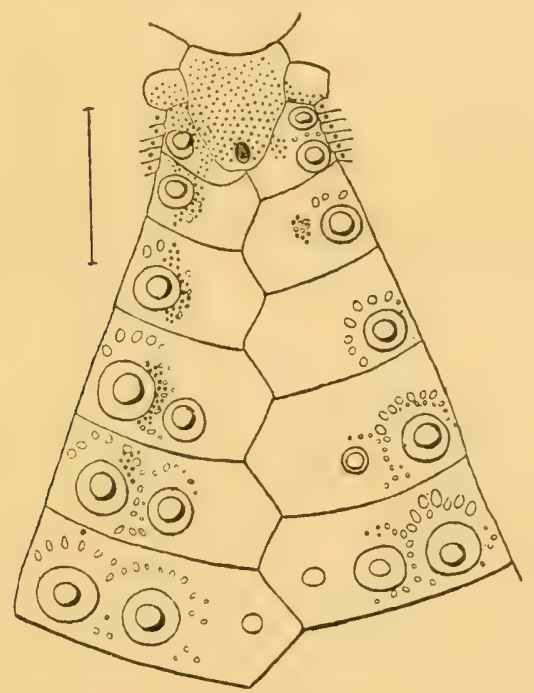

Fig. 4. - Mème individu. Madréporite et Interradius correspondant, montrant l'extension des pores madréporiques. 
connaitre de nouveaux exemples de pores génitaux multiples. Nous y avons décrit le cas, très remarquable, d'un Arbacia qui présente, non-seulement deux plaques basales avec pores génitaux doubles, mais, de plus, des pores madréporiques s'étendant hors du Madréporite.

Trois autres exemples sont fournis par des Cidaris de la Craie.
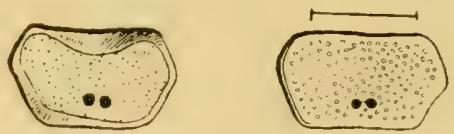

Fig. 3. - Cidaris peronata Forlıes (Collection Ch. Janet). Basale présentant denx pores génitaux. A droite, face externe; at grauche, face interne. Les pores génitaux restent nettement séparés surr la face interne.

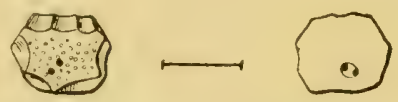

Fig. 6. - Cidaris sceptrifera Mantell (Collection Ch. Janet). Basale présentant deux pores génitaux disposés obliquement par rapport à l'axe de la pièce. A gauche, face externe; à droile, face interne. Sur la lace interne les pores génitaux se trouvent au fond d'une fossette commune.
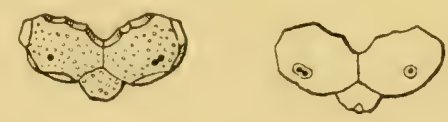

Fig 7. - Cidaris sceptrifera Mantell (Collection Ch. Janet). Basale présentant deux pores génitanx presque fusionnés en un pore bilobé La basale voisine présente un pore simple normal. A gauche, face externe; à droite, face interne. Sur la face interne, le pore bilobé et le pore simple débouchent, chacun, dans une fossette.

Enfin, cette note donne le schéma auquel nous rapportons la composition de l'appareil apical des jeunes Echinodermes.

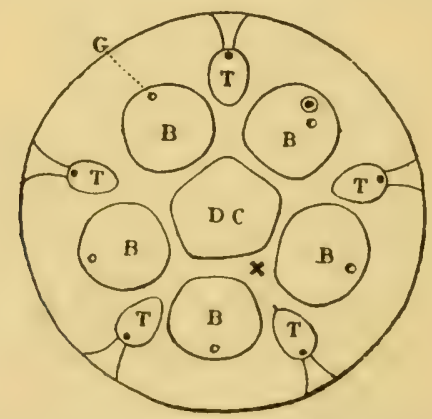

Fig. 8. - Schéma de l'appareil apical chez un jeune Oursin. 


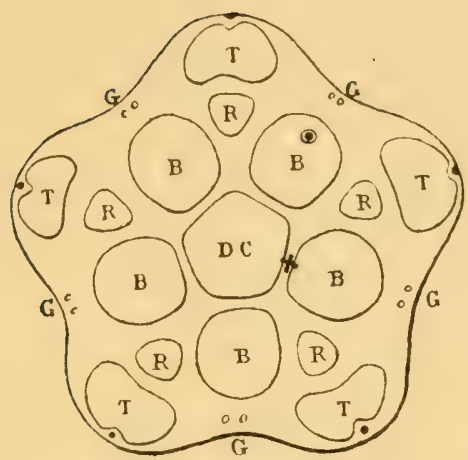

Fig. 9. - Schéma de l'appareil apical chez une jeune Astérie.

Dans les deux dernières figures : $D C$, dorso-centrale; $R$, radiales; $B$, basales (génitales des Oursins); $T$, terminales (ocellaires des Oursins); +, place ou se perforera plus tard l'anus ; on a figuré, sur la basale située en baut à droite, le pore madréporique, unique à ce stade; les tentacules terminaux sont représentés, schématiquement, par de petits points noirs, en rapport avec les plaques terminales; les orifices geenitaux $G$, bien qu'ils n'existent pas aux stades représentés, ont été mis pour faciliter les comparaisons, à ła place qu'ils occuperont plus tard.

\section{5}

\section{Note sur trois nouvelles Bélemnites sénoniennes.}

Je décris dans cette Note trois nouvelles espèces qui sont les

$$
\begin{aligned}
& \text { Actinocamax Grossouorei, } \\
& \text { Actinocamax Toucasi, } \\
& \text { Actinocamax Alfridi. }
\end{aligned}
$$

L'Actinocamax Grossouvrei ayant été trouvée à la fois dans la Craie de Beauvais et dans le Crétacé du Midi de la France, a contribué à faire synchroniser les époques de formation de couches de ces régions éloignées l'une de l'autre.

\section{6}

Note sur les conditions dans lesquelles s'est effectué le dépôt de la Craie dans le Bassin Anglo-Parisien.

Dans cette Note, je confirme, en citant des échantillons 
que j'ai recueillis, moi-même, en place, la présence de galets dans les parties de la Craie qui se sont déposées loin des rivages; mais je cherche à démontrer que, malgré la présence de ces galets, le dépôt de la Craie s'est fait, en général, dans une mer calme. Je montre, par des observations faites sur les animaux vivants, que les poissons ont pu jouer un rôle important dans la trituration et la dissémination des débris que nous retrouvons à l'état de fossile, débris qui, dans ce cas particulier, n'indiquent ni des courants rapides, ni le voisinage de rivages. Je donne, enfin, le résultat de mes observations sur les cordons de silex, sur les bancslimites que j'ai en l'occasion d'étudier dans les falaises des environs de Dieppe et sur le niveau géologique auquel appartiennent les couches de craie les plus élevées des falaises de cette région (Zone à Marsupites).

\section{7}

\section{Thermo-régulateur de construction très simplifiée pour les étuves à température constante.}

Je décris dans cette Note le Régulateur extrêmement simple que j’ai construit pour remplacer les régulateur's coûteux, compliqués et parfois très défectueux que j'employais, précédemment, pour régler la température des étuves servant à l'enrobage, dans la paraffine, des animaux, et en particulier des Insectes, destinés à être étudiés par la méthode des coupes. La pénétration de la parafline, à travers la cuticule chitineuse, est très lente, et l'opération, pour réussir, doit durer longtemps.

Les régulateurs que l'on emploie généralement dans ce but sont très fragiles et trop compliqués pour pouvoir être. en eas d'accident, réparés ou remplacés par les personnes 
qui n'ont pas une grande habitude du travail du verre. Le dispositif que j'ai combiné est tellement simple, que tout le monde peut, sans difliculté, le réaliser en quelques instants.

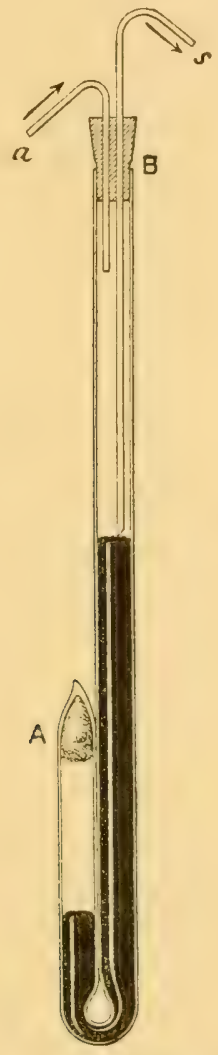

Fig. 10. - Thermo-régulateur de construction très simple pour les étuves à température constante.

Quant à son fonctionnement, il est tout à fait irréprochable. Je l'emploie, depuis plusieurs années, sans qu'il ait donné la moindre irrégularité. Dès que l'étuve est mise en marche, elle arrive, et reste invariablement, jour et nuit, pendant des semaines entières, à la température que j’ai adoptée pour mes inclusions d'Insectes. Il est à peu près insensible aux grandes variations de pression du gaz d'éclairage qui alimente 
mon laboratoire. Cet appareil simplifié est également très commode pour régler la température des étuves employées pour les recherches de bactériologie.

\section{8}

\section{Etudes sur les Fourmis. Note 1. Sur la Production des Sons chez les Fourmis et sur les Organes qui les produisent.}

Méthode permettant de prosoquer et de percevoir la stridulation chez les Fourmis. Malgré un certain nombre d'observations isolées, le fait de la production de sons chez les Fourmis était resté, jusqu'ici, problématique. Je montre que la production de sons par stridulation peut être observée, au moyen d'une expérience très simple, chez les Myrmicides de nos pays (M)rmica rubra L. Tetramorium cespitum L.

Surfaces rugueuses. De nombreuses surfaces rugueuses existent sur la cuticule chitineuse aux points où deux parties sont susceptibles de frotter l'une contre l'autre. Une de ces surfaces rugueuses constitue précisément l'appareil stridulateur.

Rugosités produisant l'effet d'un frein dans les articulalions. Aux articulations des rugosités très accentuées jouent un rôle mécanique particulier. Il suffit à la Fourmi (Myrmica), au moyen d'un effort musculaire modéré, de rapprocher, jusqu'au contact, deux parties munies de surfaces rugueuses pour obtenir, comme par l'eflet d'un frein denté, l'immobilisation des parties correspondantes. De plus, ces rugosités jouent un rỏle protecteur pour l'articulation qui constitue toujours un point de moindre résistance.

Lamelles couchées de la surface des rainures et des neroures de gruidage de l'aiguillon. Des saillies beaucoup plus fines et beancoup plus délicates de la cuticule chitineuse peuvent avoir un effet bien différent. En examinant, à un très fort grossis- 
sement, chez Myrmica levinodis, la surface des rainures des stylets et celle des nervures de guidage du gorgeret, on voit, sur toutes deux, de très petites crètes assez espacées, et fortement couchées du côté de la pointe de l'aiguillon. Ces crêtes, très minces, toutes couchées dans le même sens, ne gènent pas le glissement. Au contraire, elles forment, entre les deux parties de chaque coulisseau, un calage léger et élastique qui maintient un faible écartement et rend toute lubréfication inutile. Les glandes auxquelles on a attribué le ròle d'organes lubrélicateurs ont certainement une autre fonction dont il sera question plus loin.

\section{9}

Etudes sur les Fourmis. Note 2. Appareil pour l'Elevage et l'Observation des Fourmis et d'autres petits animaux qui vivent cachés et qui ont besoin d'une atmosphère humide.

L'appareil (nid artificiel horizontal en substance minérale poreuse) décrit dans cette Note, donne, au point de vue de l'élevage des Fourmis, des résultats tout à fait remarquables. Les Fourmis meurent rapidement lorsqu'on les place dans des récipients où l'on n'entretient pas un degré sullisant d'humidité; mais, et e'est là le point délicat, cette humidité doit être maintenue entre des limites déterminées. Les appareils qui ont été imnaginés jusqu'ici ne résolvent pas cette difliculté. De plus, ils ne se prêtent pas, commodément, à l'observation et ne permettent pas de prélever, facilement, les échantillons dont on peut avoir besoin.

Le nid artificiel est formé d'un bloc de plàtre ou autre substance poreuse, creusé d'un certain nombre de chambres placées les unes à la suite des autres et communiquant entre elles. Ces chambres sont recouvertes d'un plafond en verre, recouvert, lui-même, d'une plaque opaque destinée à maintenir 
l'obscurité dans l'intervalle des observations. Une cuve à eau, placée à l'extrémité du bloc, permet de l'imbiber d'eau. La chambre la plus rapprochée de cette cuve est la plus humide. La chambre la plus éloignée est la plus sèche. Je laisse cette
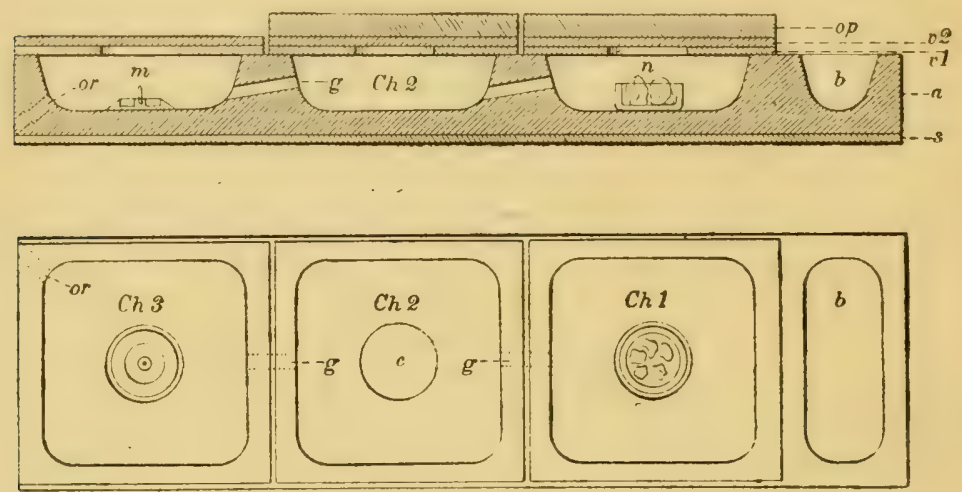

Fïg. 11. - . Ibri ì 3 chambres, en substance poreuse, disposé pour l'élevage des fourmis.

En haut, coupe longitudinale verticale.

En bas, vue en plan. Dans cette figure, les plaques opaques op de la figure 1 sont supposées enlevées et l'abri simplement recouvert de ses plaques de verre.

$a$, Abri poreux, à trois chambres ; $b$, Cuve ả eau, que l'on remplit une ou deux fois par semaine ; L'eau, s'imbibant dans la substance poreuse qui constitue l'abri, y produit une humidité graduée qui va en diminuant vers le côté opposé à la cuve ì eau; Ch. 1, Chambre d'habitation obscure et très humide; $C \%$. 2, Chambre d'halitation obscure et lécérement humide; Ch. 3, Chambre éclairée et sèche, représentant, pour les Fourmis, le monde extérieur au nid ; $g$, Galerie de communication permettant le passage d'une chambre ì l'autre; $v \ell$, Plaques de verre carrées, formant le plafond des chambres. Chacune de ces plaques est percée en son centre d'une ouverture circulaire $c$ qui permet de prendre des échantillons et qui doit ètre assez grande pour que l'on puisse y faire passer les récipients qui servent de mangeoire et d'abreuroir et tout ce qui est utile aux expériences; $v 2$, Plaques de verre carrées semblahles aux précédentes, mais sans ouvertures. Elles servent ì empècher les Fourmis de sortir pendant quion les observe ; $0 p$, Placque opaque servant à maintenir l'olscurité dans les denx chambres bumiles, $C h$. I et $C h$. \&, qui servent dhabitation aux Fourmis; $m$, Petit récipient placé dans la chambre éclairée et sèche et servant de mangeoire. On peut y mettre du miel, du sucre, du jaune d'ieuf, des Insectes, etc. Certaines espèces de fourmis ont l'habitude d'apporter dans ce petit récipient tous les détritus dont elles veulent se débarrasser, et qui se tronvent ainsi enlevés charue lous que lon change. lit mangeoire. Il en résulte qute l'abri reste parfaitement propre, mème au bout de plusieurs années; $n$, Petit récipient placé dans la chambre la plus bumide et servant d'abreuvoir. Ce petit récipient contient une éponge mouillée; or, Oritice provisoire permeltant aux Fournis d'entrer dans labri lorsqu'elles s'y installent. Lor'sque l'emménagement est terminé, on bouche définitivement cet orifice avec du plître; $s$, Plaçue de verre placee sous l'abri pour empécher lhumidité de comnuniquer à la table sur laquelle il repose.

dernière toujour's éclairée en sorte qu'elle représente, pour l'élevage mis en olsservation, un espace extérieur au nid. Si la cuve à cau a été trop fortement mouillée, les Fourmis vont dans les chambres les plus éloignées, c’est-ì-dire les plus sèches. 
Lorsque, au contraire, l'appareil tend à se dessécher, les Fourmis reviennent contre les parois de la chambre à eau qui est toujours plus humide que "le reste du nid. Elles penvent ainsi choisir, elles-mèmes, la partie du nid présentant le degré d'humidité qui leur convient le mieux.

Pour faire emménager les Fourmis dans ces nids, je les place, après y avoir pratiqué un petit orifice, au milieu d'une caisse entourée d'une paroi très inclinée de plâtre pulvérulent que les Fourmis ne peuvent franchir. C'est une légère modification du dispositif imaginé par Forel et appelé, par cet auteur, " Arène de gypse \#. Les Fourmis ainsi emprisonnées ne tardent pas à emménager dans l'appareil avec leur progéniture et leurs myrmécophiles.

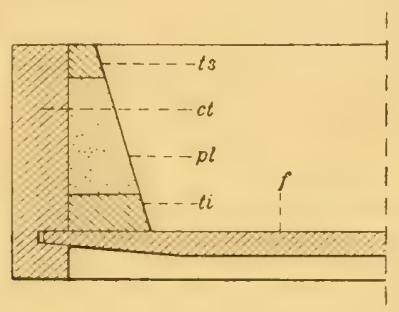

Fig. 12. - Coupe transversale de l'un des quatre cỏtès de la caisse en bois destinée à emprisonner les fourmis que l'on veut faire emménager dans un nid arlificiel. La caisse présente exactement la mène disposition sur ses quatre còtés; $c t$, còté de la caisse; $f$, fond de la crisse établi à dlilatation libre pour parer au gonflement résultant de l'humidité de la terre que l'on clémse à sa surface; $p l$, platre en poulre fine, légèrement lassé, formant une pente très ritide, infirunchissalilc pour les Fourmis: $t s$, tasseau supérieur servant a uroterger le plitre lorsquion sapouie sur les bords de la caisse; $t i$, tasseau inférieur soutenant le platre a une certaine hauteur au-dessus du fond, pour que les Fourmis ne se blanchissent pas trop a son contact et pour empècher certaines especes, telles que le Tetramorium cespitum, de creuser des galeries.

Parmi les nombreux exemples que je puis donner, pour montrer à quel point les Fourmis se plaisent dans ces nids artificiels, je citerai le suivant:

Une forte colonie de Lasius flasus accompagnés de Claviger testaceus, installée dans un de mes nids artificiels en substance poreuse, est, au bout de deux ans, en parfait état dans mon laboratoire. Les Claviger y sont encore nombreux. Les cham- 
bres d'habitation de ce nid sont entreteniues, par les Fourmis, dans un état de propreté remarquable. Sauf les petits grains de terre qui servent à recouvrir chacpue larve au moment où elle commence à tisser son cocon, et qui sont enlevés lorsqu'ils sont devenus inutiles, on ne voit, dans ces chambres, aucun débris ni aucune trace de moisissure. Tout ce qui peut nuire à la propreté des chambres d'habitation (excréments, exuvies, cocons vides, r'estes des Insectes dévorés, cadavres de Fourmis) est soigneusement transporté dans la chambre sèche et éclairée, et même le plus souvent, dans l'intérieur de la mangeoire qui est placée dans cette chambre.

Ces abris peuvent aussi être employés avantageusement pour l'élevage d'autres animaux. J'en possède un qui contient des Lépismides (Lepismina polypoda) depuis 20 mois et un autre qui contient des Myriapodes (Blaniulus guttulatus) depuis I2 mois.

\section{0}

\section{Etudes sur les Fourmis. Note 3. Nids artificiels en plâtre. Fondation d'une colonie par une femelle isolée.}

Cette Note donne quelques observations faites dans mes nids artificiels.

Une expérience de Lubbock sur la Myrmica ruginodis démontre qu'une reine f'écondée, isolée après le vol nuptial, suffit, à elle seule, pour fonder une nouvelle colonie.

Je rapporte dans cette $3^{c}$ Note une expérience un peu diflérente.

J'ai isolé une reine de Lasius alienus, non pas immédiate. ment après le vol nuptial, mais bien plus tard, à une époque où elle était déjà entourée d'un grand nombre d'ouvièeres. 
Cette reine a de nouveau fondé une colonie et a su, toute seule, subvenir à ses premiers besoins. Cette expérience montre que, contrairement à l'opinion d'après laquelle les reines des Fourmis seraient peu aptes au travail, elles peuvent encore exécuter tous les travaux nécessaires à leur entretien et à celui de leur progéniture, même longtemps après que, une première fois, elles ont fondé une colonie.

Des Formica rufa installées depuis 23 mois dans un nid artificiel présentant un orifice laissé ouvert en permanence, et dont, par conséquent, elles peuvent sortir comme bon leur semble, ne l'ont pas abandonné. Cela montre à quel point les Fourmis trouvent, dans mes appareils d'élevage, des conditions qui leur conviennent.

\section{Sur les Nématodes des glandes pharyngiennes des Fourmis (Pelodera sp.).}

\section{2}

\section{Etudes sur les Fourmis. Note 4.}

\section{Pelodora des glandes pharyngiennes de Formica rufa.}

J'ai découvert, dans la tête de certaines Fourmis (Formica, Lasius), des Nématodes (Pelodera Janeti Lacaze-Duthiers) qui viennent $y$ faire, à l'état larvaire, un séjour assez prolongé.

De chaque côté du pharynx des Fourmis se trouve une grosse glande tubuleuse dont la forme est comparable à celle d'un gant qui serait pourvu d'un très grand nombre de doigts. 


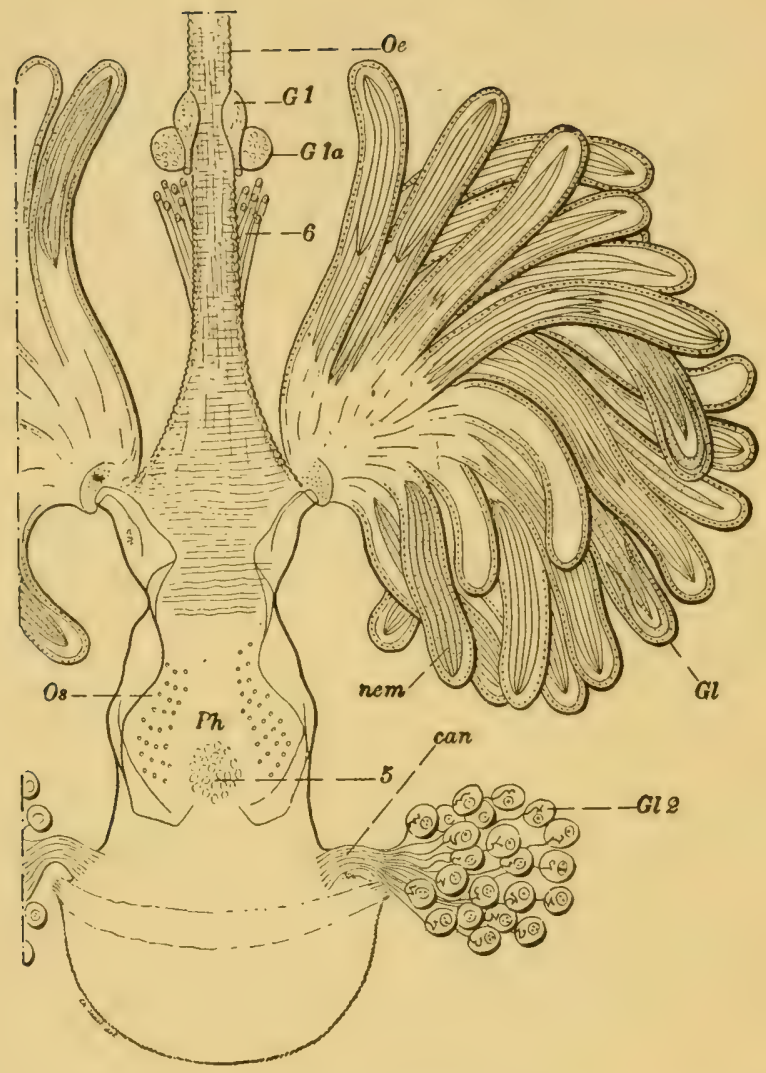

Fig. 13. - Gross. 50. Pharynx diune Formica rufa 8 dont les glandes pharyngiennes sont envahies par des larves de Pelodera.

$P h$, pharynx; Os, organes sensitifs ; 5 , insertion du grand muscle dilatateur inférieur du pharynx; Gl: glandes débouchant à peu de distance de l'orifice buccal; cron, canaux des grlandes précédentes; Oe, resophage; $\sigma$, muscles rétracteurs de la partie sous-cérébrale de l'osophage ; $C i 1$, unanglions du système sympathique ; (ila, deuxième paire de granglions du système sympathique? (Corpora incerta de lieinert); ( $i l$, tules des glandes pharyngiennes contenant des larves de Pelodera; nem, larves de Pelodera groupées pour lit plupart en paquets lusiformes.

Cies tubes digitiformes s'étalent devant le cerveau et audessus de lui. C'est dans leur intérieur que vienuent s'installer les Nématodes en question. 


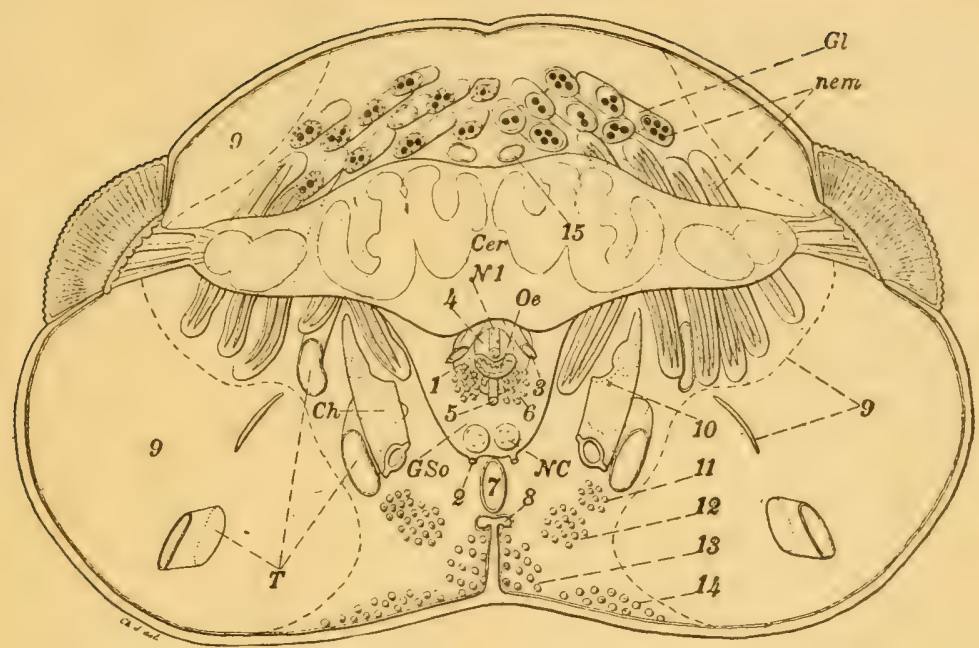

Fig. 14. - Gross. 50. Coupe transversale de la tête d'une Formica rufa vuvrière dans laquelle les tubes des glandes pharyngiennes sont envahis par un grand nombre de larves de Pelodera. La tranche relativement épaisse représentée sur celle figure est vue par sa face postérieure.

(il. tuhes des deux glandes pharyngiennes. Les uns descendent en passant devant les ganglions optiques. Les autres s'étalent au-dessus du cerveau; nem, larves de Pelodera Jogées dans les glandes pharyngiennes. Dans les tubes qui descendent devant les ganglions optiques on voit les Nématodes dans leur entier par transparence. Les Nématodes contenus dans les tubes qui s'étalent au-dessus dti cerveau sont coupés transversalement et représentés par des cercles noirs; Cer, cerveau coupé à la hauteur des yeux, montrant ses calices internes et externes. Sur les cótés on voit les masses médullaires internes et externes des ganglions optiques; 1 , trou oesophagien; GSio, ganglion sous-œsophagien; $N C$, connectifs de la chaine ganglionnaire: 2, nerfs accumpagnant les trachées et le canal de la glande cui al,outil au labium; 3, trachées du trou œosophagien; 4 , sinus oủ aboutit laorte; $N 1$, nerf viscéral impair; Oe, osophage; 5 , tendon du grand muscle dilatateur inférieur du pharynx; $\boldsymbol{G}$, brins musculaires rétracteurs de la partie sous-cérébrale de l'œsophage ; $\tau$, canal de la glande qui aboutit an labium (glande sericigène de la larve); $\delta$, crète chitineuse longitudinale ; 9, muscle adducteur mandibulaire (représenté seulement par son contour et la lame chitineuse sur laquelle il sattache); 10 , muscle adducteur maxillaire (représenté seulement par son point d'insertion sous l'une des grandes traverses); 11 , muscle adducteur labial; 12 , muscle abducteur labial; 13, muscle ablucteur maxillaire; 1t, muscle abducteur mandibulaire; $C h$, grandes traverses : ce sont deux tubes de chitine qui, partant des cótés du trou occipital dans le voisinage duquel ils sont réunis par le tentorium, traversent la tête longitudinalement de part en part et aboutissent un peu au-dessus du cadre articulaire des mandibules ; $T$, les trois grands troncs trachéens longitudinaux de la téte; 15, trachées supra-cérébrales.

Ce sont des petits Vers qui pénètrent par la bouche, et se développent aux dépens du liquide sécrété par la glande qu'ils habitent. Il y a, ainsí, dans la tête des Fourmis d'un nid infesté, un va-et-vient incessant de jeunes Vers qui y entrent aussitôt après leur éclosion et en sortent lorsque, au bout de quelques jours, ils ont acquis le développement nécessaire pour vivre à l'état libre. Les Fourmis ainsi mises 
à contribution se portent fort bien et ne paraissent pas souffrir de la présence de ces parasites, qui peuvent être, pour un seul individu, au nombre de plusieurs centaines.

La fig. 3 représente les glandes pharyngiennes isolées par dissection. La figure $\mathbf{1} 4$ représente une coupe pratiquée dans la tête d'une Fourmi. Ces préparations, faites sur des Formica rufa fixées par l'immersion dans l'eau chaude, montrent les parasites in situ dans la glande.

J'ai suivi le développement de ces Nématodes.

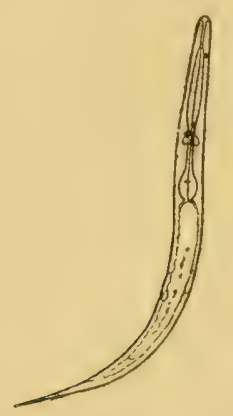

Fig. 15. - Gross. 200. Jeune larve à sa sortie de l'œuf.

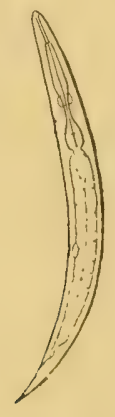

Fig. 16.- Gross. 200. Jeune larve cqui, après être entrée récemment dans les glandes pharyngiennes d'une F'ormica rufa, en est sortie spontanément lorsque la tête a été coupée et déposée dans une goutte d'eau. 


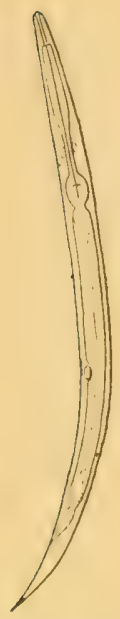

Fig. 17. - Gross, 200. Jeune larve, une quarantaine d heures après sa sortie de l'œuf.

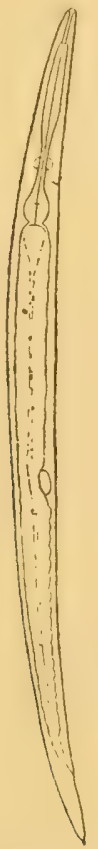

Figr. 18. - Gross. 200. Larve qui, après être arrivée au terme de son séjour dans les glandes pharyngiennes, est sortie spontanément de la mème tête de Formica que la jeune larve représentée fig. 16. 
$-24-$
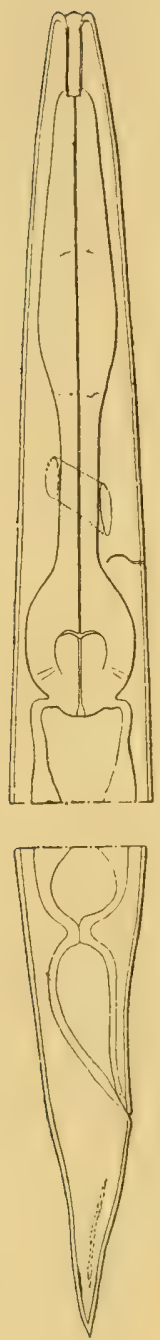

Fig. 19. - Gross. 200. Pelodera, Janeti II, de Lacaze-Duthiers. Individu long de mum, 0,900 vu de cóté. La région cosophagienne et la région caudale sont seules représentées. 


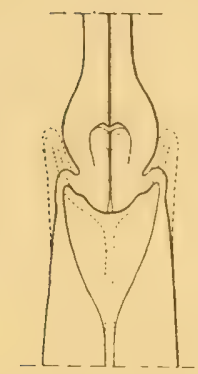

Fig. 20. - Gross. 200. Bulbe inféricur de l'resophnge chez une femelle longue de mm. 0,800. Cette figure montre en trait ponctue le changement de forme de la cavité du bulbe pendant l'aspiration des liquides. Elle montre aussi, en trait pointillé, la manière dont la partie antérieure de l'estomac vient coilfer le bulbe.

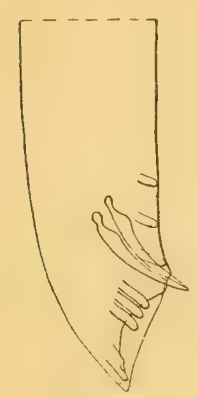

Fig. 21.

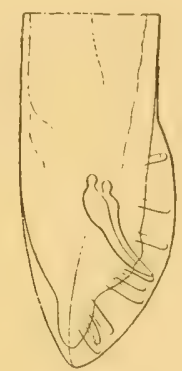

liis. 소

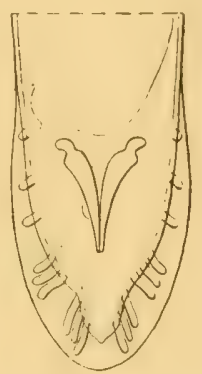

Fir. :3.

Figures 21 à 23. Gross. 400. Pelodera Janeti H. de Lacize-Duthiers. Extrémilé caudale du $O^{x}$. Figg. 21. Individu de mm. 0,700, vu de côté. - Fig. 22. Individu de mm. 0,730, vu de trois ‘uarts. - Fig. 23. Individu de mm. 0,730, vu de face.

Les individus provenant de ceux qui ont ainsi vécu en parasites dans la tête des Fourmis sont un peu différents de leurs parents et il $\mathrm{y}$ a une véritable génération alternante.

13

Études sur les Fourmis. Note 5. Sur la Morphologie du squelette des segments post-thoraciques chez les Myrmicides.

Dans la 5e Note, j'étudie d'abord le groupement des anneaux post-céphaliques, puis en détail, le squelette chitineux de chacun des anneaux thoraciques. 


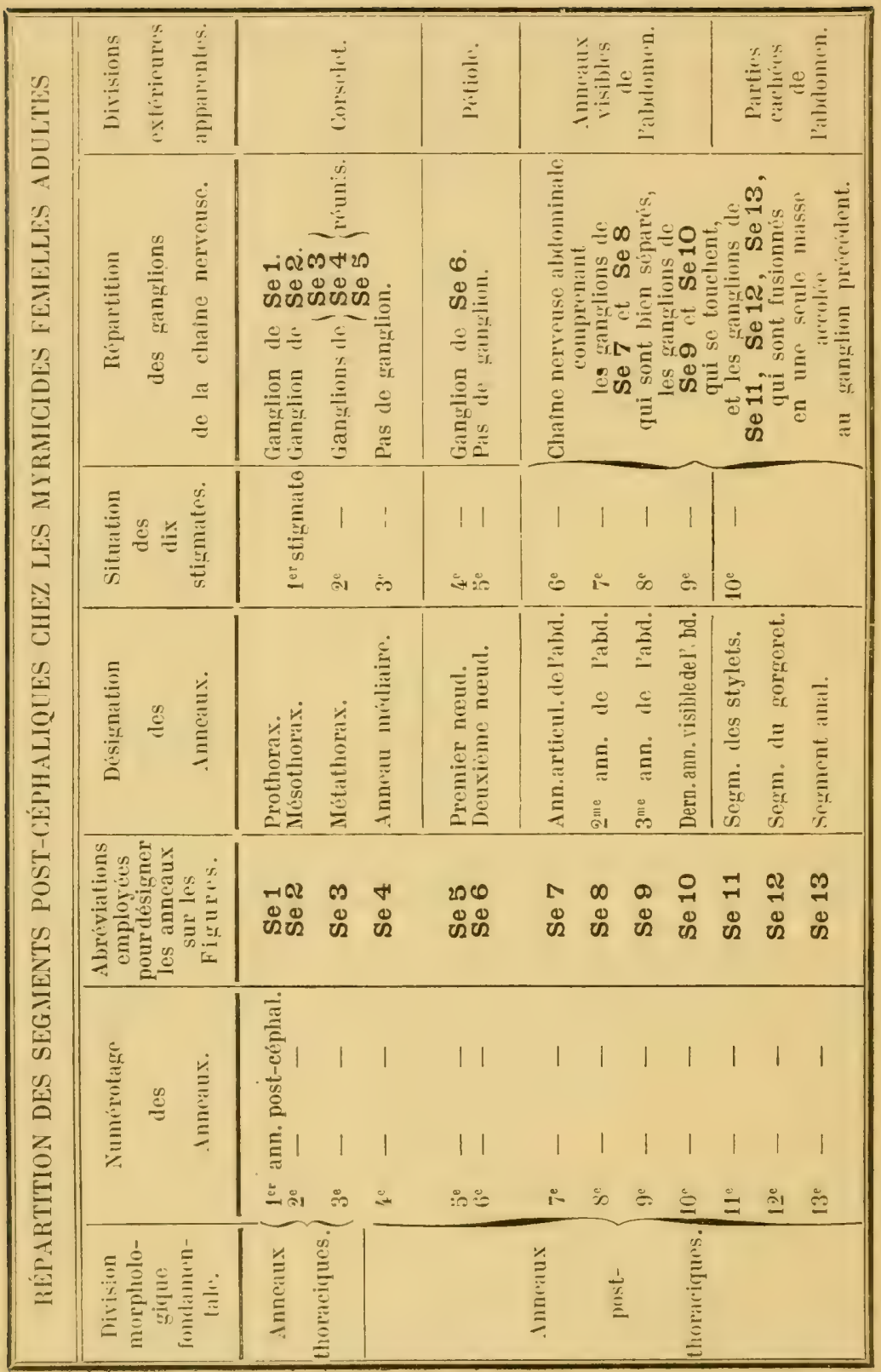


On trouvera, dans cette Note, une description détaillée du squelette chitineux des deux anneaux qui constituent le pétiole du squelette chitineux des anneaux abdominaux normaux et enfin, ce qui a été la partie la plus difficile de cette étude, la description du squelette chitineux des derniers anneaux (I I ${ }^{\ominus}$ à r3e anneaux post-céphaliques), anneaux qui, étant cachés sous les autres et servant de support à l'armure génitale, sont fortement modifiés.

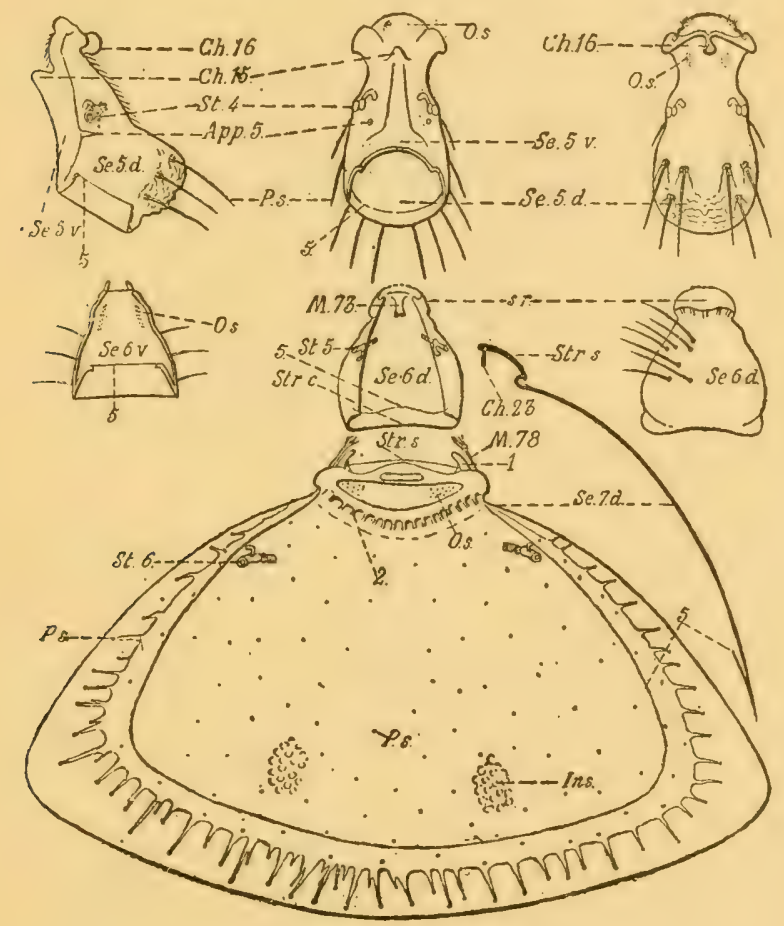

Fig. 24. - Gross. 25. Myrmica rubra L. femelle. Squelette du pétiole et arceau dorsal du premier anneau de labdomen.

En haut, premier noud : 10 Vue latérale; $2^{\circ}$ vue ventrale; 30 vue dorsale.

Au-dessous, deuxième noeud : 10 Arceau ventral vu de l'intérieur; 2o Arceau dorsal vu de l'intérieur ; 30 Arceau dorsal vu de l'extérieur.

En bas, arceau dorsal du premier anneau de l'abdomen : 10 Vue de face par transparence ; 20 Coupe sagittale. 


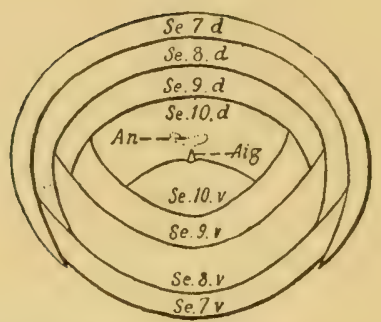

Fig. 25. - Gross. 6. Myrmica rubra L. femelle. Abdomen vu en bout de l'extérieur.

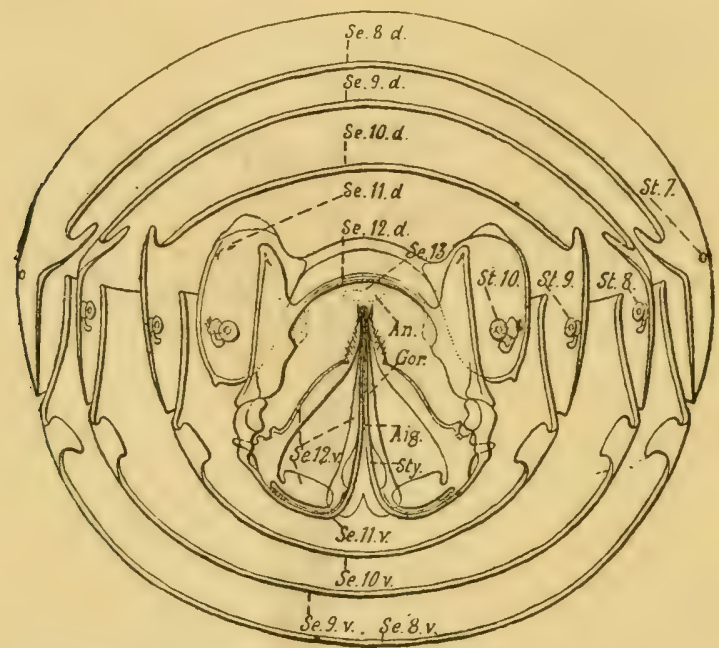

Fig. 26. - Gross. 12. Myrmica rubra L. femelle. Squelette de la partie inférisure de l'abdonen. vu en bout de l'intérieur.

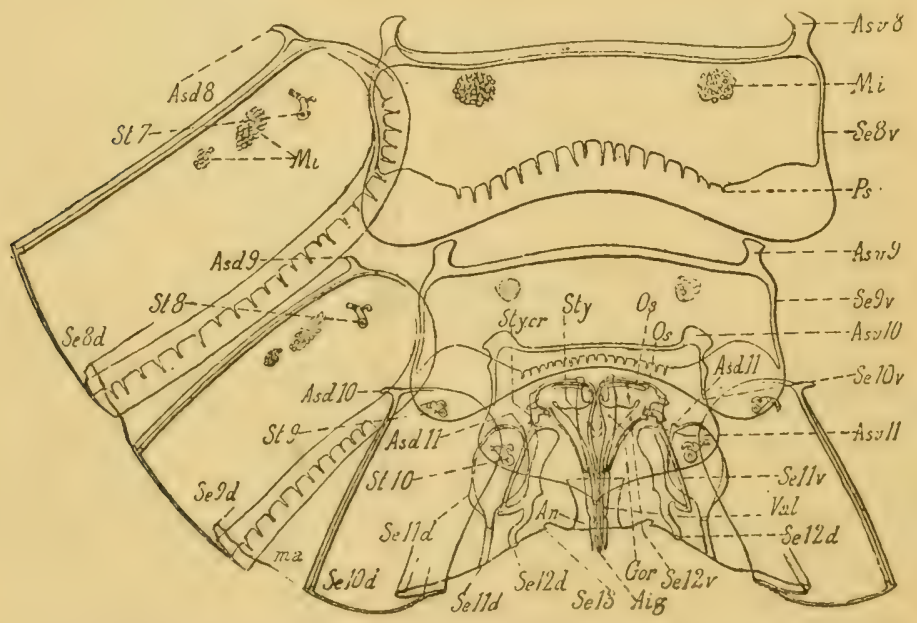

Hige. 27. - Gross. 22. Myrmica rubra L. femelle. Squelette chitineux de la partie inférienre de labdomen coupes stivant la ligne médiane dorsale el étalé entre deux lames de verre. 


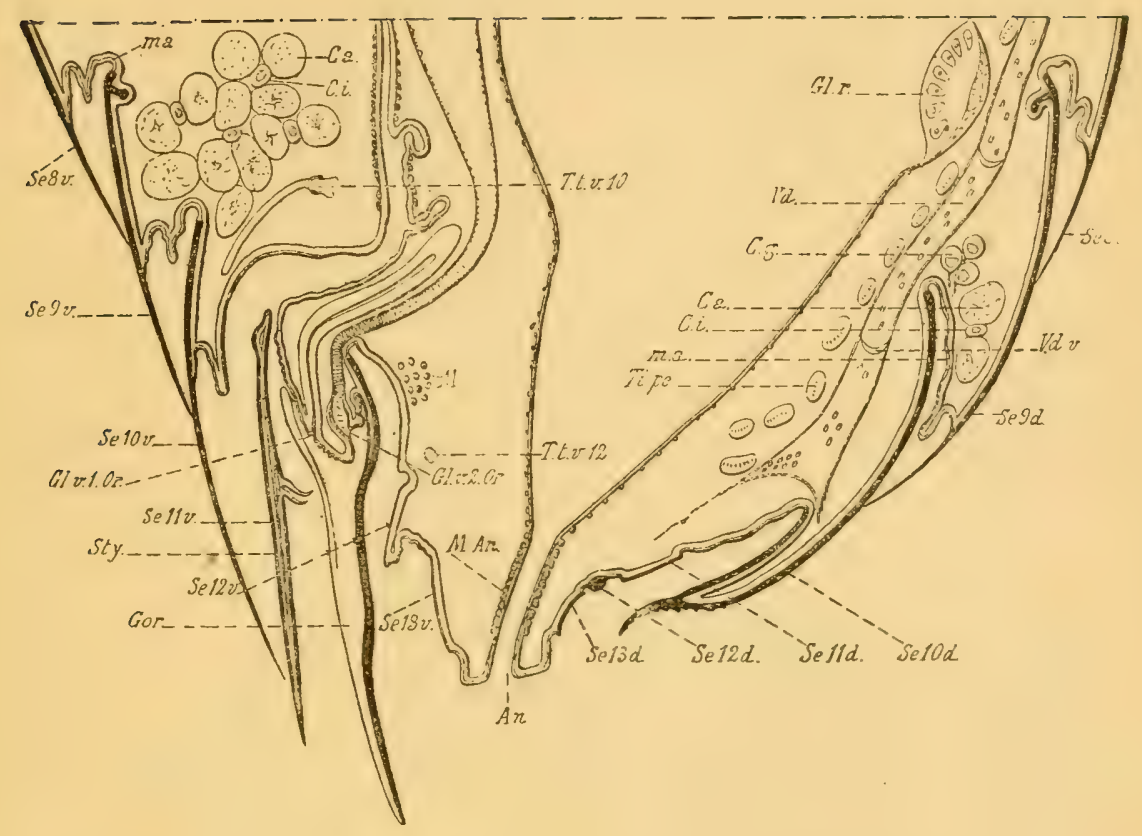

lïg. 28. - Gross. 100. Myrmica rubra L. ouvrière. Coupe sagittale de la partie inférieure de l'ablomen.

Etudes sur les Fourmis. Note 6. Sur l'appareil de Stridulation de Myrmica rubra.

Dans la I $^{\text {re }}$ Note j'ai montré que les Fourmis émettent bien réellement des sons par stridulation, et j'ai indiqué une méthode pour provoquer et percevoir ces sons chez les Myrmicides, même les plus petits, de nos pays.

Dans la présente Note je décris en détail l'organe stridulateur : cette description est accompagnée de deux figures représentant l'organe à grande échelle. 


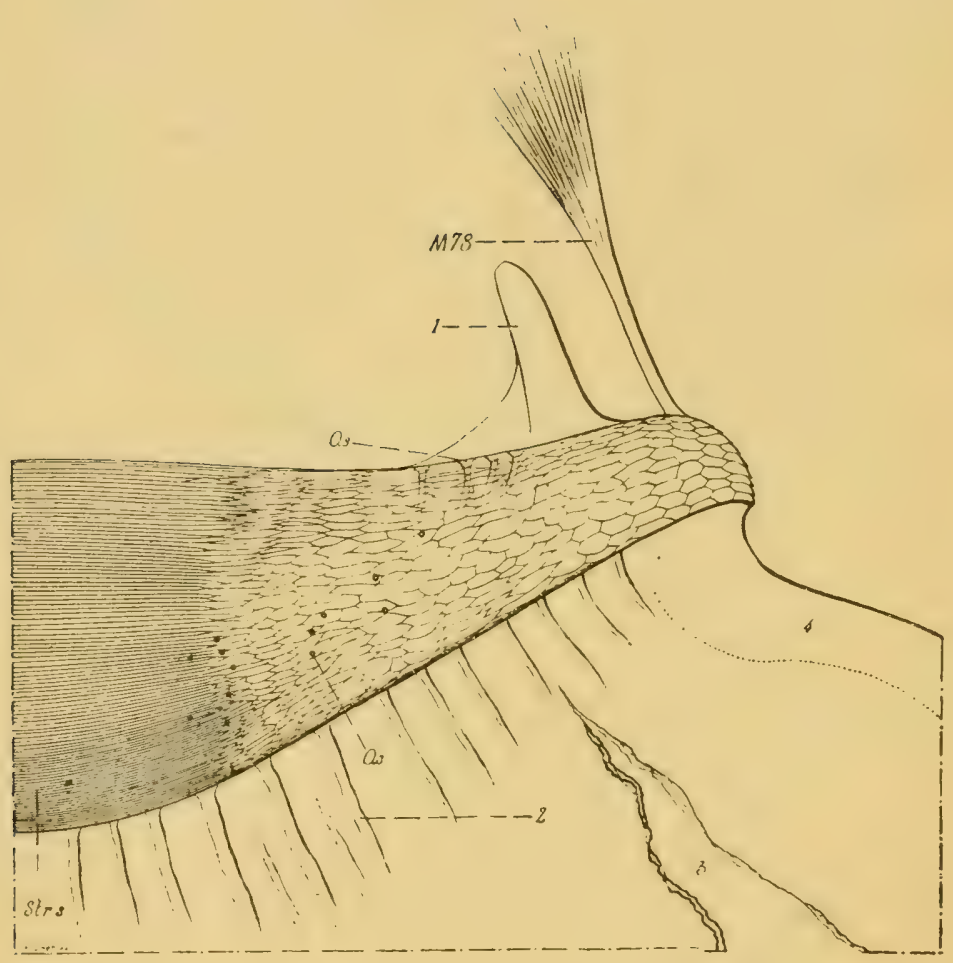

Fig. 29. - Gross. 200 fois environ. Nyrmica levinodis femelle. Vue de face du bourrelet articulaire situé à la partie supérieure de l'arceau dursal du 7̈e segment post-céphalique. Le squelette chitineux a été débarrassé des autres tissus et est assez fortement comprimé.

$S t r . s$, aire striée de l'organe de stridulation; $O s$, organes sensitifs; 1 , ap̣ophyse latérale sur laquelle sattache le muscle $M / 9$ de la figure $2 ; M 78$, tendon d'un muscle dorsal externe, dont les hrins divergents vont se fixer sur l'arceau dorsal précédent, en dehors du muscle $\lambda l 79 ; 2$, nervures inférieures au sillon situé au-dessous du bourrelet; 3 , cassure due à la compression, montrant la structure stratifice du squelette chitineux; $f$, articulation des arceaux dorsal et ventral du segment Se 7 . 


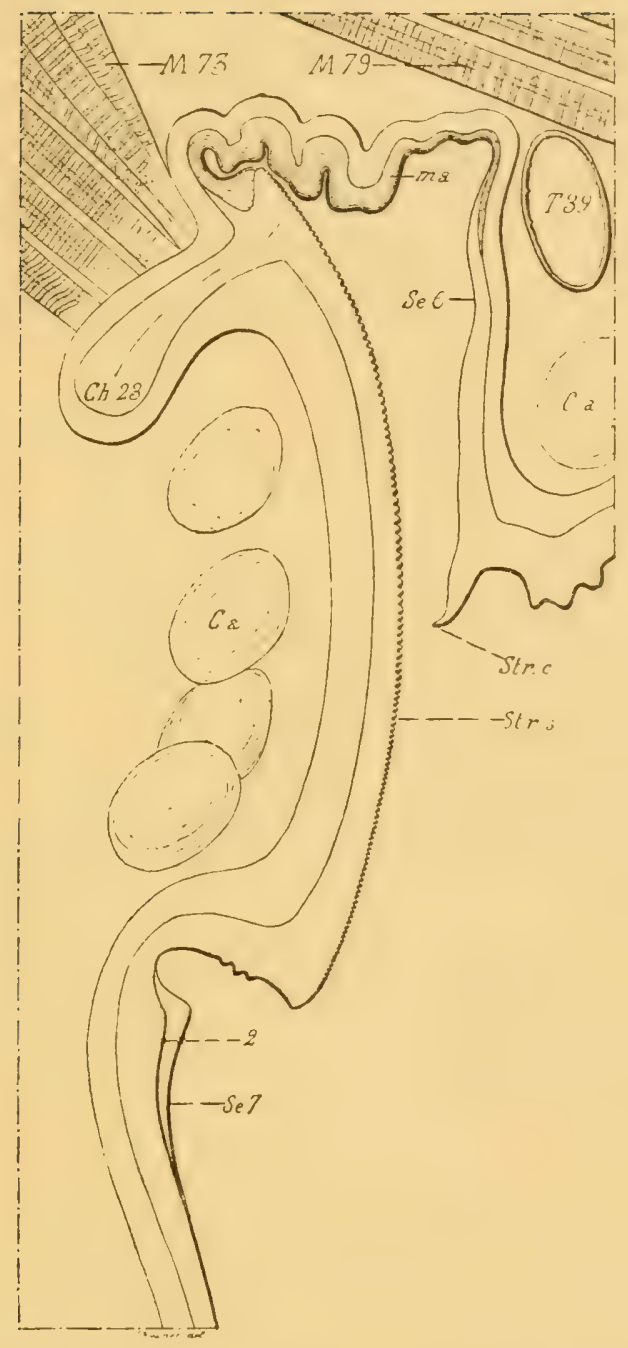

Fig. 30. - Gross. 400. Myrmica levinodis lemelle. Coupe transversale sagittale de l'appareil de stridulation.

Se 6, sixiẻme segment post-céphalique ou deuxième nœud du pétiole; Se 7, septiẻme segrment postcéphalique; Str. $s$, aire striée de l'organe de stridulation; Str. c, crite de frottement de l'organe de stridulation; $C h \approx 3$, nervure interne de la partie supérieure du bourrelet articulaire du segment Se $7 ; M a$, membrame articulaire du deuxieme neud $S e G$ arec le segment suivant: $T$. 39, tronc tracheen transversal dorsal du deuxième neud Se $6 ; 1 / 73$, muscle longitudinal dorsal. S'attache sur la région médiane de la fice supérieure de $C h$ E3 et se fixe sur la hordure de la nervure correspondant à $C h 23$ sur l'arcenu dorsal précédent; $\boldsymbol{U} 79$, muscle dorsal qui s'attache à l'apophyse latérale de larceau dorsal du segment Se $\tau$ et va en divergeant se fixer près de la ligne médiane et assez bas sur l'arceau dorsal du deuxième nocud; Ca, tissu adipeux. 


\section{5}

\section{Sur les Nerfs de l'Antenne et les Organes chordotonaux chez les Fourmis.}

Cette Note est consacrée à la description des nombreux organes qui se dirigent vers l'articulation de l'antenne de la Fourmi (Myrmica).

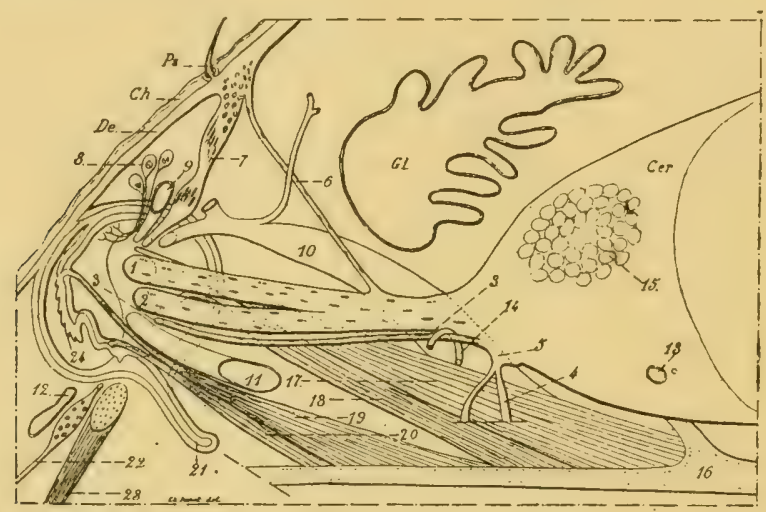

Fig. 31. - Myrmica rubra L. $\subsetneq$ Tranche comprise entre deux coupes parallèles au plan sayittal et contenant les nerf's de l'antenne droite. Gross. 160. C'er, Cerveau; Gil. Glande pharyngienne ; De, Épiderme; $C h$, Squuelette chitineux ; $P S$, Poil sensitif ; $\ell$, Nerf sensitil supéro-externe ; 2 , Nerf sensitif inféro-interne; 3 , Nerf moteur des muscles du funicule; $\boldsymbol{t}$, Nerfs moteurs des muscles du scape ; 5 , Point d'émergence des nerfs moteurs; 6 , Nerf de l'organe préantennaire ; $z$, Organe préantennaire ; 8 , Cellules glandulaires; 9 , prolongement du sac frontal ; 10 à 14, Trachées ; 15 , Glomérules olfaclifs ; 16 , Endosquelette; 17 a 20 , Muscles du scape ; 21 , Apodème ; 22, Nerf du labre; 23 , Muscle adducteur du labre; 21 , lase du scape.

Les nerfs sensitifs de l'antenne se détachent du cerveau sous forme d'un gros trone unique. Bientôt ce trone se divise en deux branches qui, tout en restant placées l'une près de l'autre, sont bien distinctes lorsqu'elles pénètrent dans l'antenne.

De ces deux branches, l'une doit être considérée comme olfactive. Les coupes montrent que ses faisceaux d'origine sortent de la région des glomérules olfactifs du cerveau.

Je considère l'autre comme étant un nerf' auditif parce que ses faisceaux ont dans le cerveau une origine diflérente de celle des faisceaux du nerf précédent et que ce nerf, avant 
de pénétrer dans l'antenne, envoie une branche vers un organe chordotonal (organe auditif) bien caractérisé.

Get organe chordotonal, situé au contact des téguments, se dirige vers l'antenne et $\mathrm{y}$. pénètre.

Un peu au-dessous du point d'émergence des nerfs sensitifs de l'antenne se trouve le point d'émergence des nerfs moteurs des muscles de cet organe. Il y a, d'abord, un fin filament nerveux qui accompagne les deux gros nerfs sensitifs et pénètre avec cux dans l'intérieur de l'antenne pour aller innerver les muscles qui font mouvoir ses articles les uns par rapport aux autres.

Deux autres nert's moteur's, émergeant du mème point du cerveau, vont innerver les muscles moteurs du scape de l'antenne.

Ces muscles, qui produisent les mouvements d'ensemble de toute l'antenne, sont au nombre de 4. Ils sont attachés par des tendons sur le bord articulaire du scape, tandis que leur's brins divergents vont se fixer sur le tube chitineux qui traverse de part en part la tète de la Fourmi.

Deux trones trachéens, passant le long des muscles moteurs du scape, pénètrent dans l'antenne.

Le sac frontal, qui est chargé d'assurer la circulation du sang dans l'antenne, envoie, dans cette dernière, un prolongement en forme de tube.

Enfin, un petit groupe de cellules glandulaires fait déboucher ses canaux excréteurs dans des lossettes à la base du scape.

En résumé quinze organes viennent aboutir à l'articulation de l'antenne de la Fourmi, à savoir: deux gros nerfs sensitifs, un nerf chordotonal, un organe chordotonal, trois nerf's moteurs, quatre muscles, deux trachées, un prolongement du sac frontal et un faisceau de cellules glandulaires.

La figure 3i représente l'ensemble de ce disposil compliqué. 
La même Note signale un autre organe chordotonal situé entre le gros ganglion prothoracique et les téguments.

\section{6}

\section{Transformation artificielle en Gypse du Calcaire friable des fossiles des Sables de Bracheux.}

Je rapporte dans cette Note une expérience qui m'a permis de transformer, sur place, en sulfate de chaux relativement solide, des fossiles qui se trouvent, dans les Sables de Bracheux, à l'état de Calcaire farineux tellement friable que leur extraction directe est absolument impossible. Une transformation semblable a eu lieu, dans la nature, pour les fossiles de certaines couches du Sparnacien.

\section{7}

Etudes sur les Fourmis.

Note 7. Sur l'Anatomie du Pétiole de Myrmica.

Lor'squ'on examine les Hyménoptères à abdomen pédonculé, on est frappé de l'extrème réduction que le corps peut subir entre le corselet et l'abdomen. Chez les Evanides, les Sphégides et les Formicides la minceur du pétiole est telle que Girard, dans un Traité d'Entomologie, dit que cette extrême ténuité "rend bien diflicile l'hypothèse d'une circulation. du sang y) commune entre les régions antérieure et postérieure du ") corps $\%$.

La $z^{c}$ Note domne, pour la Mrrmica rubra, l'anatomie complète de cette partic si rétrécie du corps. 


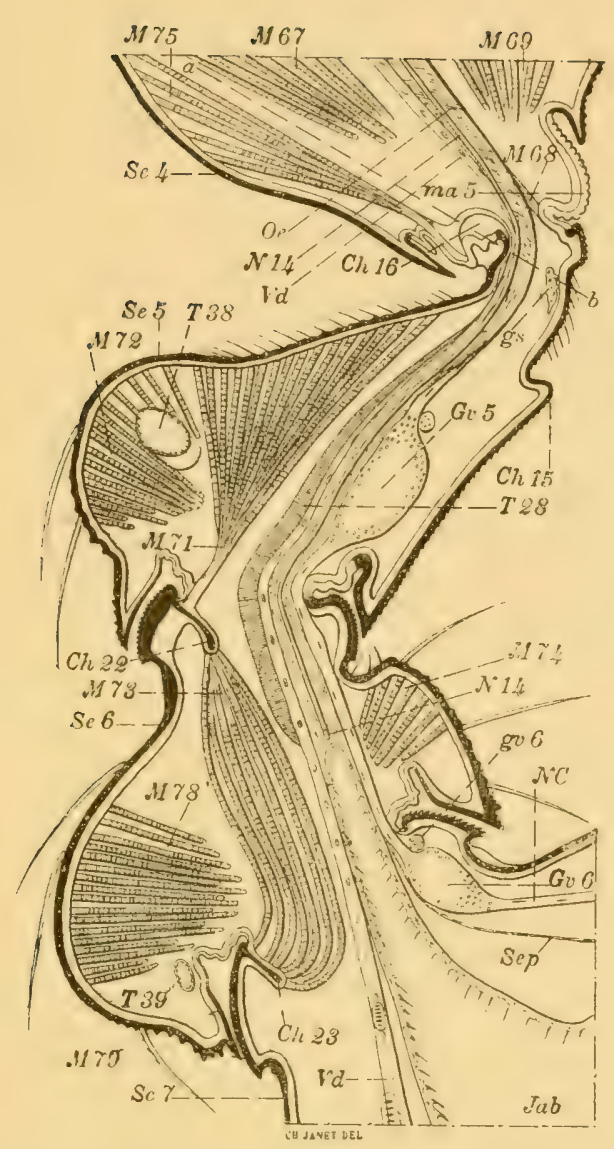

Fïg. 32. - Gross. 100. Myrmica rubra I, ouvière. Pétiole. Tranche comprenanl le plan sagittal.

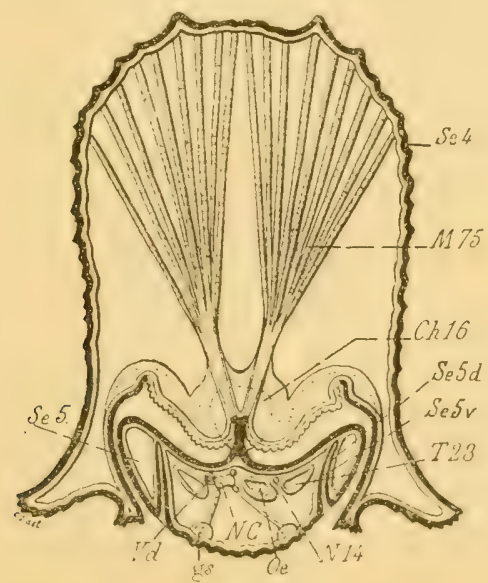

Fig. 33. - Gross. 100. Mlyrmica rubra L. ouvrière. Tranche dont le plan supérieur est intiqué approximativement par la trace $a b$ marruce à la parlie supérieure de la figure 32. 


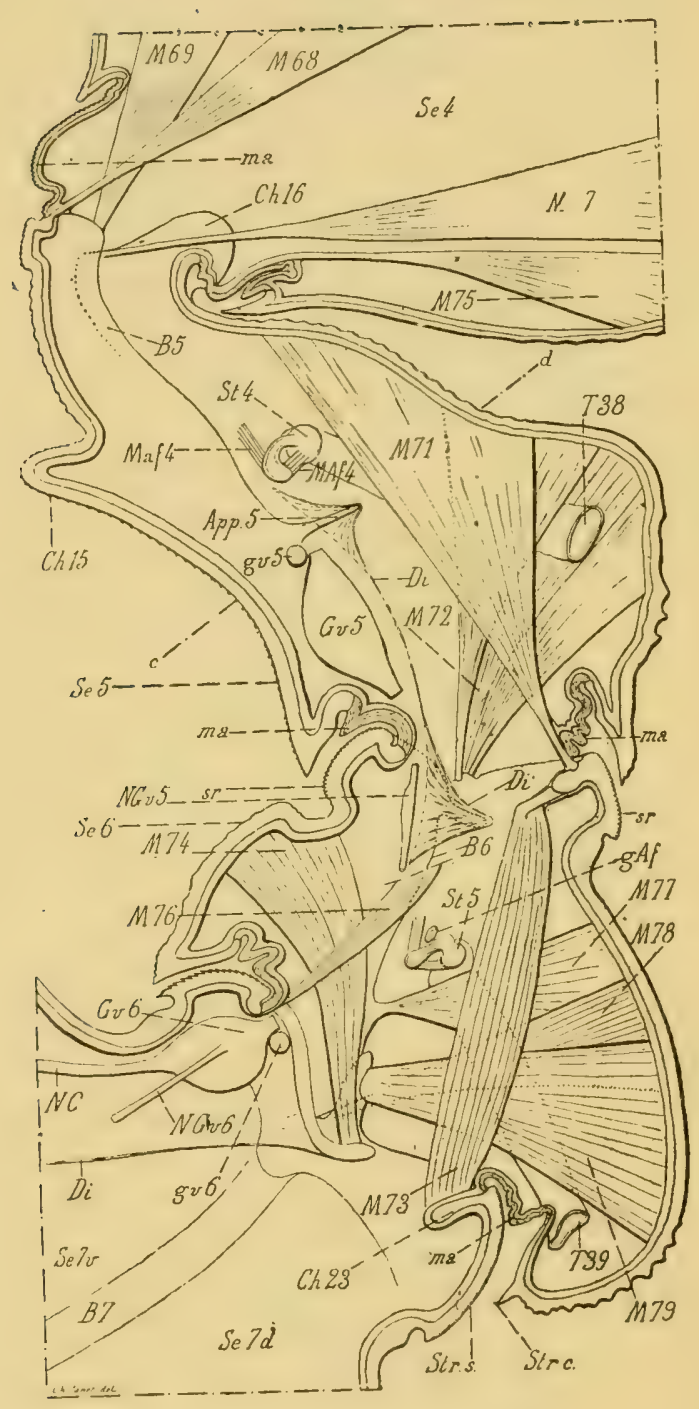

Fï. 31. - Gross. 100. Myrmica rubra L. femelle ailée. Woitié du pétiole conpé suivant son plan sagrittal pour montrer l'ensenhle de sa musculature. Tous les viscères sont supposés enlevés, à lexception d'une partie du système nerveux, d'une partie du diaphragme et des organes de fermeture des stigmates (Pour le muscle margué $\boldsymbol{M}$. $\mathbf{7}$, il faut lire $\mathbf{M} \mathbf{6} \mathbf{6}$ ). 


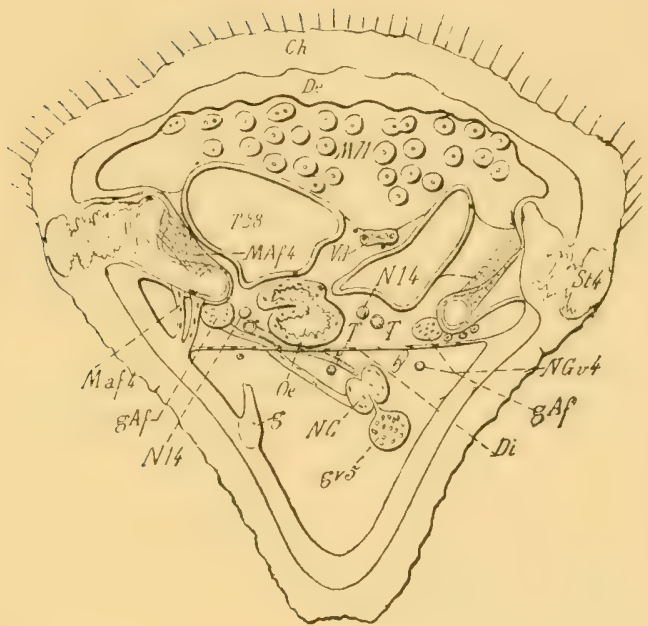

Fig. 33. - Gross. 200. Myrmiç rubrı. Femelle ailée. Tranche transversale clont la face inférieure est représentée approximativement par la trace $c d$ sur la figure 34.

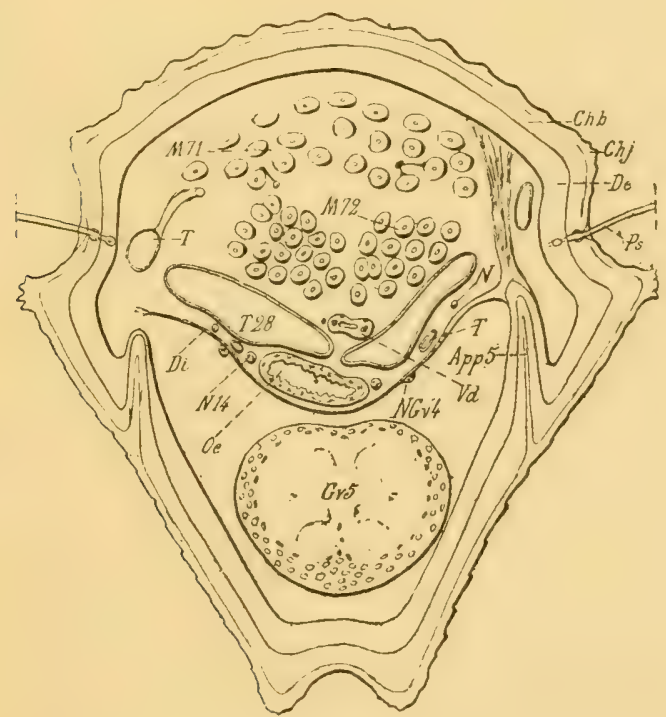

Fig. 36. - Gross. 200. Myrmica rubra L. Femelle ailée. Tranche transversale dont la face supérieure est représentée approximativement par la trace $c$ d sur la figure 34. 


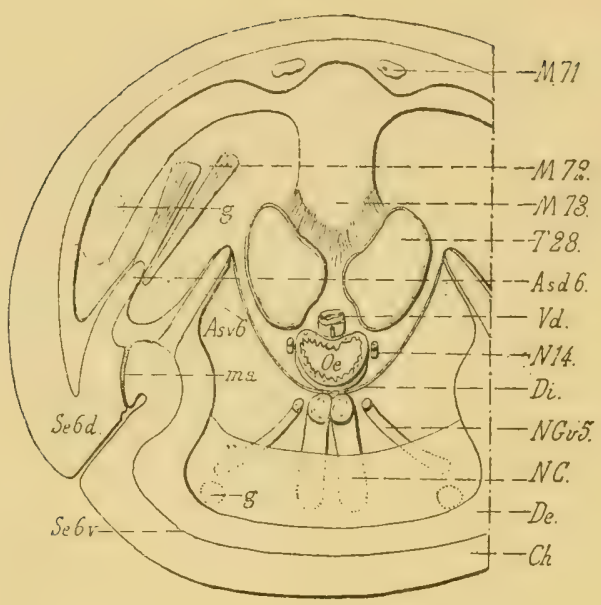

Fig. 37, - Myrmica rubra L. - Femelles ailées. Tranche transversale comprenant la partie tout à fait supérieure du 2 e nœud du pétiole. Gross. 200.

Explication des abréviations employées dans les figures 32 à 37.

A pp.5, apophyses internes des côtés de l'arceau Se.5.v (arceau ventral du premier nœud du pétiole). Asd.6, apophyses latérales de la bordure supérieure de l'arceau $S e .6 . d ; A s v .6$, apophyses latérales de la bordure superieure de l'arceau Se.G.v; $a b$, trace approximative, sur la fig. 32, du-plan supérieur de la tranche représentée par la fig. $33 ; \boldsymbol{B} .5$, bourrelet articulaire des arceaux dorsal et ventral du segment Se.5; B. 6 , bourrelet articulaire des arceaux dorsal el ventral du segment $S e .6 ; B .7$, bourrelet articulaire des arceaux dorsal et ventral du segment $S e .7 ; C h$, squelette chitineux; $C h . b$, partie blanche peu chitinisée du squeletie ; $C h . j$, partie jaune fortement chitinisée du squelette; Ch.15, butoir médian silué à la partie antérieure de l'arceau Se.5.v; Ch.16, articulation dorsale à tète sphérique de la partie supérieure de l'arceau Se.5.d (1er noud); Ch.2Q, nervure en forme de lame transverse de la partie supérieure de l'arceau Se.6.d. (20 noud); Ch.23, nervure en forme de lame transverse de la partie stupérieure de l'arceau Se.7.d; crl, direction approximative, sur la fig. 34 , des coupes qui ont fourni les tranches représentées par les fig. 33 et 36 . La figure 35 comprend les parties situées au-dessus, tandis que la figure 36 comprend les parties situées au-dessous de cd. Sur lindividu qui a fourni ces deux dernières figures, le ganglion $G v .5$. et le petit ganglion viscéral gv5 étaient placés un peu plus haut que ne l'indique la figure 34. C'est pour cela que le petit ganglion gvas est compris dans la figure 35; $D e$, épiderme tégumentaire (Derme, Hypoderme); $D i$, diaphragme (Septum); Gv.5, ganglion de la chaine nerveuse ventrale logé dans le 5e anneau post-céphalique (Se.5, ter nœud), mais appartenant morphologiquement au segment Se.6. qu'il innerve ; Gv.6, ganglion de la chaîne nerveuse ventrale logé dans la partie súpérieure de l'anneau Se.7, auquel il appartient morphologiquement; $g$, petits ganglions nerveux ; $g \mathrm{~d} f$, ganglions des organes de fermelure des stigmates; $g s$, ganglions sensitifs; $g v .5$, ganglion viscéral situé à la partie supérieure du ganglion Gv.5, de la chaîne nerveuse et, comme lui, appartenant non pas ì l'anneau Se.j, dans leqquel il est logé, mais au segment suivant Se.6 (2e neud) ; gv.6, ganglion viscéral situé à la partie supérieure du ganglion $G v .6$ de la chatne nerveuse et, comme lui, appartenant au segment Se.7, dans lequel il est logé; Jab, jahot; $M I .73$, (dans le seym. Se.6 ou ¿'e nuxud). Muscles releveurs du segm. Se.7;M. 6 (dans le segm. Se.6, ou 20 nœud). Muscles abaisseurs du segm. Se.7; M.79 (dans le segm. Se.6 ou 20 noud). Muscles rotateurs dorsaux du segm: Se.7; M.78 (dans le segm. Se.6 ou 2e nœud). Mluscles rotateurs dorsaux externes du segm. Se.7; $M .74$, (dans le segm. Se.6 ou $2 \bullet$ noud). Muscles rotateurs ventraux du segm. Se. $7 ; \boldsymbol{M} .7 \overline{7}$, (dans le segm. Se. 6 ou 2e nœud). Muscles dorso-ventraux du segm. Se.6 ou 2e noud; $M .71$, (dans le segm. Se.5 ou fer noud). Muscles releveurs du serm. Se. $G$ on $2^{\circ}$ næud; $M .72$, (dans le segm. Se.5 ou 1or nœud). Muscles rotateurs du segm. Se.G ou 2e noud; M.75, (dans le segm. Se. 1 ). Muscles releveurs du segm, Se.5 ou ter noud; M.68. (dans le segm. Se.f). Museles abaisseurs du segm. Se.5 ou ter noud; $\boldsymbol{M} .67$, (dans le segm. Se.1). Muscles rotateurs dorsaux du segm. $\mathrm{Se} .5$ ou ter nœud; $M .69$, (dans le segm. Se.4). Muscles rotaleur's ventraux du segm. Se.5 
ou $\mathbf{f e r}$ rícud; $\mathbf{M A}$, muscle adducteur du levier de l'appneil de lerueture diun stigmate; MAf.t, muscle adducteur du levier de l'appareil de fermeture du te stigmate situé dans le segm. Se.5; Maf, muscle abducteur da levier de l'appareil de fermeture d'un stigmate; Maf.t, muscle abducteur du levier de lappareil de fermeture du 4e stigmate situe dans le segm. Se.5; ma, membrane articulaire du squelette; ma.5, membrane articulaire entre le thorax et le ler noud (entre $S e . t$ et $S e .5) ; N$, nert ; $\boldsymbol{N} .11$, paire de nerl's viscéraux accompagnant l'vesophatge; $N C$, connectifs de la chaine ganglionnaire ventale; $N G w^{\circ}, 5$, grands nerfs émis par le ganglion Gv.5; $N G v .6$, grands nerfs émis par le gangliou $G v .6$; Oe, wophage; $O s$, organes

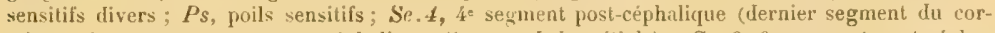
selet); Se.5, je segment post-céphaliqute (1er noud du pétiole); Se.6, 6e segment post-céphalique ( 2 e noud du péttole); Se.7, $7^{\star}$ segment post-céphalique; Se.5. $l$, arceau dorsal du segment Se.5; Se.6.d, arceau dorsal du segment Se.6; Se.7.d, arceau dotsal du segment Se.7; Se.5.v, arceau ventral du segment $S e .5 ; S e .6 . v$, arceat ventral du segment $S e .6$; Se.7.v, arceau ventral du segment $S e .7$; Scp, septum (diaphragme); sr, surlace rugueuse; St.1, 4e stigmate situé sur le segment Se.5 (1or noud du pétiole); St. 5, õe stigmate situé sur le segrment Se.6 ('e noeud du pétiole); $S t r c$, appareil de stridulation, créte de frottement; Strs, appareil de striIlulation, aire striée; $T$, trachee; $T .2 S$, gros troncs trachéens longitudinaux du thomx et du pétiole; $T .38$, tronc transverse dorsal du premier noud; $T$..39, tronc transverse dorsal du deuxième norud; $\mathbf{Y} d$, vaisseau lorsal.

On sait que le corselet des Hyménoptères est formé de l'ensemble de 4 anneaux qui sont: le prothorax, le mésothorax, le métathorax et le $\Psi^{e}$ anneau post-céphalique. Ce dernier anneau contient une musculature bien développée dont tous les éléments s'attachent sur le cadre articulaire supérieur du pétiole. Il ne contient, d'ailleurs, aucun autre muscle : sa musculature est consacrée, tout entière et exclusivement, aux mouvernents du pétiole, mouvements très importants puisqu'ils se transmettent, intégralement, à toutes les parties suivantes du corps. On conçoit l'avantage que présentent ces dispositions. Les trois anneaux thoraciques ont déjà à fournir des muscles nombreux et puissants po:r les pattes et les ailes; le concours d'un $4^{\mathrm{e}}$ anneau qui, lui, est dépourvu d'appendices, vient, bien utilement, les affranchir de la nécessité de pourvoir encore aux mouvements des anneaux suivants. Il n'y a, d'ailleurs, aucun inconvénient à ce que le nombre de ces derniel's soit un peu diminué. Le squelette chitineux de l'abdomen peut toujours se développer suflisamment pour loger tous les organes qui lui sont dévolus. Ici, outre le $4^{\mathrm{e}}$ segment post-céphalique, deux autres anneaux lui sont encore enlevés, ce sont les deux anneaux du pétiole, partie rétrécie qui est destinée à lui assurer, en tous sens, des mouvements aisés et de grande amplitude. Il 
retrouve bien facilement tout le volume qui lui est utile, simplement par le très grand développement d'un seul de ses anneaux qui est le $\tau^{\mathrm{e}}$ anneau post-céphalique.

Dans la partie inférieure du thorax, à la hauteur de la suture du $3^{\text {e }}$ et du $4^{e}$ anneaux, les viscères présentent une disposition relative normale.

L'osophage occupe une situation centrale. Sur ses côtés, à droite et à gauche, courent les deux grands trones trachéens longitudinaux. Entre ces trones trachéens et l'œesophage, accolés aux côtés de ce dernier, mais un péu rapprochés de sa face ventrale, sont les deux nerfs gastriques $\left(\begin{array}{ll}N & I\end{array}\right)$.

Le cour s'étend le long de la face dorsale de l'œsophage et les connectifs le long de sa face ventrale.

Le cour, l'oesophage et les connectifs sont, ainsi, dans un même plan sagittal.

Les muscles $M 68$ passent ì droite et à gauche le long des connectifs (fig. 32 et 34 ).

Les muscles $M 6 \mathrm{~g}$ passent à droite et ì gauche le long du coeur.

Les muscles $M 75$ sont situés dorsalement le long de ces derniers.

Extérieurement, à droite et à gauche, tout cet ensemble de muscles et de viscères est flanqué d'un énorme paquet de grosses cellules glandulaires, dont les canaux excréteurs, tout en restant distincts, forment des faisceaux qui aboutissent à des cribles situés dans la partie la plus élevée de chacune des deux grandes chambres latérales creusées dans les côtés du $4^{\mathrm{e}}$ segment.

A la partie tout à fait inférieure du thorax, il ne reste plus, de tout l'ensemble que je viens de décrire, que l'oesophage avec ses deux nerfs, les deux trones trachéens, le coeur et les connectifs accompagnés des filets nerveux destinés à l'innervation 
du premier noud. Ces organes se déplacent, peu à peu, les uns par rapport aux autres et finissent par prendre une disposition nouvelle. lls s'alignent tous, non plus dans le plan sagittal, mais dans un plan transversal de manière à se prêter, sans danger, aux mouvements de charnière, si répétés et de si grande amplitude, auxquels ils sont soumis. Cette disposition se voit sur la figure 33 . Les filets nerveux $N$ if ont pris une position un peu plus dorsale pour être aussi près que possible de l'axe des mouvements de charnière. Les trones trachéens ont pu rester dans leur situation normale, à droite et à gauche de l'oesophage, mais celui situé à la droite de l'animal s'est écarté pour fournir de la place aux connectifs nerveux et au cour. Ces deux organes ont quitté la situation qu'ils occupaient dans le plan sagittal; ils se sont dirigés l'un vers l'autre, se sont accolés et se sont placés : les connectifs, sur le flanc droit de l'œsophage; le cœur, sur le flanc gauche de la trachée droite.

Peu après avoir franchi cet étroit passage, les viscères tendent à reprendre un groupement se rapprochant de la disposition normale que nous avons vue à la base du corselet. Ce groupement est indiqué par les figures 35 et 36 , et surtout par la figure 37 .

La chaine ganglionnaire est logée dans le plan médian, immédiatement au-dessous de l'oesophage, dont elle n'est séparée que par le diaphragme (fig. 37).

L'œsophage reste toujours accompagné de ses deux nerfs gastriques ( $N$ I 4$)$.

L'aorte $(V d)$ qui a repris sa place sur la face dorsale de l'oesophage, se loge (fig. 37) dans une légère dépression de cette face. Sur la figure 35. on voit des filaments conjonctifs qui la soutienment et la relient aux trachées. Les coupes montrent les filets nerveux qui laccompagnent (fig. 35, 36, 37). 
Seuls les deux trones trachéens n'ont pas repris tout ì fait la place qu'ils occupaient dans le thorax. Au lieu de se placer à droite et à gauche de l'œesophage, ils se rapprochent l'un de l'autre et restent un peu plus dorsaux.

L'étude anatomique du pétiole montre done que, malgré la grande ténuité de cette partie, tous les viscères y occupent une situation normale. Ce n'est que, juste au niveau de l'articulation, qu'ils viennent, tous, sur un parcour's réduit, s'aligner dans dans un même plan transversal, de manière à se prêter, sans danger, aux grands mouvements de charnière auxquels il sont soumis.

Le pétiole est parcouru par deux gros trones trachéens longitudinaux, munis, dans chacun des deux nœuds, de troncs stigmatiques qui émettent des ramifications ventrales et un tronc transversal dorsal. Les stigmates y sont absolument normaux avec leur appareil de fermeture mù par un muscle adducteur et un muscle abducteur.

L'aorte y fait passer, d'une façon normale, le courant ascendant du sang qui trouve, pour redescendre, un passage relativement grand.

L'œesophage, llanqué des deux nerfs gastriques, le traverse en restant accolé au diaphragme.

Ce dernier y est partout d'une netteté remarquable.

Le ganglion appartenant au premier nœud est remonté dans le corselet.

Le ganglion du $2^{\mathrm{e}}$ nœud est remonté dans le $\mathrm{I}^{\mathrm{er}}$ nœud.

Le ganglion du segment Se z est resté dans son anneau; en sorte que le $2^{\mathrm{e}}$ næud ne contient pas' de ganglion (et il en est de même chez le Lasius, où le segment abdominal Se 6 qui correspond au $2^{\mathrm{e}}$ nœud des Myrmicides a été, lui aussi, abandonné par son centre nerveux).

Quant à la musculature, dont la composition est franchement celle d'anneaux abdominaux, elle a subi, dans le dernier 
segment du corselet et surtout dans le I $^{\text {er }}$ nœud, d'importantes réductions qui n'ont guère frappé le $2^{\theta}$ nœud.

Les muscles qui produisent la stridulation ne sont autres que les museles normaux chargés des mouvements relatifs du segment Se $J$ par rapport au segment Se 6 .

18

\section{Sur le système glandulaire des Fourmis.}

Je n'aborde dans cette Note que le système glandulaire tégumentaire, y compris les glandes de la région buccale, mais je laisse de côté les glandes du tube digestif et celles de l'appareil vénénifique. Je n'adopte pas, dans cette Note, la méthode, généralement usitée, qui consiste à donner à une glande un nom tiré de la situation si secondaire et si variable que ses acini occupent dans le corps de l'Insecte, les homologies, et par conséquent les dénominations, des glandes des Arthropodes doivent ètre établies d'après la situation de leurs orifices, e'est-à-dire d'après la situation morphologique des points où les glandes prennent naissance pendant le développement.

La conclusion de cette Note est que chaque segment, ì l'exception de quelques-uns oì elles ne se sont pas développées, possède un groupe pair de cellules glandulaires en rapport avec le tégument du corps.

19

Etudes sur les Fourmis. Note 8. Sur l'Organe de nettoyage tibio-tarsien de Myrmica levinodis.

Les deux faits nouveaux que je fais connaitre dans cette Note sont :

Io L'existence d'un organe glandulaire le long du premier article du tarse des Fourmis. 
$2^{\circ}$ Le mode de nettoyage de l'antenne, et le mode de rejet, sous forme de corpuscules enroulés, moulés dans une cavité supralabiale, des détritus de nettoyage.

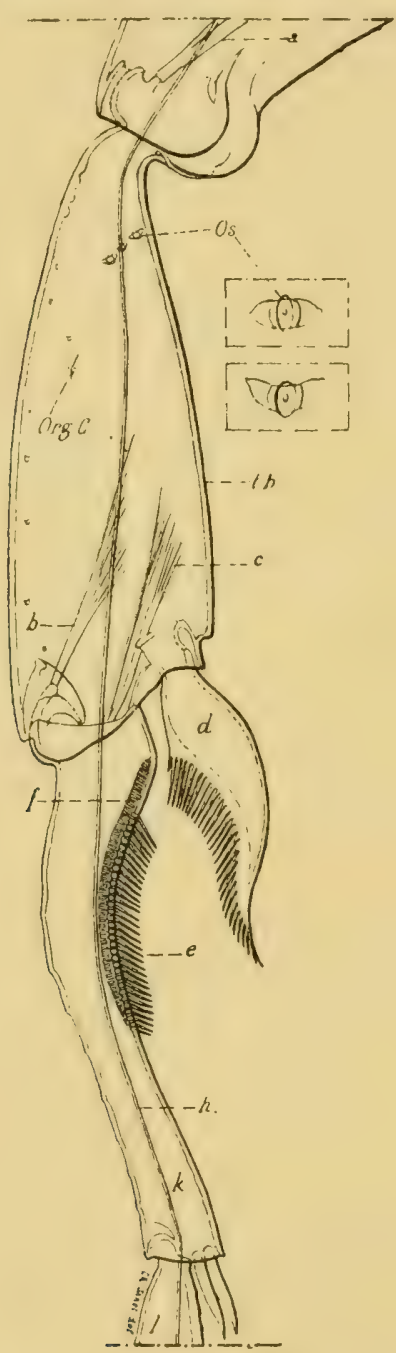

Fig. 38. Myrmica rubra L. (levinodis Nyl.) ouvrière inago. Tibia et premier article du tarse de la patte antérieure gauche vus par la face postérieure. Gross. 100 . Sur la partie gauche du libia, on voit la tache ressemblant a une petite cicatrice qui correspont à l'organe chordotonal tibial. $A$ la partie supérieure sont figurés quelques-uns des organes sensitifs allongés qui se trouvent sur les deux faces, anlérieure el postérieure, à lextrémité proximale du tibia. Deux de ces organes sont figurés a droite a un grossissement quatre fois plus fort; $a$, tendon du muscle releveur du tibia; $\downarrow$, tendon du muscle releveur du tarst; $c$, tendon du muscle abaisseur du tarse; d, éperon pectiné ; $e$, peigne tarsien; $f$, bande poreuse; $h$, long tendon du muscle fléchisseur des grilles ; $k$, premier article du tarse; $l$, deuxième article du tarse. Org. $c$, trace externe de l'organe chordotonal tibial. Os, organes sensitifs. 


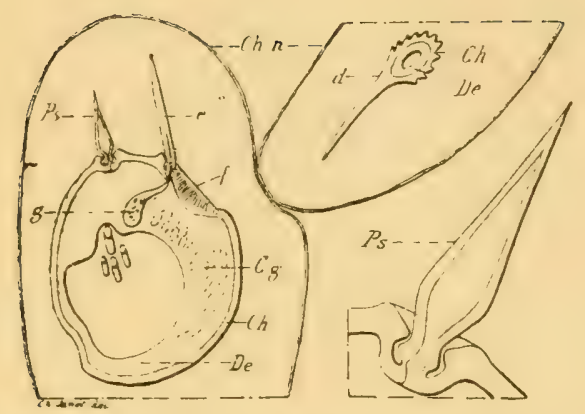

Fig. 39. - Myrmica rubra L. (levinodis Nyl.) femelle, nymphe sur le point d'éclore.

Coupe transversale de l'organe pectiné. Gross. 200. $\mathrm{Cg}$, cellules épidermiques glandulaires; $C h$, squelette chitineux; $C h n$, cuticule chitineuse nymphale; $d$, éperon pectiné; $D c$, épiderme; $e$, peigrné tarsien; $f$, hande poreuse; $g$, ganglion nerveux d'une dent du peigne tarsien; $P_{s}$, un des gros poils sensitifs épars, situés, par rapport au peigne tarsien, du còté opposé à celui de la bande poreuse. Gross, 800 sur la fig. en bas à droite.

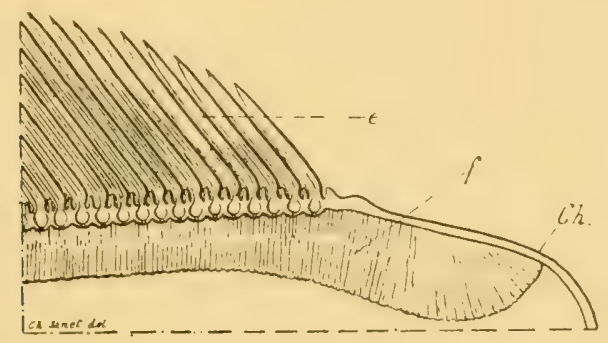

Figr. 40. Myrmica rubra L. (levinodis Nỵl.) femelle. Organe pectiné tibial, vu de còté, (iross. 400. $C h$, squelette chitineux; $e$, peigue tarsien; $f$, bande poreuse.

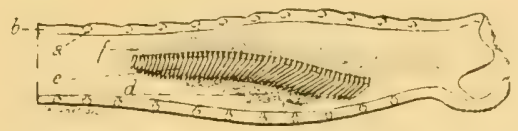

Fig. 11. - Gross. 100. Myrmica rubra L. (levinorlis Nyl.) reine, imago. I'remière patle. Partie proxinale du premier article du tarse droit, vu par son còlé ventral et montrant ainsi lé peigne tarsien, vu de face. Les poils de l'organe forment une rangée simple et sont inclinés à la fois vers l'extrémité distale de l'article et vers le còté anal de l'animal. Au-dessous de la rangée de poils, on voit l'accumulation des détrilus enlevés anx antennes el, du cóté opposé, le bourrelet criblé de pores.

$a$, fossettes d'insertion de poils sensitifs ; $b$, squeletle chitineux ; $d$, détritus ; $e$, peigne tarsien ; $f$, bande poreuse. 


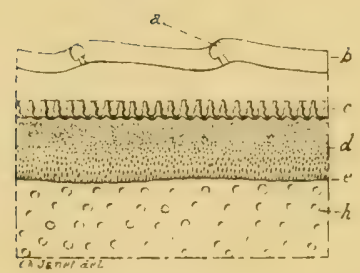

Fig. 42. - Gross. 200. Myrmica rubra L. femelle, imago.

l'ortion du peigne tarsien. Les poils articulés qui constituent les dents du peigne sont supposés enlevés et représentés seulement par teurs fossettes d'insertion.

$a$, fossettes dinsertion de gros poils sensitifs; $b$, contour apparent montrant lépaisseur du squelette chitineux; $c$, rangée des fossettes d'insertion des dents du peigne tarsien; ces fossettes sont vues par transparence en coupe longitudinale; les poils sont inclinés du còté opposé à la bande criblée ; $d$, bande poreuse longeant le peigne; en haut, ies pores, vus en lout, sont représentés par des points; en bas, par suite de leur divergence, ces pores sont vus obliquement et se traduisent non plus par des points, mais par de petites lignes; $e$, contour apparent, vu par transparence, de lia Face interne de la hande poreuse ; $h$, fossettes d'insertions de poils sensitifs ordinaires.

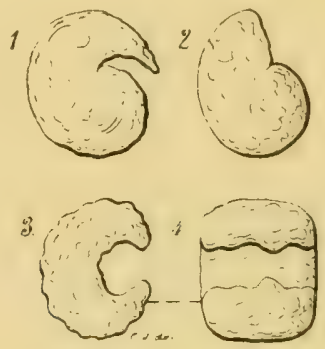

Fig. 43. - Formica rufa. Petits corpuscules enroulés provenant du platre que les Fourmis ont enlevé au moyen de leur's mandibules aux parois d'un nid artificiel (Gross. 6), 1, 2,3 , trois de ces corpuscules vus de còté; 4 , vue de face du corpuscule 3 .

Les conclusions qui terminent cette Note sont:

L'organe de nettoyage tibio-tarsien des Mrrmica comprend: I $^{\circ}$ Un éperon pectiné à dents pleines dont tout l'ensemble n'a que la valeur d'un seul poil sensitif articulé. Outre ses dents, ce peigne porte un grand nombre de poils fins, non articulés, qui en font une véritable brosse.

$2^{\circ}$ Un peigne tarsien dont chaque dent consiste en un poil sensitif articulé : ces dents sont serrées les unes contre les autres et forment une rangée simple. Ce peigne est incliné, dans le sens voulu, pour que son action soit aussi eflicace que possible, et e'est dans langle aigu, formé par son plan et la 
surface de l'article qui le porte, que s'accumulent les produits du nettoyage.

$3^{\circ}$ Une bande longitudinale poreuse, formée par une partie, modifiée et épaissie vers l'intérieur, du squelette chitineux. Les innombrables pores qui criblent cette bande sont en rapport avec des cellules épidermiqutes devenues glandulaires, et sont gorgés du produit de ces glandes. Cette bande poreuse sécrétrice longe le peigne tarsien et est située du côté opposé à celui vers lequel les dents de ce peigne sont inclinées. La surface de l'antenne n'arrive, ainsi, en contact avec cette bande sécrétrice qu'après avoir été nettoyée par le peigne. Il est vraisemblable que la sécrétion qui imbibe cette bande poreuse joue un róle dans la lubrification et le nettoyage des surfaces sur lesquelles elle passe et en particulier de l'antenne.

$4^{\circ}$ De gros poils sensitif's articulés, isolés, qui sont situés le long du peigne tarsien, du côté opposé à celui de la bande poreuse et qui jouent un certain ròle dans l'enlèvement des corps étrangers.

L'organe de nettoyage tibio-tarsien des Hyménoptères peut ètre employé au nettoyage de plusieurs régions du corps, mais d'accord avec Forel et avec Pérez, et contrairement à l'opinion de Canestrini et Berlese, il faut admettre que le rôle, sinon exclusif, du moins de beaucoup le plus important, est le nettoyage de l'antenne située du même côté.

Lorsqu'une Fourmi fait passer son organe tibio-tarsien audessous de ses mandibules, ce n'est pas, comme l'admettent Canestrini et Berlese, pour nettoyer la langue; mais au contraire pour enlever, au moyen des peignes et poils des organes buccaux, les détritus qui encombrent l'organe tibio-tarsien. Ces détritus, dans le cas de poudres inertes, sont repris par la langue et moulés dans une cavité supralabiale, sous forme de petits corpuscules enroulés sur eux-mêmes, dont l'animal se 
débarrasse ensuite facilement. Je retrouve ces corpuseules, parfois en abondance, dans mes appareils d'observation.

\section{0}

Etudes sur les Fourmis, les Guêpes et les Abeilles. Note 9. Sur Vespa crabro. Histoire d'un nid depuis son origine.

Cette Note donne l'histoire complète d'un nid de Frelons observé, d'une manière continue, depuis le jour de son apparition, au mois de mai, jusqu'à l'extinction de la colonie, au mois de novembre.

Le 15 mai, le nid débutait par une petite tige de quelques millimètres de longueur et bientôt apparaissaient, au bout de cette tige, les premier's alvéoles.

Je montre que les alvéoles tendent à se grouper autour d'une figure nucléale formée par les 4 premiers d'entre eux (fig. 44 à 49).

La figure 63, reproduction de celle donnée généralement pour représenter la symétrie d'un gâteau normal, ne peut lournir une idée exacte de l'ordre d'apparition des premiers alvéoles, tandis qu'au contraire la figure 64 dérive, tout naturellement, des figures représentant les premiers accroissements du gâteas.

Les figures 44,45 et 50 montrent les accroissements successil's de la première enveloppe. Elle n'est arrivée à être complète qu'au bout de quarante et un jours. Sa forme rappelle alors celle d'une montgolfière et sa fonction principale est de conserver la chaleur dégagée, dans son intérieur, par la mère. 


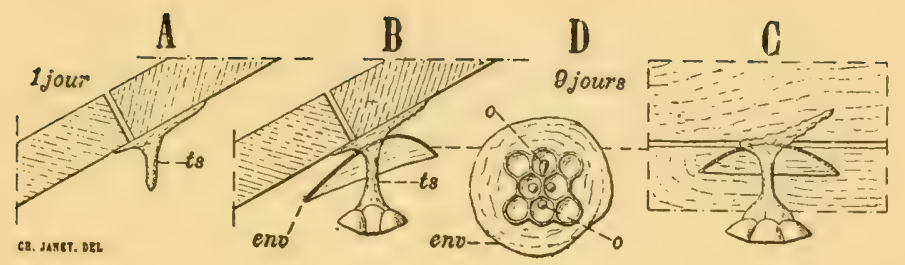

Figr. 44. - A, ébauche de la tige de suspension; $B$, état du nid ì 9 jours, vu de còlé $; C$, vue de cóté, perpendiculaire a la précédente; $D$, le nid vu par dessous; en $B$ et $C$, la moitic de l'enveloppe est supposée enlevé Rèd. 0,5.

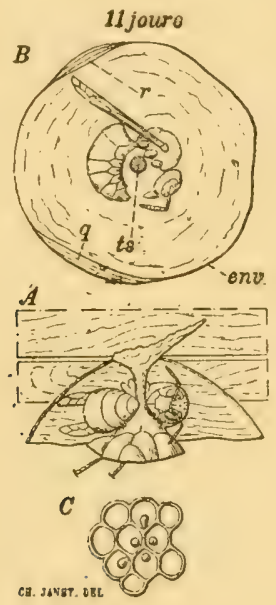

Fig. 4.). - Etal du nid, ì 11 jotrs, avec la mère dans sa position de repos, enroulée atutour de la tige de suspension et reposant sur le sommet du gatteau alvéolaire. $\Lambda$, le nid vu de cóté, la nıoitié de l'enveloppe étant supposée enlevée; $B$, le nid vu par dessous, le griteau alvéolaire étant supposé enlevé ; env, enveloppe; $t s$, tige de suspension; $q$ et $r$, deux parties ajoulées à l'enveloppe et provenant de l'emploi complet d une seule bonlette de pite de bois; $C$, fice inférieure du gàteau alviolaire, liéd. $0,3$.

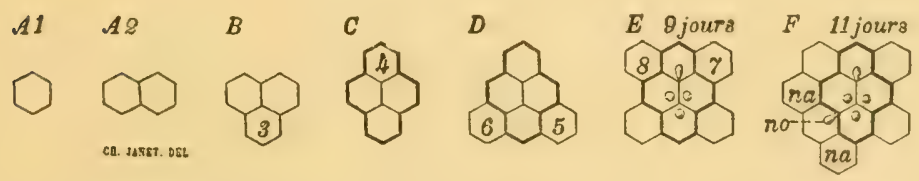

Fig. 46. - Ordre dapparition des 10 premiers alvéoles. Le contour de la ligure nucléale, furmée par les 4. premiers alvéoles, est intigué par un trait renforcé. 

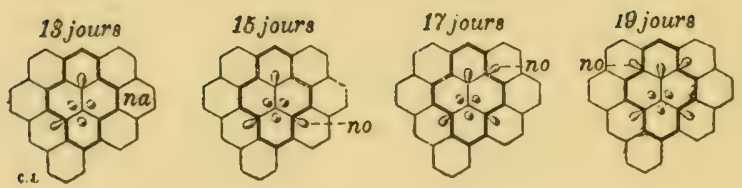

Fig. 17. _ Schema de lélit du fer gâteau i $13,15,17$ et 19 jours.
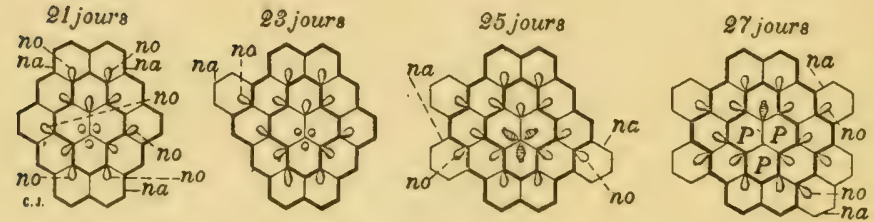

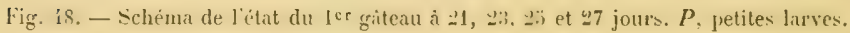

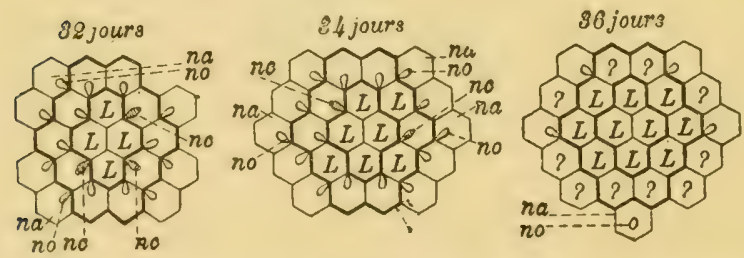

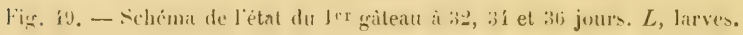
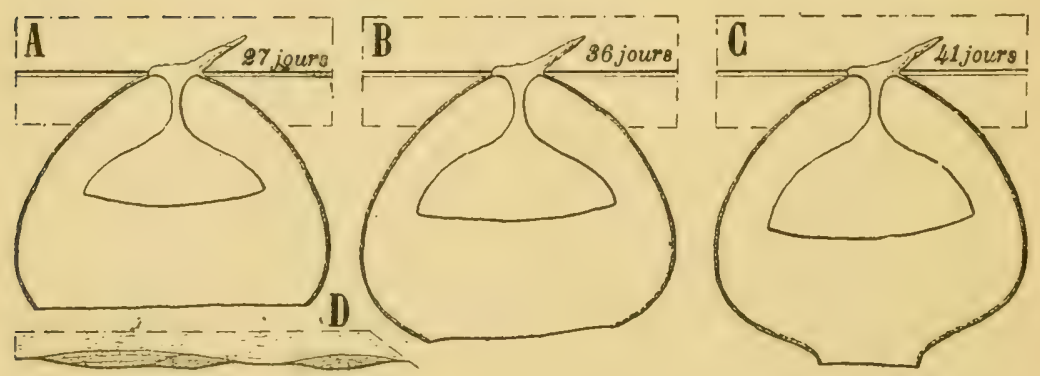

Fig. $50 .-A, B, C$, état de l'enveloppe à $2 \bar{i}, 36$ et 41 jours; la moitié de l'enveloppe est supposée enlevée; $D$, trois lambeaux fabriqués avoc une seule buulette de pate de bois. Réd, $0,3$. 

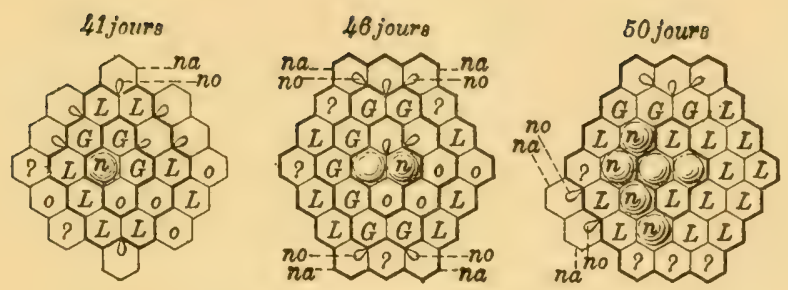

Fï. 51. - Schéma de l'état du 1er gâteau, ì 41,46 et 50 jours.

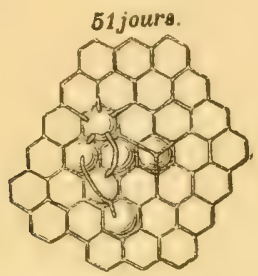

Fig. 5:. - Amorces anormales de cloisons construiles à la surface des opercules. Réd, 0,5.
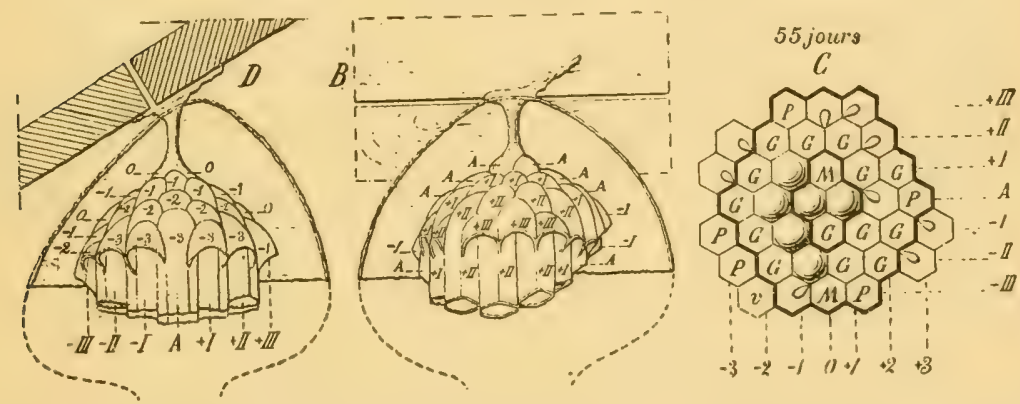

Fijg. 33. - Etat du nid (5ว jours) la veille de l'éclosion de la première ouvrière. Réd. 0,$5 ; b$, vue de côté; $D$, vue de côté perpendiculaire à la précédente; $C$, schémà de l'état d'avancement du nid. Le ler et le $3^{e}$ contours sont indiqués par un trait renforcé. Les œeufs sont indiqués dans la situation qu'ils occupent réellement.
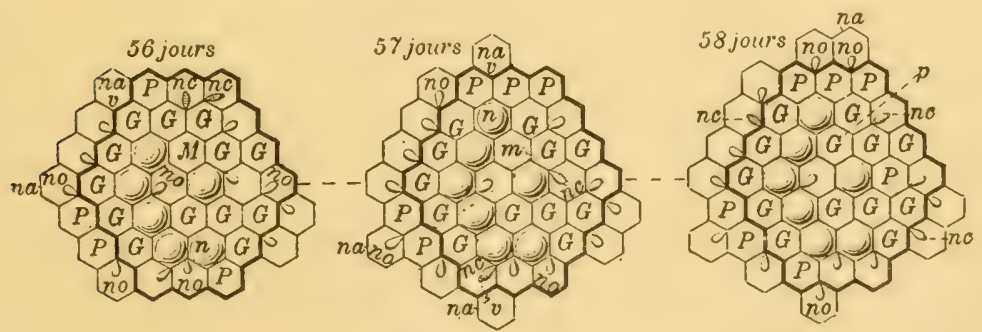

Fjg. 5\%. - Schéma de l'état du nid à 56,57 et 58 jours. 

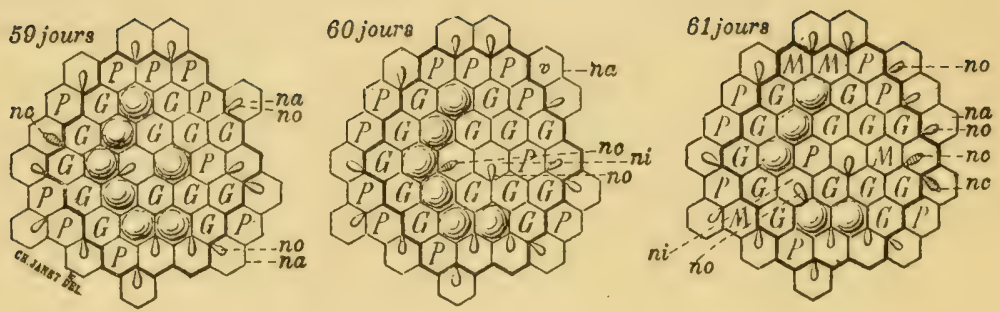

Fig. Ji). - Schéma de l'état du nid à 59, 60 et 61 jours.
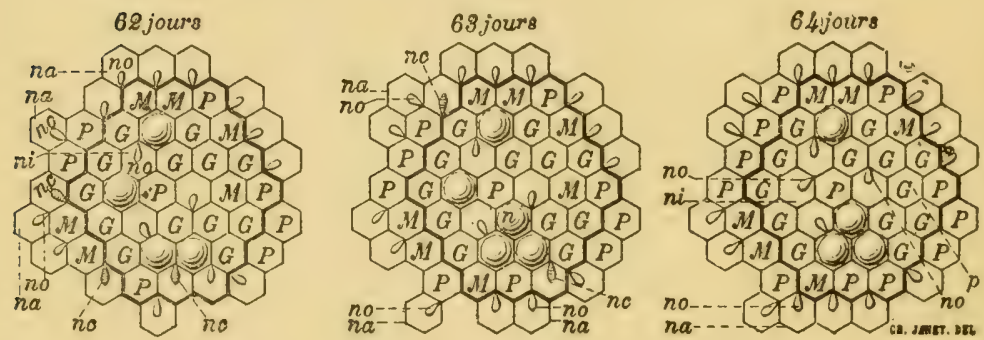

Fig. 56. - Schéma de l'état du nid à 62,63 et 64 jours.
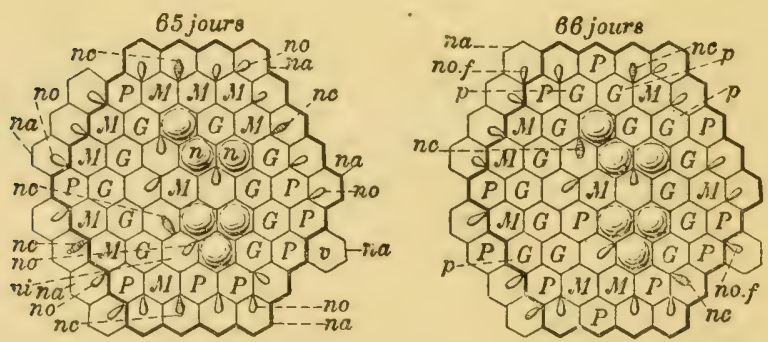

Fig. 57. - Schéma de l'état du nid ì 6 ô et 66 jours.
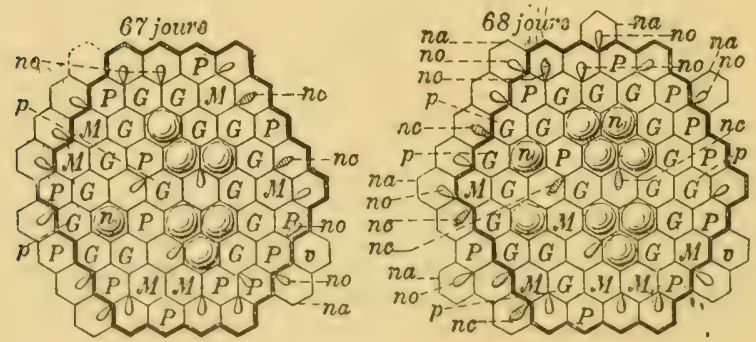

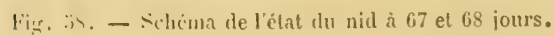




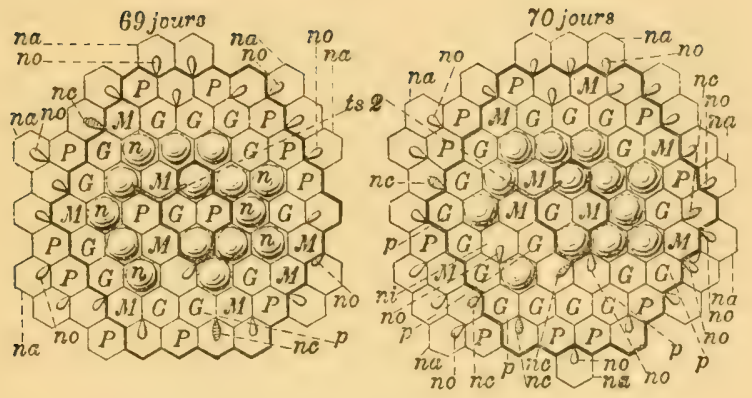

Fig. 59. - Schéma de I'état du nid à 69 et 70 jours.
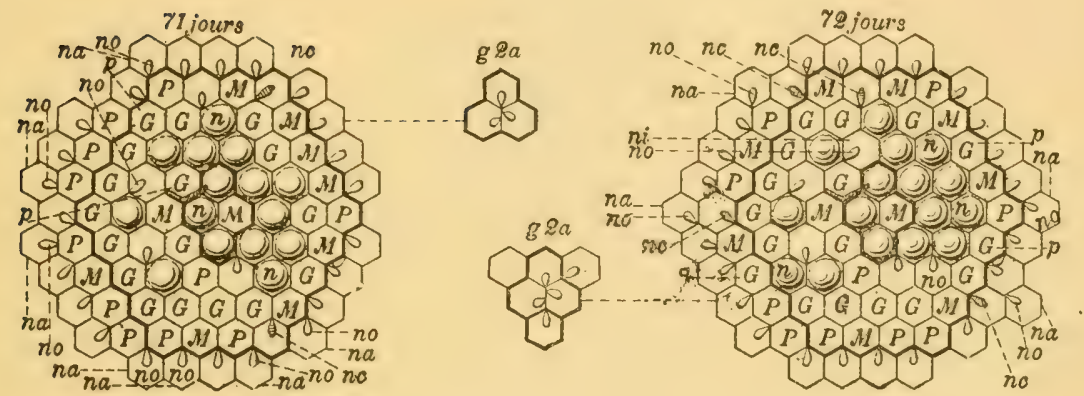

Fig. 60. - Schéma du nid à 71 et 72 jours.

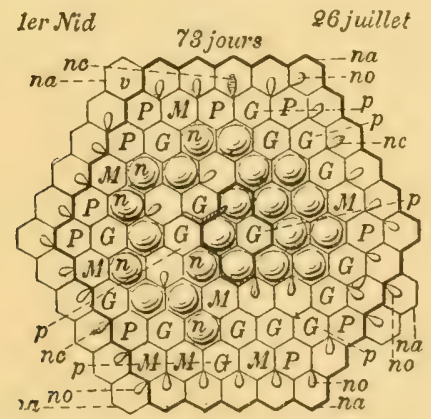

Fig. 61. - Schéma du nid à 73 jours avant l'enlèvement d'une partie des alvéoles. 

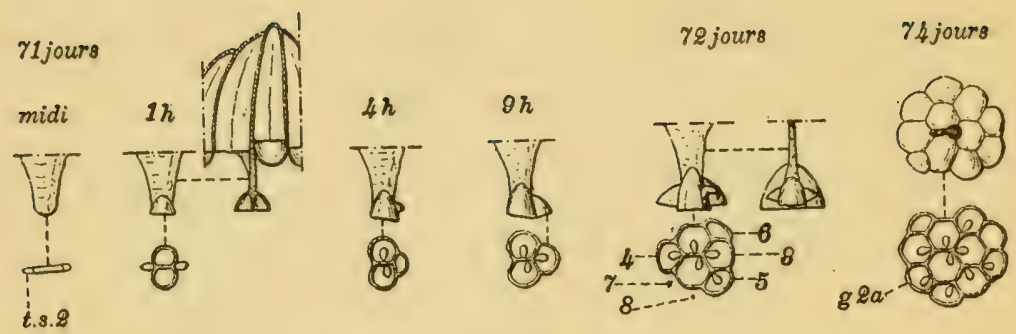

Fïr. 62. - Formation du 2e griteau alvéolaire. Réd. 0,5

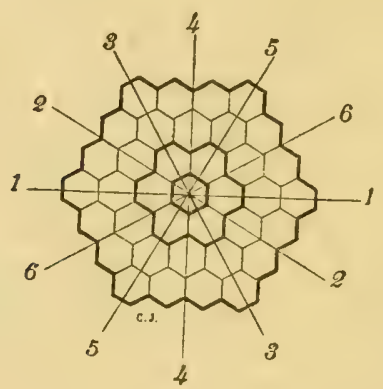

Fig. 63. - Figure symétrique autour d'un alvéole pris comme alvéole central, et possédant 6 axes de symétrie. Cette figure correspond à l'état du nid à l'àge de 56 jours mais ne représente pas l'ordre d'apparition des premiers alvéoles.

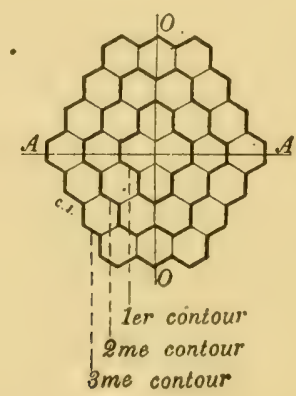

Fig. 64. - Figure à 2 axes de symétrie correspondant à l'état du nid à l'àge de 46 jours. Cette figure dérive d'une façon naturelle de l'ordre d'apparition des premiers alvéoles. Les traits forts représentent les contours successivement formés autour de la figure centrale. 


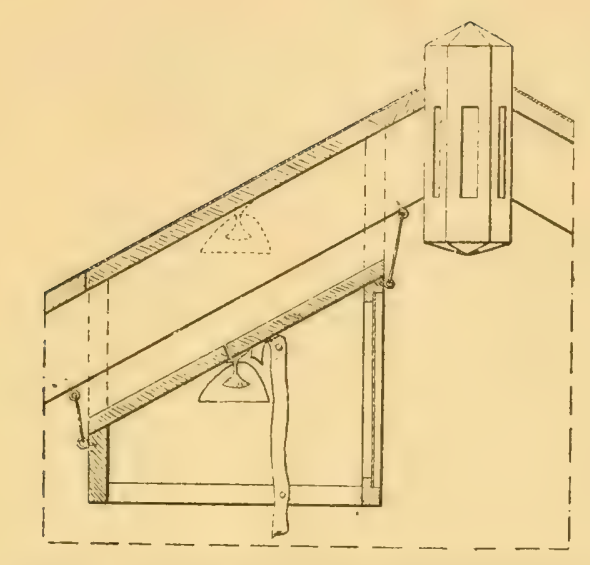

Fig. fii. - Pose de la ciage destinie il lentevement du nis\}.

Jusqu'au moment de l'éclosion des premières ouvrières (cinquante-six jours), la mère qui doit, à elle seule, construire le nid et subvenir à tous les besoins de sa progéniture, fait des courses nombreuses. Ces comrses peuvent ne durer que trois ou quatre minutes pour la récolte de la pâte de bois; mais elles peuvent être beaucoup plus longues et durer jusqu’à quarante minutes, lorsqu'il s'agit de rapporter de la nourriture.

Après avoir employé sa boulette de pâte ou distribué les provisions destinées à ses larves, la mère procède, générale. ment, à un grand nettoyage de tout son corps, puis à une visite des alvéoles, dans lesquels elle introduit sa tête, les antennes tendues en avant.

Puis, cinq à dix minutes après son retour, elle se met au repos et prend, pour cela, une position tout à fait spéciale (fig. 45). Elle grimpe au-dessus du gâteau et s'enroule, en anneau, autour de la tige de suspension du nid, son extrémité abdominale arrive presque au contact de ses mandibules. Elle reste dans cette position, le plus souvent pendant dix it vingt minutes et, parfois, lorsque le temps est très mauvais, 
beaucoup plus longtemps. Dans cette situation, non-seulement la mère peut se reposer plus longuement, mais, de plus, elle occupe la position la plus favorable pour faire profiter

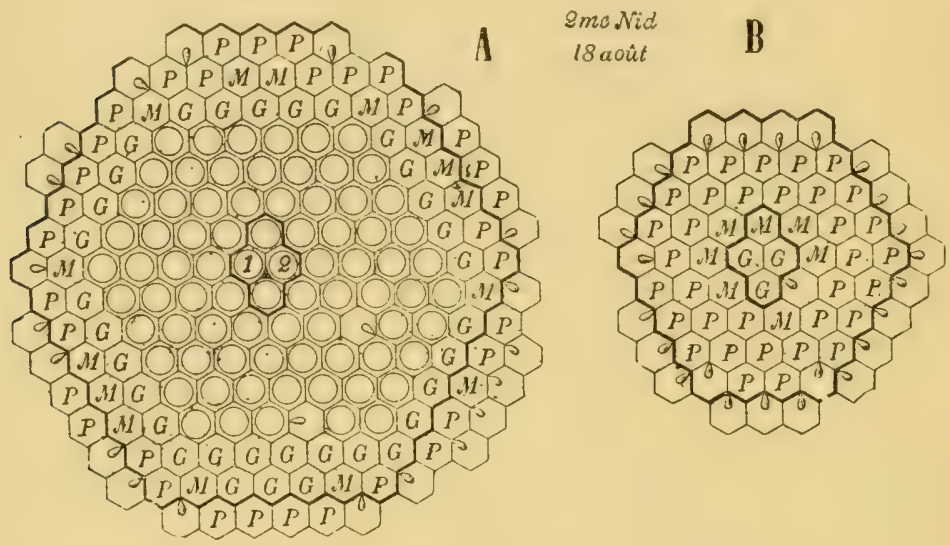

Fïg. 66. - 2e nid. Schéma de l'état des gàteaux le 18 août, jour de la caplure; $A$, premier gåteau: $B$, deuxième gâteaı. Les opercules sont représentés par des cercles. Les culs sont figurés dans la position qu'ils occupent réellement. $P, M, G$, petites, moyennes et grosses larves.
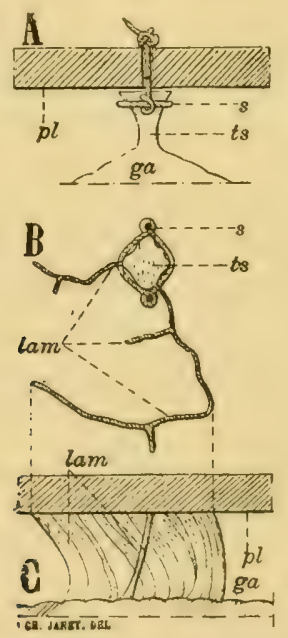

Fig. 67. - Lames construites par les ouvrières, pour consolider la suspension de leur gâteau alvéoliare suspendu par un fil au plafond d'une cage; $A$, suspension établie au moment de l'installation; $B$, vue en plan des lames ajoutées. Ces lames sont supposées décollées du plafond de la cage. $C$, une partie de ces lames, vues de còté; $p l$, plafond de la cage ; $s$, fil de suspension; $t s$, tige de suspension; ga, gâteau alvéolaire; lam, lames de consolidation. 
ses œufs et ses jeunes larves de la chaleur qu'elle dégage, chaleur qui s'emmagasine dans l'intérieur de l'enveloppe et

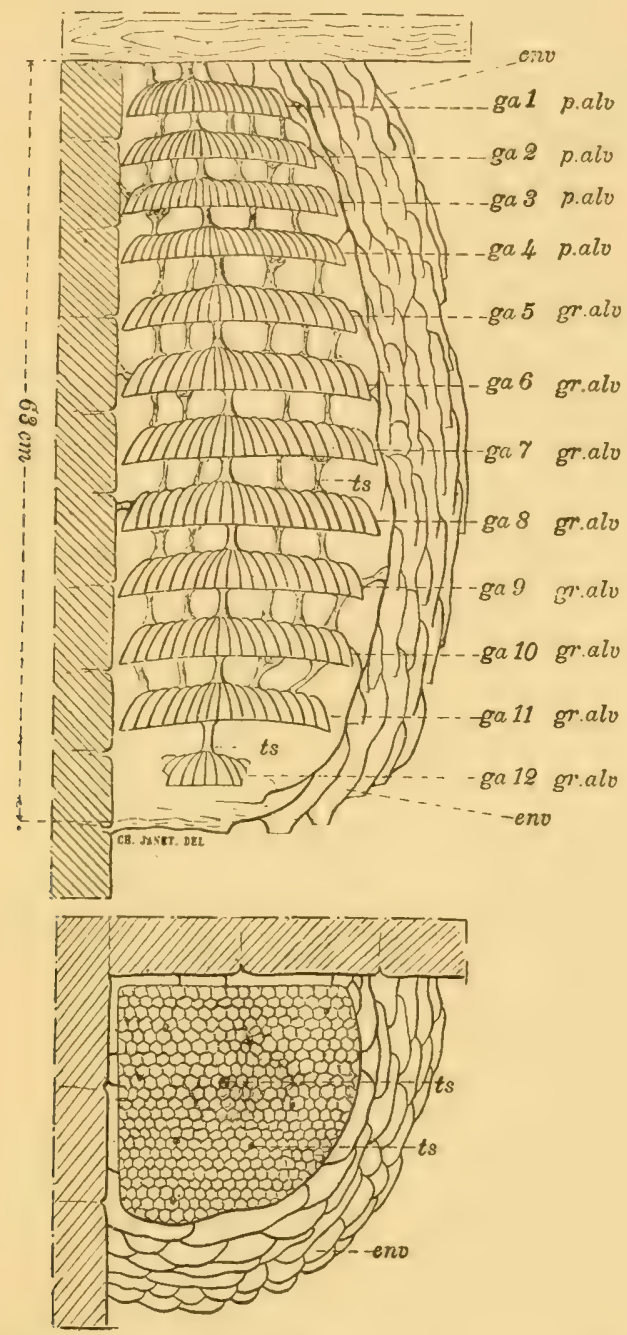

Fig. 68. - Grand nid construit dans l'angle d'un grenier. Réd. 1/3. Aspect latéral du nill décollé du mur; 1 à 1 , les 4 premiers giteaux formés de petits alvéoles; 5 ì $\ell 2$, les 8 gâteaux suivants formés de grands alvéoles; ga 12,1 , griteaú en cours de construction; $e n v$, enveloppes couvertes de longues tubulures.

Fig. 69. - Le mème nid coupé transversalement au nivean de sa plus grande largeur; $t s$, tiges de suspension. 
qui est bien utile pour hâter le développement de la progéniture à cette époque encore froide de l'année.

Lorsque la reine est ainsi enroulée en anneau, autour de la tige de suspension de son nid, elle est assez difficile à voir, et cest pour cette raison que cette position de repos n'a pas été remarquée par les anciens observateurs.

Je décris ensuite un grand nid en cours de développement (fig. 66 et $6 \mathrm{~g}$ ).

Comme troisième exemple, je figure un très grand nid arrivé au terme de son développement (fig. 68 et 69).

A la suite de' ces trois exemples, j'étudie, d'une façon générale, les nids de Frelons dans leurs diverses parties, et d'abord les enveloppes et les tubulures qui les recouvrent, leur mode de formation, leur rôle.

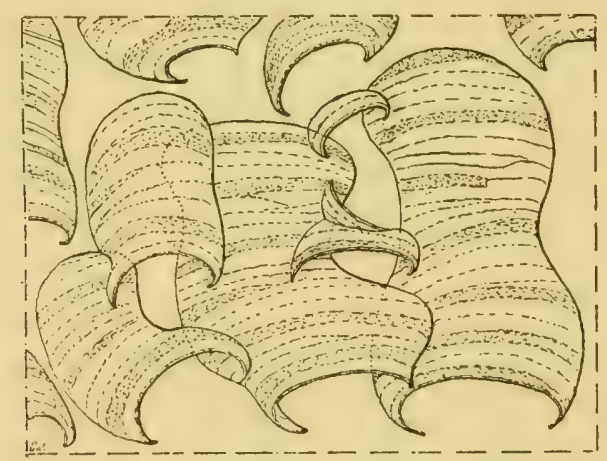

Fig. 70. - 1er nid. Tubulures naissantes construiles à la surface de la dernière enveloppe continue.

Lorsque, dans un nid aérien, libre sur toutes ses faces, les gâteaux ont acquis leur diamètre définitif et que les enveloppes simples qui les entourent n'ont plus besoin d'être démolies pour être remplacées par de plus grandes, les ouvrières les recouvrent extérieurement d'un grand nombre de lames formant des sortes de boursouflures (fig. go) qui s'accumulent les unes sur les autres et finissent par se fermer à leur partie inférieure. Il en résulte une véritable muraille cloisonnée où l'air ne peut 
se renouveler et qui constitue une enveloppe éminemment lavorable à la conservation de la grande quantité de chaleur dégagée dans le nid par ses nombreux habitants.

La première enveloppe est entièrement construite par la mère, et reste intacte jusqu'à l'apparition des premières ouvrières. Ce sont ces dernières qui construisent de nouvelles enveloppes plus grandes et démolissent ensuite l'enveloppe primitive, devenue insuffisante.

Les nids de Frelons établis dans les cavités des arbres et des murs sont toujours, à l'origine, comme les autres, pourvus d'une petite enveloppe complète, construite par la mère. D'autres enveloppes, extérieures à la précédente et de plus en plus grandes, sont toujour's construites par les ouvrières au fur et à mesure de la démolition des enveloppes internes et de l'accroissement des gàteaux. Mais, lorsque les dernières enveloppes arrivent au voisinage des parois de la cavité, elles ne peuvent plus être remplacées après avoir été détruites, et le nid en reste dépourvu. C'est ce qui est arrivé sur les trois quarts du pourtour du nid que j’ai représenté dans les figures 68 et 69 et sur la totalité du pourtour d'un nid figuré par de Saussure. L'absence d'enveloppe ne doit donc pas être attribuée à l'instinct des Frelons qui n'en construiraient pas pour cette raison qu'elles sont inutiles, mais simplement à ce fait que, après la destruction des enveloppes devenues trop petites, un obstacle mécanique s'oppose à la construction d'enveloppes plus grandes.

Tandis que les Frelons manifestent une vive colère, lorsqu'on fait subir une mutilation aux gâteaux alvéolaires de leur nid, mutilation qu'ils reconnaissent mème lorsqu'elle a eu lieu en leur absence, j’ai pu constater qu'ils ne prêtent, pour ainsi dire, ancune attention aux dégâts que l'on fait subir à l'enveloppe. Il semble que l'état de cette dernière, sur laquelle d'ailleurs ils ne circulent que très exceptionnellement, ne laisse 
aucune trace dans leur mémoire, tandis que l'état de leurs gàteaux, sur lesquels ils circulent sans cesse, semble y être gravé exactement.

J'étudie ensuite les tiges de suspension principales et secon-

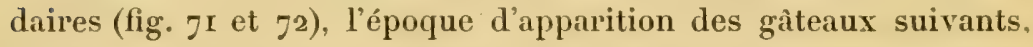
leur nombre et leur composition, puis la forme et la disposition des alvéoles (fig. 73 et 74 ).

Rouget dit que dans les nids de $V$. crabro, les alvéoles destinés aux reines n'ont pas un diamètre plus grand que les

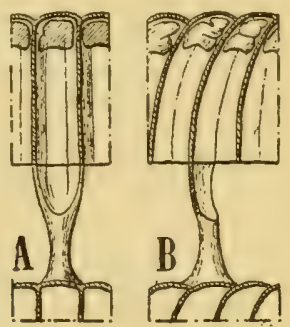

Fig. 71. - Une tige de suspension, avec cavité correspondant à un opercule; A, vue de face; B, vue de côté, la moitié de la partie mince de la tige est supposée enlevée pour laisser voir sa concavité. En haut les sacs noirs desséchés. Réd. 1/2.
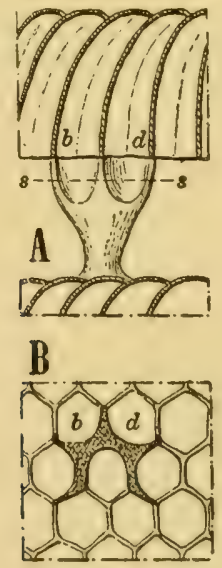

Fig. 72. - Tige de suspension, avec 5 cavités correspondant à 5 opercules; $A$, vue du côté des cavités surmontant les deux alvéoles $b$ et $d$, de la figure suivante; $B$, la tige de suspension coupée qu niveau du trait pointillé ss de la fig. A. Réd, 1/2. 


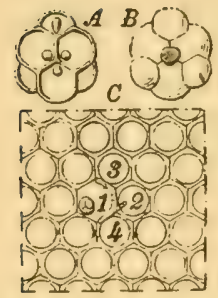

Fìg. 73. - Réd. 0,37õ. A, 3e gâteau du ler nid vu par dessous; $B$, vu par dessus; $C$, région centrale du ${ }^{e}$ gàteau avec l'insertion de la lame de suspension du $3^{\mathrm{e}}$.
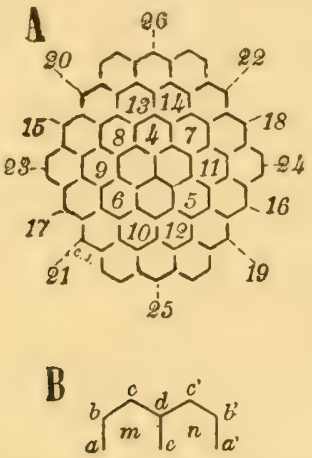

Fig. 74. - A, Schéma donnant, pour les 28 alvéoles compris dans l'intérieur du 3e contour : 10 l'ordre d'apparition; et $2^{\circ}$, indiquées par de petits espaces laissés en blanc, les limites ou lignes de sulures des cloisons; $B$, modification survenant lorsque les alvéoles ont grandi.

autres, mais sont seulement plus profonds. Cela n'est pas exact. Les gâteaux supérieurs sont formés d'alvéoles de $8 \mathrm{~mm}$. et les gâteaux inférieurs d'alvéoles de ro $\mathrm{mm}$. 5 .

Tandis que dans les nids de $V$. germanica on a constaté P. Marchal) que le nombre des gàteaux à grands alvéoles est inférieur à celui des gàteaux à petits alvéoles, on a, pour les grands nids de $V$. crabro, une proportion inverse. J'ai observé un nid dans lequel quatre gàteaux à petits alvéoles étaient suivis de huit gåteaux à grands alvéoles.

Les Frelons emploient le bois pourri pour construire leur nid. On a dit qu'ils employaient aussi à cet usage les écorces des arbres vivants. Cela me paraît être inexact, car, bien que mes Frelons aient, en septembre et en octobre, attaqué l'écorce 
des Frènes du voisinage, il m'a été impossible de trouver dans leurs nids des parties construites avec ces écorces.

Le véritable motif pour lequel les Frelons attaquent, en fin de saison, les arbres vivants, paraît ètre uniquement le besoin qu'ils éprouvent de se procurer la sève qui suinte des écorces entamées.

Tandis que les Frelons, en arrivant au nid, partagent le plus souvent les boulettes de pâtée alimentaire qu'ils rapportent. ils ne partagent jamais les boulettes de pâte de bois. Chacun emploie intégralement la totalité de la boulette qu'il a récoltée. Presque toujours, dans les jeunes nids, les ouvrières, après avoir employé la majeure partie d'une boulette à la construction de l'enveloppe, en conservent un petit reliquat, qu'elles utilisent, après un malaxage complémentaire, pour la construction des alvéoles.

La température intérieure des nids est assez élevée. Le 8 octobre, à 2 heures de l'après-midi, les 3 thermomètres de l'une de mes cages d'observation donnent :

$\begin{array}{cllll}\text { Température extérieure. . . . . } & \text { I6 degrés } \\ \text { - } & \text { du laboratoire . . . } & 20 & - \\ \text { - } & \text { intérieure du nid. . } & 32 & -\end{array}$

La diflérence entre la température du laboratoire et celle du nid est ainsi de 12 degrés. Cette différence se maintient, avec de faibles variations, jusqu'au i9 octobre. A partir de cette date, cette diflérence s'abaisse rapidement, d'une manière continue, ì raison d'environ $\mathrm{I} / 2$ degré par jour. Le 4 novembre, elle tombe à 2 degrés $\mathrm{I} / 2$. La population du nid se trouve alors réduite à 5 ouvrières, encore bien vigoureuses, et à 5 larves.

La ponte peut être observée, dans de bonnes conditions, lorsqu'elle a lieu dans un alvéole situé sur le bord d'un gàteau et, par conséquent, encore peu profond. L'abdomen 


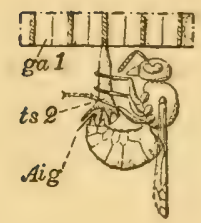

Fig. 73. - La mère déposant un ceul dans le ler alvéole du $2^{\circ}$ gàteau. Réd. $1 / 2$; ga $t$, les gàteau alvéolaire; $t s 2$, tigge de suspension du ge gâteau. Aig, aiguillon en grande extension et ramené vers le dos. Entre les deux arceaux du dernier segment visible on voit l'ouf presque entièrement sorti. La moitiẻ antérieure des deux alvéoles est supposée enlevée.
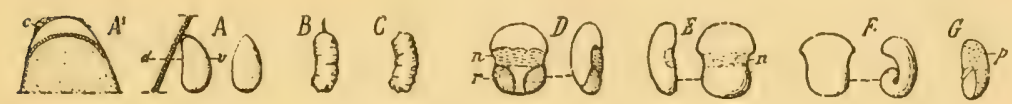

Fig. 76, $-A$, ouf pondu par la mère, gross. 2, vu de côté et vu de face : $v$, còté ventral; $d$, còté dorsal. $A \ell$, extrémité pointue d'un ouf tout récemment pondu et tombé sur le plancher en verre de la cage; l'enveloppe de l'œuf est nettement écartée des parties sous-jacentes; $c$, substance adhésive. $B$ et $C$, excreta émis par une ouvrière après l'éclosion, gross. $4 ; D$ à $G$, boulettes de nettoyage, gross. 5 .

est alors fortement allongé et les deux arceaux du dernier anneau visible bâillent considérablement. Ils laissent sortir l'aiguillon qui, en grande extension, rebroussé vers le dos de l'animal, dirige sa pointe vers l'extérieur de l'alvéole et est visible sur la presque totalité de sa longueur. On a dit que l'aiguillon des Hyménoptères vulnérants pouvait jouer un certain rôle dans la ponte. On voit qu'il n'en est rien chez les Frelons et que, loin de servir au guidage de l'œuf, l'aiguillon s'éloigne le plus possible. Après une série de mouvements qui, pour chaque ponte, se répètent à peu près exactement dans le même ordre, on voit apparaitre la pointe la plus effilée de l'oeul', et, par une légère pression, cette pointe, qui est pourvue d'une substance adhésive, est collée sur le fond de l'alvéole.

J'ai observé la ponte un très grand nombre de fois, aussi bien pour la reine que pour les ouvrières.

Lor'sque, accidentellement, deux oufs sont pondus, le même jour, dans un même alvéole, ils éclosent en général tous deux et les deux larves sont nourries simultanément par 
les ouvrières. Deux jour's après l'éclosion, l'une des deux larves, celle qui occupe la meilleure position, a reçu plus de nourriture et a grossi plus que l'autre. La différence saccentue, pour ainsi dire, dheure en heure, et, bientôt, la larve privilégiée occupe tant de place dans l'alvéole que sa sœur, ne pouvant plus rien recevoir, meurt et se dessèche sur place. La présence de son cadavre, formé d'un petit cylindre noir, recouvert d'une pellicule ratatinée, ne gêne nullement le développement de l'autre larve.

Les oufs ont absolument besoin de la température élevée qui règne dans le nid. Au mois de mai, la température atmosphérique n'étant pas encore très élevée et la première enveloppe n'étant pas encore complète, les œuf́s n'éclosent qu'au bout d'une vingtaine de jour's. En été, l'éclosion a lieu cinq jours après la ponte. $\mathrm{Si}$, à cette époque, on sépare du nid un gâteau pourvu d'œufs, on constate que, seuls, les œufs pondus au moins depuis quatre jours peuvent éclore, tandis que le développement des oufs plus jeunes est complètement arrêté.

Viennent ensuite des observations sur les larves (Mues, Rotation, Serrage des larves dans leurs alvéoles, Matière visqueuse à l'extrémité anale des grosses larves).

Les grosses larves font fréquemment entendre un bruit très prononcé en grattant la paroi de leurs alvéoles. Si on examine une larve faisant ainsi du bruit, on voit qu'elle rejette sa tête en arrière en écartant ses mandibules, puis qu'elle la ramène vivement vers sa face ventrale, en même temps que tout sou corps rentre un peu plus profondément dans l'alvéole. P'endant ce mouvement, les mandibules grattent si fortement la paroi alvéolaire qu'elles en détachent de petits fragments et qu'elles finissent même quelquefois par la perforer. Lorsqu'une larve se met ainsi à gralter à intervalles courts et réguliers la paroi 
de son alvéole, la vibration produite détermine instantanément les larves voisines, et même parfois la totalité des grosses larves du nid, à faire le mème mouvement. Souvent, dans ce cas, elles écartent toutes fortement leurs mandibules et produisent chacune un frottement accompagné d'un bruit très net. C'est alors un véritable concert dans lequel la mesure déterminée par celle qui a commencé est exactement suivie. D’autres fois elles agissent pour ainsi dire automatiquement. La vibration produite par la larve qui commence à gratter avec bruit, les détermine bien encore, instantanément, à faire toutes ensemble le même mouvement de la tête qui est brusquement ramenée vers la face ventrale après avoir été rejetée en arrière; mais il semble, malgré la simultanéité de leurs mouvements, qu'elles agissent inconsciemment, car elles sont à chaque fois, comme brusquement surprises, n'écartent pas leurs mandibules et ne produisent ni grattage, ni bruit.

J'examine ensuite le tissage du cocon, le sac noir contenu dans l'intestin, le rejet de ce sac à la fin de la vie larvaire, l'éclosion de l'imago, le premier repas de l'imago.

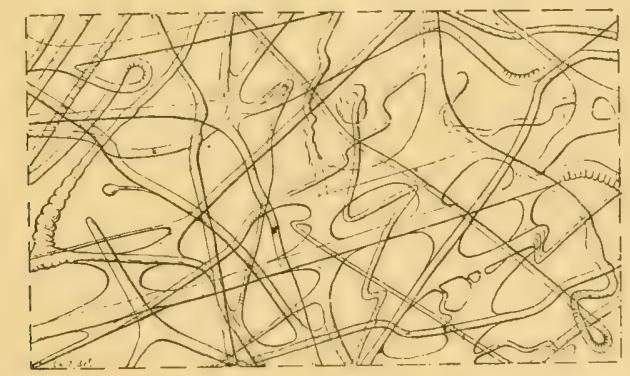

Fig. $7 \overrightarrow{7}$ - Giross. j0. Fragment du sommet de lopercule enlevé at moment où cc sommet commence à se fermer.

P. W. J. Müller dit que la nouvel-éclose rentre dans son alvéole pour le nettoyer el le mettre en état de recevoir un nouvel ouf. Brehm voit la " un exemple de sentiment de l'or- 
dre et de la propreté qui n'est pas l'effet de l'éducation, mais qui est bien véritablement inné ». Malheureusement cela n'est pas exact. Jamais un imago venant d'éclore ne proce̊de au nettoyage de l'alvéole quil vient de quitter.

Les r'estes de l'opercule sont enlevés soigneusement, non pas par la nouvel-éclose, mais par les autres ouvrières qui consacrent un temps assez long à ce travail. Souvent j'ai vu la mère travailler, comme ses ouvrières, à l'enlèvement des restes de l'opercule, immédiatement après une éclosion.

En dehors des débris de l'opercule, il n'est rien enlevé de l'alvéole.

La masse gluante, brune, sortie de l'intestin postérieur et contenant les excreta larvaires des tubes de Malpighi, forme un vernis adhérent au fond de l'alvéole.
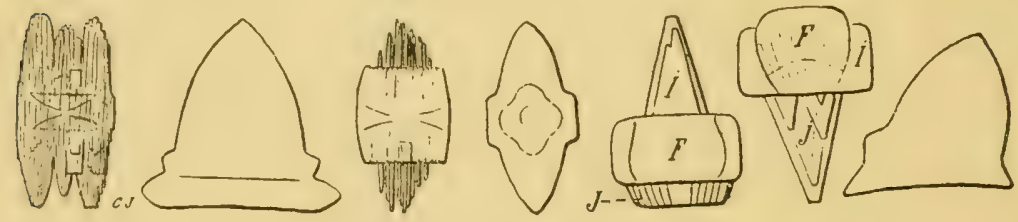

Fig. 78. - Cristaux obtenus par l'action le l'acide acétique sur les excréments clairs et limpides comme de l'oau des imagos tout à fait adultes.

La masse noire, sortie de l'estomac de la larve, au commencement de la nymphose, s'est monlée sur le fond de l'alvéole où elle reste collée tonte desséchée et durcie. Sa surface libre a pris une forme concave et constitue le fond de la partie désormais utilisable de l'alvéole qui retrouvera, bientôt, par un accroissement de longueur de ses côtés, ce que cette masse noire, assez volumineuse, lui a fait perdre en prolondeur.

Les paragraphes suivants ont trait à : Premiers travaux des nouvel-écloses; repos dans un alvéole; nourrissage des larves; fondation de nouveaux alvéoles; premières sorties; excreta larvaires; excréments larvaires; excreta nymphaux; excréments des imagos. 
Si l'on examine attentivement le contenu d'un alvéole dont vient de sortir un imago, on y trouve :

I $^{0}$ Des exuvies rejetées par la larve et restées adhérentes au fond de l'alvéole.

$2^{0}$ Une petite couche brune, brillante, produit de la dessiccation d'une matière visqueuse provenant de l'intestin postérieur, qui est alor's sans communication avec le reste du tube digestif. L'examen microscopique de cette couche y fait reconnaître des cristaux et des substances verdâtres, identiques à ce que l'on trouve dans les tubes de Malpighi de la larve vivante. Cette masse contient, ainsi, des produits d'excrétion de la vie larvaire, probablement mèlés à des produits des glandes rectales.

3o Une couche de soie formant le fond du cocon.

$4^{\circ}$ Les résidus chitineux de la totalité des boulettes alimentaires reçues pendant la vie larvaire. Ces résidus s'accumulent dans une sorte de sac formé de cuticules fournies par l'intestin moyen, lequel, pendant toute la durée de la vie larvaire, est sans communication avec l'intestin postérieur. Ce sac est libre de toute adhérence, sauf à sa partie supérieure, où il se rétrécit en un goulot soudé avec l'extrémité de l'intestin antérieur. Peu de temps après que la larve a terminé son cocon, cette attache se rompt et le sac est expulsé, avec son contenu, par l'intestin postérieur qui est, maintenant, en communication avec l'intestin moyen. Le sac se replie sur luimême et la larve le tasse tout au fond de son cocon.

$5^{0}$ Les exuvies de la nymphe, exuvies qui tombent parfois, mais peuvent aussi rester au fond de l'alvéole.

Si l'alvéole sert au développement de deux ou même de trois Frelons, on y retrouve deux, ou dans le dernier cas, trois fois tout ce que je viens d'énumérer.

Nous venons de voir que des produits d'excrétion, et la totalité des excréments de la vie larvaire, se retrouvent dans 
les alvéoles. Pendant la vie nymphale, l'animal ne prenant plus de nourriture, il n'y a plus de résidus de digestion, mais d'aboudants produits d'excrétion s'accumulent dans son intestin. Ces excreta sont rejetés par l'imago, peu de temps après sa sortie du cocon. Pour cette opération, le Frelon, accroché au moyen de ses grilles, le dos en bas, à la face inférieure du dernier gâteau, fait subir à son abdomen un mouvement d'extension très prononcé, à la suite duquel son extrémité anale se trouve dirigée vers le sol, bien exactement au-dessus de l'orifice du nid. Grìce à cette posilion, les excreta émis tombent par terre, hor's du nid, sans souiller les enveloppes.

Cies excreta consistent en gouttelettes d'un liquide blanc, laiteux, accompagné d'une douzaine de petits corpuscules blanes, opaques, cylindriques, légèrement recourbés, de I à $2 \mathrm{~mm}$. de longueur. Ces corpuscules, entourés d'une cuticule chitineuse, fournie par l'intestin postérieur, sont formés en grande partie d'urates.

Le pliage des ailes présente quelques particularités intéressantes. On sait que les Guêpes sont caractérisées par la plicature des ailes supérieures pendant le repos. André (Species des Hyménoptères, p. 4r 4) dit " Le but de cette disposition spéciale n’a pas encore été découvert. ))

La raison d'être de cette plicature et le mécanisme qui la produit (les ailes ne sont pas pliées au moment de l'éclosion) ressortent de ce qui suit : Lorsque, pour aller sur la face supérieure du gâteau alvéolaire, la mère passe entre le bord de ce gâteau et l'enveloppe, la partie supérieure des premiers arceaux dorsaux de l'abdomen subit, de la part de l'enveloppe, à cause de l'étroitesse du passage, un frottement considérable. Les deux mères des deux nids que j'ai observés avaient, de bonne heure, du fait de ce frottement, la partie médiane des arceaux dorsaux de deux anneaux (Se 6 et Se z) 
notablement usée. Cette usure était surtout bien marqquée près du bord libre de l'arceau Se $6 d$, sur deux petites surfaces situées un peu à droite et à gauche du plan médian.

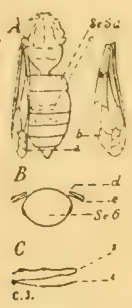

Fig. 79. - U'sure de la région dorsale de l'abdomen d'une reine. Le plissement des ailes supérieures met leur bord mince à l'abri de l'usure; $A, S$ e $5 d$, arceau dorsal du 5 e anneau postcéphalique ; $c$, une des quatre surfaces fortement usées sur les 6 e et $7 c$ anneaux; $b$, aile antérieure droite détachée el dépliée; $a$, aile antérieure gauche en place et pliée. Réd, 1/2; $B$, schémi d'une coupe transversale passant par l'anneau $S e 6$; l'aile supérieure pliée en $d$, est unie en $e$ a l'aile inférieure par les crochets de cette dernière; $C$, gross. 2, schéma de la coupe transversale des ailes gauches; $s$, aile supérieure; $i$, aile inférieure. $A$ gauche l'aile inférieure est unie par ses crochets avec l'aile supérieure.

Les ailes supérieures sont, au repos, pliées longitudinalement, suivant un pli sensiblement rectiligne, sans rapport avec les nervures (fig. 79). La moitié postérieure ou anale de l'aile est ramenée sous la moitié antérieure ou costale. Il en résulte qu'à l'endroit où l'aile a sa plus grande largeur, cette largeur se trouve réduite exactement à sa moitié.

Cette disposition présente une grande importance pour la conservation des ailes. Si, en ellet, au lieu de se plier, elles restaient étalées, leur partie la plus mince et la plus délicate reposerait sur le dos de l'abdomen, précisément aux endroits signalés ci-dessus où l'usure est le plus accentuée.

Si l'on examine une ouvrière, immédiatement après sa sortie du cocon, on constate que ses ailes supérieures ne sont pas pliées en deux. Elles arrivent non-seulement au contact l'une de l'autre, sur le dos, mais, même, elles empiètent, l'une sur l'autre, de I millimètre environ, recouvrant précisément les parties du dos de l'abdomen les plus exposées au frottement. Si l'on excite quelque peu cette ouvrière, par 
exemple en soufllant légèrement sur elle, on la voit battre des ailes supérieures qui, par suite de la rapidité de leur mouvement, deviennent peu visibles, tandis que les ailes inférieures, tout à fait découvertes et immobiles, reslent bien visibles.

Bientôt la Guêpe cesse ce mouvement et ramène ses ailes supérieures à leur position de repos. Au moment où le bord mince d'une de ces ailes passe sur le bord épais de l'aile inférieure correspondante, elles s'accrochent l'une à l'autre, et alor's deux cas peuvent se présenter. Dans le premier, l'aile supérieure ne se plie pas encore en son milieu, mais reste plane. L'aile inférieure est alor's entraînée et vient se placer, juste au-dessus du milieu du dos, occupant ainsi une position anormale. C'est souvent ainsi que les choses se passent, aи moins d'un côté de l'animal, la première fois qu'il est excité à battre des ailes. Lorsque le jeune Frelon bat de nouveau des ailes, l'int’érieure reste accrochée à la supérieure et, entraînée par le mouvement de cette dernière, elle devient cette fois, elle aussi, peu visible. Assez fréquemment, les deux ailes restent acrrochées d'un côté, tandis qu'elles ne le sont pas encore de l'autre; l'aile inférieure de ce dernier côté reste alors, toute seule sur les quatre, entièrement immobile.

Au bout d'un certain temps, au moment où les ailes se mettent au repos, l'aile supérieure, tout en restant solidement accrochée à l'aile inférieure, ne l'entraîne plus au-delà de sa position normale de repos. Cette dernière s'arrête, au contraire, dans cette position, et c'est l'aile supérieure qui serait obligée de rester beaucoup en dehor's de sa position normale si, tout à coup, elle ne se pliait en deux, ce qui lui permet de venir, sans quitter l'aile inférieure, se placer exactement au-dessus d'elle (fig. 79). 
Il résulte de ce qui précède qu'il suflit d'enlever, à un Frelon, venant d'éclore, une aile inférieure, pour empècher l'aile supérieure correspondante de se plier.
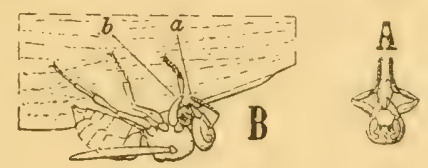

Fig. 80, - Réd. 1/2. A, la tèle et les palles antérieures d'un Frelon suspendu à la face inférieure du gaileau alvéolaire par ses deux paires de pattes postérieures et occupé à malnxer le thorax d'une Abeille; B, Frelon posésur la tranche de l'enveloppe de son nid et occupé à y ajouter une bande de carton; $a b$, angle décrit par les mandibules pour faire reculer la boulette de pâte.

Les paragraphes suivants ont pour titre : Observations sur la manière dont le Frelon prend son vol; nourriture des imagos et des larves; boulettes de pàtée alimentaire; animaux capturés; dépeçage des Insectes; distribution de la pâtée; boulettes préparées arec des larves ou des nymphes déchiquetées: sève des arbres employée comme nourriture; nourrissage par dégorgement de nourriture liquide; liquide nutritif ou salivaire dégorgé par les larves.

Lorsqu'on touche, légèrement, la tète d'une grosse larve, on la voit écarter ses mandibules, se rejeter en arrière, comme pour laisser, entre sa bonche et la paroi alvéolaire, la place nécessaire pour loger une boulette alimentaire, et, en même temps, elle dégorge une gouttelette d'un liquide limpide.

Une semblable gouttelette est dégorgée chaque fois qu'une ouvrière se présente avec une boulette alimentaire, et, dès que la part destincé à la larve a été appliquée devant sa bouche, on voit la gouttelette liquide s'étaler sur toute la surface de la portion de pâtée nutritive. Son principal usage paraît ètre, ainsi, d'humecter et de délayer les substances alimentaires contenues dans les boulettes nutritives.

Une semblable gouttelette est, encore, dégorgée lorsqu'une ouvrière vient mordiller la tête d'une larve. Si la gouttelette 
r'este sans emploi, elle est réingurgitée par la larve : on la voit diminuer rapidement et disparaitre totalement. Mais l'ouvrière qui, par l'attouchement de ses mandibules, a provoqué la sortie de la gouttelette, sait aussi s'en emparer et la faire passer dans son propre jabot.

On conçoit l'importance que ce fait peut avoir pour la bonne répartition des vivres dans la colonie. Des liquides nutritits sont ainsi tenus disponibles, non seulement chez les i.nagos, mais aussi chez les larves. Les larves destinées it devenir des ouvrières contribuent peut-être ainsi, avec les imagos, it l'élaboration de liquides nutritil's ou digestil's utilisés pour la nourriture des larves destinées à devenir des reines.

Lorsqu'un imago vient de quitter son cocon, une de ses premières opérations, opération qui est même souvent tout à lait la première et que je lui ai vu faire, parfois, deux on trois secondes après sa sortie du cocon, consiste à donner de petits coups de mandibules sur la tête de l'une des premières grosses larves qu'il rencontre et à boire la gouttelette liquide que cette dernière dégorge. J'ai pu voir cela plusieurs fois à la loupe, lor's d'éclosions ayant lieu sous mes yeux. J'ai, dans ces conditions, vu nettement la gouttelette sourdre de la bouche de la larve et l'imago l'absorber avidement pour passer ensuite successivement aux "larves voisines qui lui fournissent chacune uue gouttelette semblable. Une dizaine de larves peuvent être miscs ainsi à contribution pour ce premier repas. La nouveléclose circule ensuite sur le nid, se nettoie à plusieurs reprises ct étend ses ailes.

Les mâles savent aussi demander et boire ces mêmes gouttelettes émises par les larves. Lorsque, à la fin de septembre, je démolis l'enveloppe de l'un de mes nids, je mets à découvert sur tout le pourtour du gâteau, des larves si grosses qu'elles font saillie de près d'un centimètre hors de leurs alvéoles. 
C'est sur ces larves, faciles à examiner de très près, et dont rien ne vient masquer la partie antérieure du corps, que je vois le plus facilement les màles boire le liquide dégorgé. Comme les mâles sont alors très nombreux dans le nid, il y en a toujours une dizaine qui sont occupés à visiter les alvéoles et j'en vois, assez souvent, qui passent sur toute la rangée des grosses larves bien découvertes du pourtour du premier gàteau. Les mâles mordillent la tête et la partie antérieure du corps de chaque larve. Tantôt, c'est le cas des plus grosses, peu éloignées du moment où elles fileront leur cocon, elles ne dégorgent aucune gouttelette, et le mâle passe aussitòt à la larve voisine; tantôt, au contraire, on voit apparaître une gouttel̄ette de liquide que le mâle absorbe avidement.

Comme les Fourmis, les Frelons rejettent les résidus de leur nourriture et le produit du nettoyage de leur corps, sous forme de corpuscules enroulés, de la carité supralabiale.

lls prennent, pour se reposer, des positions caractéristiques.

J'ai eu l'occasion d'observer dans mes nids de Frelons des sortes de rixes très bizarres.

Les premières de ces rixes ont eu lieu vers le I septembre, entre la reine et une ouvrière. Les deux individus avaient une position du corps analogue à celle que je décris plus loin, pour le cas de deux ouvrières, mais de plus ils se mordaient les pattes, et l'ouvrière dardait son aiguillon comme pour blesser la reine. Au contraire, dans les rixes entre deux ouvrières, ces dernières ne font que se mordiller réciproquement les mandibules, ne dardent pas leur aiguillon et sortent indemnes du combat.

C'est surtout après la mort de la reine que les rixes sont devenues fréquentes.

Le If septembre, à une heure, au moment où j'enlève la. 
mère mourante pour suivre son agonie, il y a cinq couples d'ouvrières qui sont ainsi aux prises et ces rixes continuent, sans interruption, toute l'après-midi.

Les deux ouvrières sont placées dans un même plan, la face ventrale de l'une tournée vers la face ventrale de l'antre. Les abdomens sont fléchis, de sorte que le corps de chacun des deux individus est courbé en demi-cercle, et l'ensemble des deux corps forme, à peu près, un cerele complet. Chacune des deux ouvrières est accrochée au nid par une-seule de ses pattes de la troisième paire. Le cercle formé par les deux ouvrières est placé horizontalement, et les deux pattes accrochées au nid figurent deux fils de suspension diamétralement opposés. L'abdomen de l'une des ouvrières semble menacer sans cesse la région ventrale de l'autre, et les dix pattes disponibles s'agitent mêlées les unes dans les autres. Mais ce sont les mandibules qui montrent les mouvements les plus énergiques. Ces mouvements rappellent ceux d'une ouvrière qui vient demander à manger à une de ses compagnes, mais ils sont bien plus violents et, une fois commencés, durent extrêmement longtemps, sans s'arrêter un seul instant. Les deux Frelons se mordillent mutuellement les mandibules, sans, cependant, se faire de mal. Les deux corps, ainsi suspendus, oscillent sans cesse pendant cette rixe; mais autour d'eux les autres ouvrières vaquent à leurs travaux. J'ai observé, pendant 35 minutes, deux ouvrières qui étaient ainsi aux prises. Elles ont, pendant tout ce temps, conservé leur position et n'ont pas cessé une seconde de se mordiller. A un moment donné, les griffes de l'une des pattes ont perdu prise, et, pendant une minute, sans qu'il y ait eu pour cela la moindre interruption dans le mordillage, la couple est restée suspendue, en tout, par une seule patte de l'un des individus, jusqu'au moment où la patte de suspension de l'autre a fini par rencontrer une bordure d'alvéole où elle 
a pu s'accrocher. An bout de 35 minutes, une ouvrière qui passe près d'elles dégorge une gouttelette de liquide devant les têtes des combattants et le mordillage cesse aussitôt. L'un des individus absorbe la gouttelette, l'autre s'éloigne avec empressement, et c'est ainsi que la rixe prend fin.

Les ouvrières d'un certain âge, mais cependant encore bien actives au travail, cessent à peu près complètement de fonder de nouveaux alvéoles, tandis que les plus jeunes ouvrières s'adonnent, avec ardeur, à celte occupation. Dès le lendemain de leur éclosion, ces dernières savent aller enlever, sur le bord de l'enveloppe, de la pâte molle qu'une ouvrière âgée vient de poser, la malaxer à nouveau et l'employer à la londation de nouveaux alvéoles.

Un tableau servant à établir qu'il n'y a guère de division du travail dans les colonies de Frelons, indiquent quelles étaient les occupations de cinq ouvrières lors de 30 observations faites, à raison de 3 par jour, pour chacune d'elles, pendant ro jours consécutifs, du $\mathrm{I}^{\mathrm{er}}$ au ro aoùt.

La mort normale des Frelons est précédée d'une longue agonie.

Le I I septembre, la reine de l'un de mes nids est aux prises avec une de ses ouvrières. Le if septembre, je trouve cette mère mourante et je l'enlève pour suivre son agonie. Les mouvements cessent d'abord dans les antennes et les pièces buccales, puis, successivement, dans les trois paires de pattes. Plusieurs heures après la complète cessation des mouvements de tous ces appendices, l'abdomen se meut encore, et darde son aiguillon lorsqu'on saisit l'animal. Ce n'est qu'au bout de trente-trois heures que ces derniers mouvements ont cessé à leur tour.

Un paragraphe donne le résultat de mes observations sur la durée de l'état d'œuf, de l'état larvaire, de l'état nymphal et sur le sort final des colonies. 
Les piqûres des Guèpes et, surtout, celles des Frelons peuvent être fort dangereuses et même mortelles. Je donne pour ces motit's quelques indications sur la façon dont il faut procéder pour capturer les nids.

L'anesthésie et, surtout, l'asphyxie, sont évidemment des méthodes recommandables lorsqu'on veut psocéder, purement et simplement, à la destruction des nids.

Pour des études d'Histoire naturelle, on peut être amené à opérer sur des nids dont les habitants sont en pleine activité et à l'état normal, et, pour cela, choisir, par une belle journée, les premières hcures de l'après-midi.

Dans ces conditions, il est de toute nécessité de se mettre, d'une façon absolue, à l'abri des piqùres. De Réaumur, qui a capturé tant de nids de Guêpes, dit bien qu'il n'est guère possible de les éviter complètement; que, malgré la précaution que l'on prend de s'envelopper, les millier's de Guèpes qui vous entourent finissent toujours par trouver un point insuffisamment protégé et que les gants de chamois les plus épais sont traversés par les aiguillons; mais je sais, par expérience, et je puis aflirmer, qu’en opérant avec les précautions que j’indique en détail, on ne sera jamais piqué.

Au moment où, par une belle et chaude journée, on attaque ainsi un nid bien peuplé, des millier's de Guêpes se précipitent à la fois sur le masque et sur les gants. Sur le masque e'est, pendant quelques minutes, un fort bruit de grêle produit par le choc violent des assaillants. Sur les gants un grand nombre de Guêpes sont retenues par leur aiguillon qu'elles ont enfoncé si profondément qu'elles ne peuvent plus le retirer, et l'on voit alors un spectacle assez surprenant. Les Guêpes ainsi retenues font, avec leurs pattes et avec leurs ailes, des eflorts inouïs pour se dégager, et leur abdomen s'allonge dans des proportions extraordinaires. 


\section{$-z-$}

Enfin la traction est si forte que toute la partie terminale du corps se rompt. Le réservoir du venin, puis tonte la glande vénénifique sortent peu à peu du corps. Les Guèpes volent sur place pendant quelques secondes ainsi retenues aux gants par un long boyáu de près de 2 centimètres. La fine pointe de la glande, et les ramifications trachéennes qui la retiennent encore, finissent, cependant, par se rompre, et les Guêpes, ainsi mutilées, prennent leur essor et disparaissent.

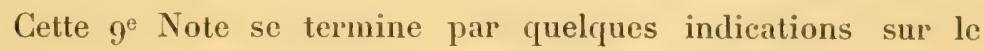
maniement des Frelons mis en observation, sur les époques où on les rencontre, sur leur habitat et sur quelques-uns des animaux qne l'on rencontre auprès d'eux.

\section{1}

\section{Sur les Nids de la Vespa crabro L.; Ordre d'apparition des Alvéoles.}

\section{2}

Etudes sur les Fourmis, les Guêpes et les Abeilles. Note 10. Sur Vespa media, V. silvestris, V. saxonica.

Dans cette Note, je reprends, sur les Guêpes du groupe de Vespa media, e'est-à-dire à nids aériens, l'étude faite sur les Frelons et j'y examine successivement :

La fabrication du papier du nid;

Les excreta de la vie nymphale;

Les nids et leurs emplacements;

Les alvéoles des màles;

Des exemples de familles réduites à des mâles. 


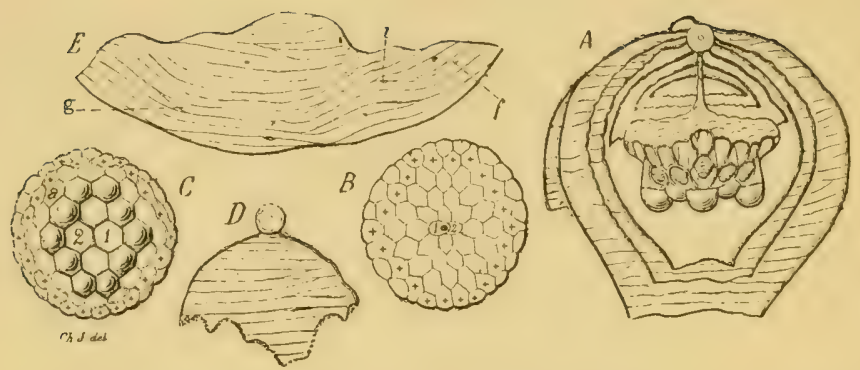

Fig. 81.- V. Media. Nid 4. Réd. 1/2. A, ensemble du nid dessinè après l'enlèvement de la moitiè de loutes les enveloppes; $B$, le gâteau alvéolaire vu par sa face supérieure; $C$, le gîteau alvéslaire vu par sa face inférieure; $D$, La $3^{e}$ enveloppe déjì fortement déchiquetée; $E$, Commencement d'une je enveloppe décollée sans aucune déchirure.

Lettres communes aux figures 81 et 82 .

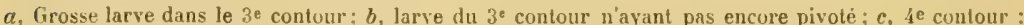
sur les figures $\mathrm{B}$ et $\mathrm{C}$, les 22 alvéoles qui forment ce $4^{\circ}$ contour sont marqués d'une petite croix ; $d$, alvéoles restint à construire pour compléter le 5e contour; $e$, les 14 alvéoles déjà construils du $5^{\text {e }}$ contour; $f$, bande colorée en gris très foncé sur la $7^{e}$ enveloppe; $g$, bande tout a fait blanche sur la $7^{\text {e }}$ enveloppe; $i$, petites lacunes formant trous dans les enveloppes ; $m$, alvéole qui sera operculé le $1^{\text {er }}$ dans le $3^{\mathrm{e}}$ contour; 1 ì 1 , figure nucléale formée des 4 premiers alvéoles ; 5 à 9 , alvéoles ayant fourni les $5^{e}$ it ge éclosions.

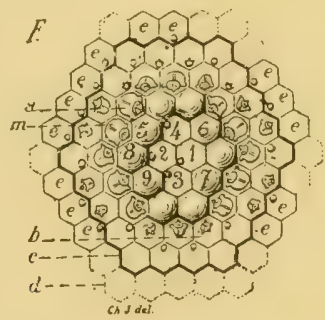

Fig. 82. - Schéma du nid 4 représenlé par la figure précédente, donnant son degré d'avancement au moment de la capture.

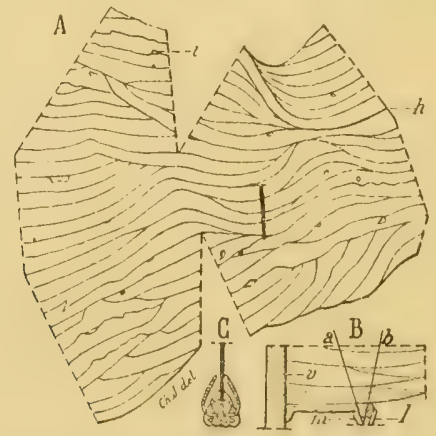

Fïg. 83. - $V$. media. Nid 4. Réd, 1/2. 4 , la moilié de la 6 e enveloppe étalée et représentéc nvec toutes ses bandes d'accroissements successifs; ; $B$, emploi d'une boulette de pâte (les mandibules et le libhium sont représentés schématiquement en $m \in t$ l) (gr. nat.); $C$, la tête de la Guèpe pendant celte opération (gr. nat.); $h$, limite inlérieure de la $6^{\circ}$ enveloppe it un stade où elle aval une forme analogue a lit forme actuelte de la $j e$ enveloppe (liq. $1, E$ ); $i$, petites lacunes formant des trous dans les crivelopper. 


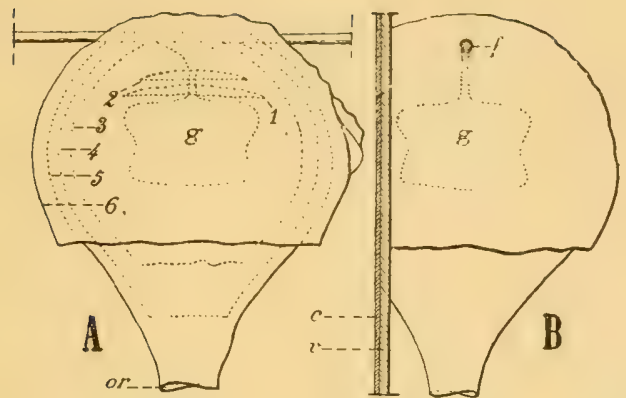

Fïg. 84. - V. media. Nid 5. Réd. 1/2. A, ensemble du nid; $B$, le nid avec ses enveloppes sectionnées sur le cỏté de manière à présenter une ouverture permettant de voir dans l'intérieur. Cetle ouverture est appliquée contre un verre à vitre $v$ recouvert d'une feuille de carton $c$ mobile; 1 à 6 , les 6 enveloppes; or, orifice dı nid; $g$, gàteau alvéolaire; $f$, fil de fer sur lequel le nid a été construit; $v$, verre à vitre recouvrant l'ouverture découpée sur le cóté des enveloppes; $c$, feuille de carton recouvrant le verre ì vitre.

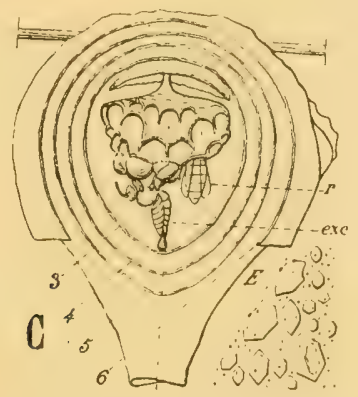

Fig. 85. - Réd, 1/2. l', le nid avec ses enveloppes sectionnées sur le còté (comme l'indique la figure $4, B$ ) vu du còté ouvert et laissant voir le gâteat alvéolaire et deux ourrières; $r$, jeune ouvrière au repos; exc, ouvrière nouvel-éclose Jaissant tomber dans l'axe de l'orifice du nid le liquide laiteux el les corpuscules blancs représentant les excreta accumulés dans le tube digestif pendant la nymphose; $E$, cristaux hexagonaux contenus avec un grand nombre de Bactéries dans les corpuscules blancs des excreta.

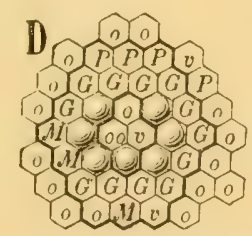

Fig. 86. - V. media. Nid 5. $D$, schéma de l'état du nid au moment de la capture. 

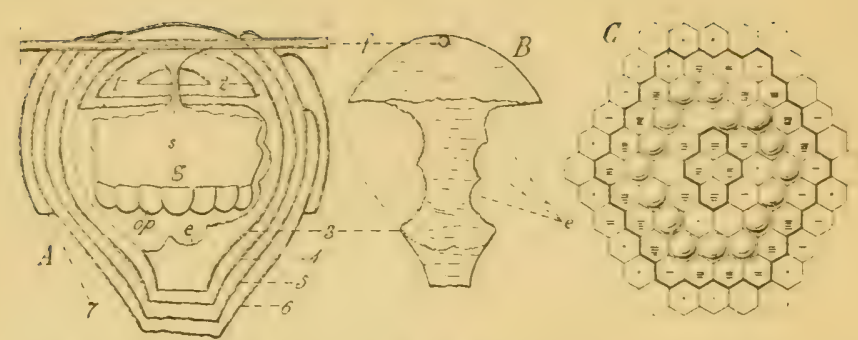

Fig. 87. - V.media. Nid 6. $A$, ensemble du nid, les enveloppes étant coupées suivant le plan médian. Réd. $1 / 2 ; B, 3$ e enveloppe non coupie, clans l'état oil elle se trouvait au moment de la capture. Réd. $1 / 2 ; C$, schéma de l'état du nid au moment de la capture. Le contour de la figure nuclẻale et aussi celui du fe contuur, le dernier complet, sont figurés par des traits renfurcés. Les alvéoles qui restent à construire pour compléter le öe contuur sont tigurés en ponctué. Quelques alvèoles sont vides. Lin point placé au centre de l'alvéole indigue qu'il contient un cuf. Les larves sont indiquées, approximativement, suivant leur taille, par une, deux, trois ou quatre petites barres. Une seule barre indique les larres yui sont à peine plus grosses que les ucufs. Quatre barres indiquent les larres les plus grosses. Les cocons non encore éclos sont igalemen! représentés.

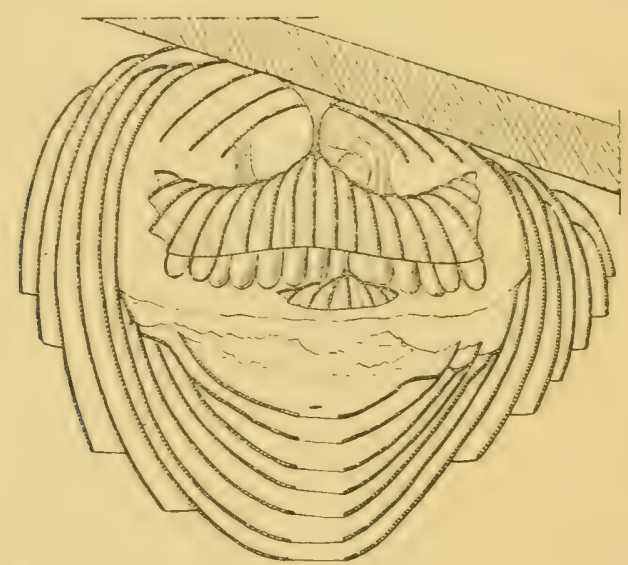

Fig. 88. - 15. silvestris. Nid 7. Réd. \$/2. Coupe par un plan médian.
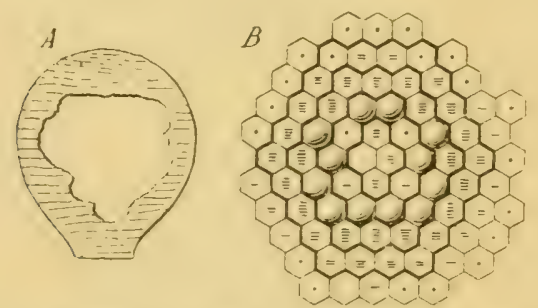

Fig. 89.- V. saxonica, var, norvegica. Nid 8. A, la 30 des 6 enveloppes, déjà rongée sur un còté. liéd. 1,2 . B, schéma de l'ètat du griteau alvéolaire au monent de la capture: un point indique les alvéoles qui contiennent un nuf. De petites barres indiquent les abéoles qui contiennent des larves. Les opercules, également indigués, forment une ligure symilrique parr rapport all grand axe de la ligure nucléate. 


\section{3}

Sur la Vespa crabro. Ponte. Conservation de la Chaleur dans le Nid.

\section{4}

Etudes sur les Fourmis, les Guêpes et les Abeilles. Note 11. Sur Vespa germanica et V. vulgaris.

Après avoir étudié, dans la Note précédente, nos Guêpes indigènes à nids aériens, j'étudie ici celles à nids normalement souterrains, c'est-à-dire les Guêpes du groupe de Vespa germanica. Je donne la description de nids tout à fait naissants, l'ordre d'apparition des alvéoles, la description et la coupe d'un grand nid in situ dans la terre et, enfin, sur la construction des nids et les mœurs des espèces du groupe, des détails correspondants à ceux des deux Notes précédentes.

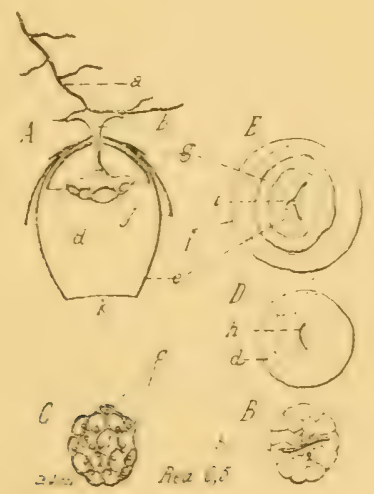

Fig. 90. - V. germanica, Nid 9 (16 alvéoles), Réi. 0,5. 1, coupe longitudinale par un plan médian (la lame de suspension et le gâteau alréolaire ne sont pas coupés); $B$, gaiteau alvêlaire vu par-dessus; $C$, gaitenu alvéolaire vu par-dessous; $D$, première enveloppe vue par-dessus; $E$, ensemble des Ze, je el fe envelopjes vu par-dessus; $a$, radicelle juise comme surface datlache; h. lame de suspension; $1.2,3$, premier, deuxième et troisiène alvéoles; $c$, les deux derniers alveoles construits; $d$, première enveloppe; $e$, deuxième enveloppe entourant completement le nid; $f$, troisième enveloppe; $g$, quatrieme enveloppe; $h, i$, orifices pour le passarge de la lame de suspension; $j$, gâteau alvéulaire; $k$, ouverture du nid. 


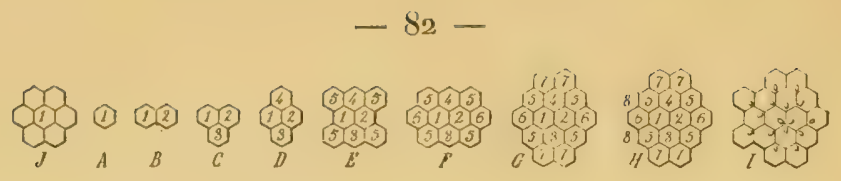

Fig. 21. - V.germanica. Nid 9. $A$ ì $H$, ordre d'apparition des alvéoles; $A$ à $C$, les trois premiers alvéoles; $D$, figure nucléale formée par les 4 premiers alvéoles ; $G$, stade du ge contour ; $I I$, état du nid au moment de la capture; $I$, situation des ceufs indiquant l'angle dans lequel l'alvéole a pris naissance; $J$, figure symétrique autour du premier alvéole. Celte figure ne se rẻalise grénéralement pas ; $l, 2,3,1$, premier, deuxième, troisiẻme et quatrième alvéoles formant par leur ensemble la figure nucléale; 5, 6, 7, groupes d'alvéoles apparaissant successivement et rétablissant, dès que chaque groupe est complet, la symétrie par rapport au grand axe de la figure nucléale.

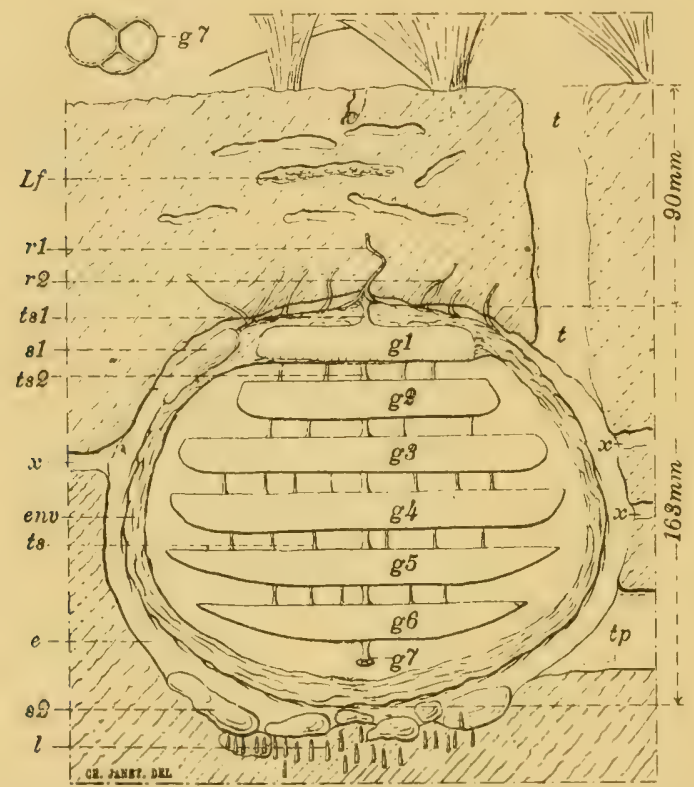

Iig. 92. - V. germenica. Nid 10, coupe par un plan médian. Réd, $0,25: t$, galerie d'accès; $t p$, trou de laupe; $x$, petiles grileries latérales; $e$, vide autour de l'enveloppe; $L f$, nid de Lasius flavus immédiatement all-dessus du nid de Vespa; $l$, nombreuses larves (Pegomya (Acanthiptera) inanis Fill. ?) placces verlicalement dans la terre au-dessous du nid; s1, caillou pris dans l'enveloppe: $s \otimes$, cailloux du déblai, descendus au fond de la cavité: $m$, racine ò laquelle est attachée la lame de suspension primitive du nid; $r 2$, autres racines auxquelles le nid a été successivement altaché ; $g 1$ à $g 6$, six griteaux alvéolaires; $g \tau$, gâteau naissant ne comprenant encore que la lame de suspension et J'amorce de 3 alvéoles; $: 1 s 1$, lame de suspension primitive du premier taiteatu ; $t s 2$, lame de suspension primitive du deuxième gàlean ; $t s$, tiges de suspension secondaires; en haut, i gratuche; $y^{7}$, vil par dessous, grossi 1 fois $1 / 2$.

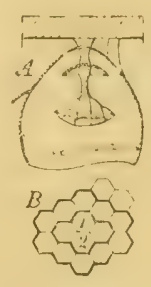

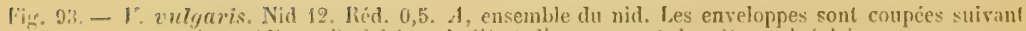
im plan médian; $b$, Schéna de l'élal d'avancement du tgâteau alvéolaire. 


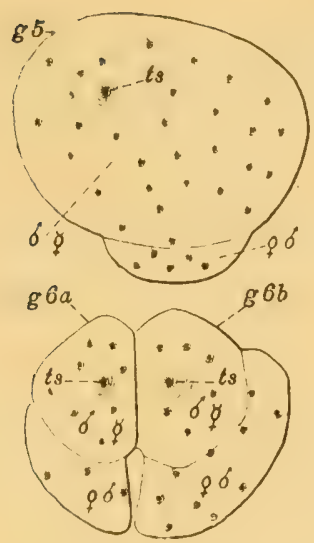

Fig. 94. $-V$. vulgaris, Nid 13. Réd. 1:8. $g 5$, cinquième gâteau vu par-dessus; $g 6 a, g 6 b$, deux gâteaux construits séparément puis soudés; $t s$, tiges de suspension surmontant les cònes iniliaux. Les parties formées de petits alvéoles contiennent des uuvrières et des màles; les parties formées de frands alvéoles contiennent des reines et des måles; les points noirs représentent les tiges de suspension secondaires.

\section{5 \\ Observations sur les Frelons.}

\section{6 \\ Sur les Muscles des Fourmis, des Guêpes et des Abeilles.}

\section{7}

Etudes sur les Fourmis, les Guêpes et les Abeilles. Note 12. Structure des Membres articulaires, des Tendons et des Muscles des Fourmis, des Guêpes et des Abeilles.

Dans la première partie de cette Note j'étudie, au moyen de coupes minces, la structure intime des membranes articulaires qui relient les anneaux fortement chitinisés du squelette (fig. 95), puis je donne quelques détails sur une catégorie particulière de membranes articulaires ì surface chagrinée (fig. $9^{6}$ ). 


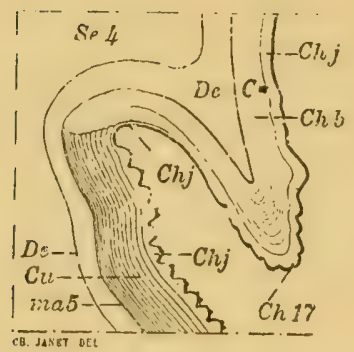

Hig. 95. - Gross. 400. Myrmica rubra. Coupe de la membrane articulaire du corselet et du petiole. Se 4, anneau médiaire; $C / h$ 17, crète saillante de la partie inféro-ventrale du corselel; $m a 5$, membrane articulaire; De, hypoderme; $C u$, cuticule chitineuse; $C h b$, zone chitineuse incolore; $C h j$, zone chilineuse colorée en jaune. (Voir note 7 , fig. 1, dans l'angle supérieur de droite).
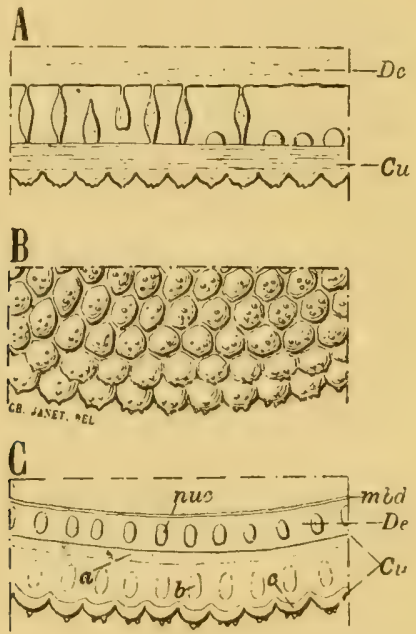

Fig. 26. - Gross. 400. Myrmica rubra. A, fragment de la membrane articulaire du corselet et du pétiole, dessiné d'après une coupe analogue à celle représentée note 7, p. 187, fig. 2 . Par suite de l'action des réaclil's la cuticule chitineuse $C u$ s'est détachée de l'hypoderme De et l'on voit, dans l'intervalle, des fuseaux, probablement de nature nerveuse, qui ont été arrachés au droit de chaque mamelon; $B$, portion, vue de face, de la membrane articulaire mamelonnée, analogue à la précédente, située entre la lête et le prothorax; $C$, fragment de la membrane articulaire de la lète et du prothorax, coupée transversalement; mbd, membrane basale; nuc, noyaux do l'hypoderme; $C u$, cuticule chitineuse dans laquelle on distingue une zone interne $a$, une zone moyenne avec parties sombres $b$, et une zone externe $c$ mamelonnée, fortement chitinisée.

Ce sont des membranes qui prennent fréquemment des positions dans lesquelles elles ne sont plus protégées par les parties fortement chitinisées des anneaux voisins, et qui, pour ce motif, sont pourvues, à leur surface, de mamelons protecteurs ayant une structure tout à fait spéciale. Enfin, un paragraphe 
est consacré aux dispositifs ayant pour effet de limiter l'amplitude de mouvements qui, s’ils étaient exagérés, pourraient produire la rupture des membranes articulaires (articulation du pétiole).

Dans une deuxième partie, je décris la composition des muscles et la façon dont les fibres qui les composent s'insèrent sur le squelette chitineux (fig. 9J).

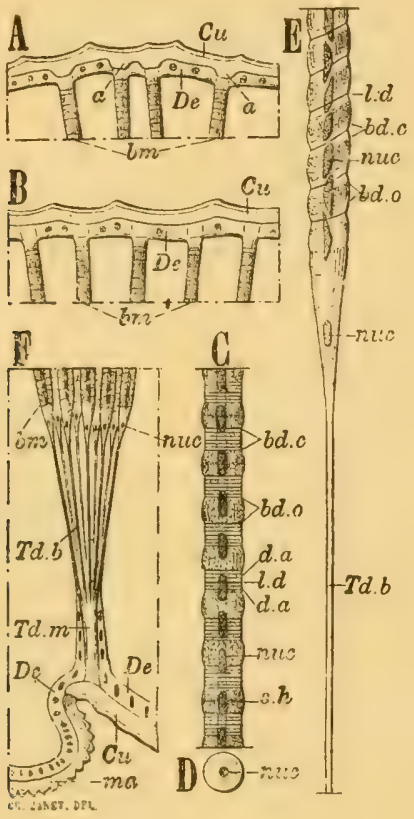

Fig. 97. - Nyrmica rubra. A, B, F, gr. $200 ;$ C, D, E, gr. 400. A, B, insertions, sur la cuticule chitineuse du squelette tégumentaire, de fibres musculaires divergentes; $C$, fragment d'une fitre musculaire fixée et colorée; $D$, coupe transversale d'une fibre musculaire, vue à un faible grossissement; $E$, tendon d'une fibre musculaire; $F$, tendon d'un muscle. Explication des lethes communes nux figures $97,98,101,102: a$, tubercule faisant saillie a la face interne de la cuticule, au droit de l'insertion d'une fibre musculaire; bm, fibre musculaire; bule, bande claire; bdo, bande obscure; $C u$, cuticule chitineuse dı squelelle tégumentaire; $D e$, bypoderme; $d a$, disques accessoires; $\mathrm{l} l$, ligne de Dobie correspondant ì un étage de filaments rayonnants; $m a$, membrane arliculaire à surlace chagrinée; $n u c$, noyaux musculaires; sh, strie de Hansen, souvent absente; Tilb, tendon d'une fibre musculaire; Tdm, tendon d'un muscle; Sarc, sarcolemme; $N$, nerf; $T$, trachée. 


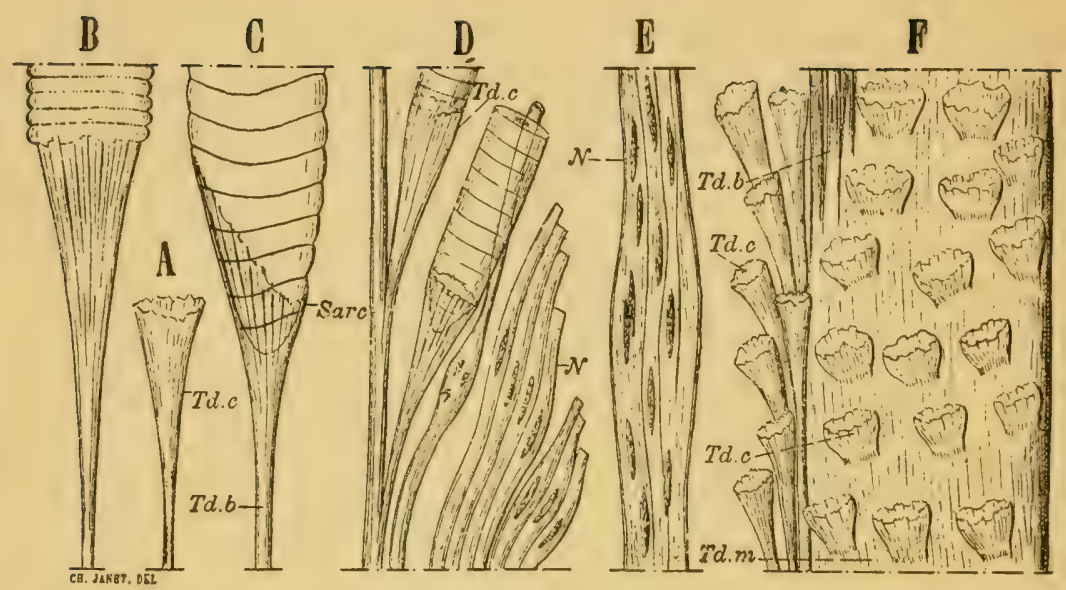

Fig. 98. - Vespa crabro, ouvrière, fixée par la chaleur et l'alcool quelques heures après son éclosion. Muscle adducteur des mandibules : A à E, gross. 425; F, gross. 212. A, cupule terminale du tendon dune fibre; $B, C$, union de filores avec leur tendon; $D$, branche du tendon dun muscle émettant, sur ses côtés, des tendons de fibres. Celle branche est accompagnée de nontlreuses ramifications nerveuses; $E$, fragment du nerf qui fournit les ramifications de la fig. $D$; $F$, frogment du tendon du muscle adducteur des mandibules. On voit, ì gauche, des cupules terminales de tendons de fibres; ì droite, sur le corps du tendon, des cupules sessiles, dont chacune forme l'attache d'une fibre. Les fibres musculaires n'ont pas été représentées pour ne pas surcharger la figure.

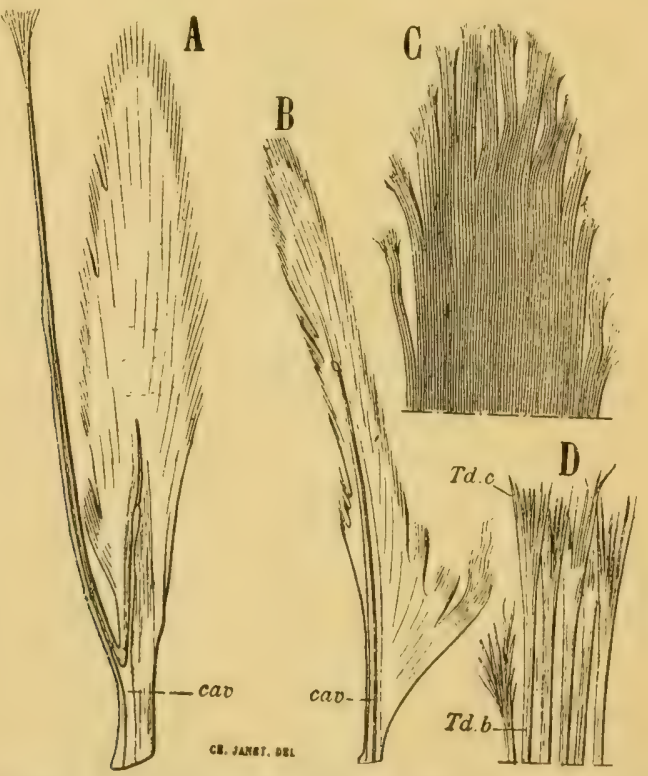

Fig. 99. - Apis mellifica, ouvriẻre. Tendons des muscles moteurs des mandibules. A, gross, 125. tendon de l'adducteur se divisant en une branche principale et une branche secondaire; $B$, gross. 125, tendon de l'abducteur; $C$, gross. 250 , extrémité d'un tendon; $D$, gross. 500, groupe de tendons de fibres de l'extrémité de l'abducteur; cav, vide axial des tendons; Talb, tendons des fibres; Tde, cornets terminaux dissociés. 
Les tendons ont été l'objet de préparations nombreuses. Chaque fibre musculaire est reçue, à l'une de ses extrémités, dans une cupule chitineuse, en forme de cornet qui termine une longue tigelle. A leur base, toutes ces tigelles se r’éunissent et forment le tendon proprement dit. Pour les fibres des muscles adducteurs des mandibules, un grand nombre de ces cupules d'insertion sont sessiles.

La cavité axiale, plus ou moins réduite, que l'on peut reconnaìtre dans ces tendons, et l'enveloppe hypodermique qui les entoure témoignent de leur mode de formation par invagination du tégument.
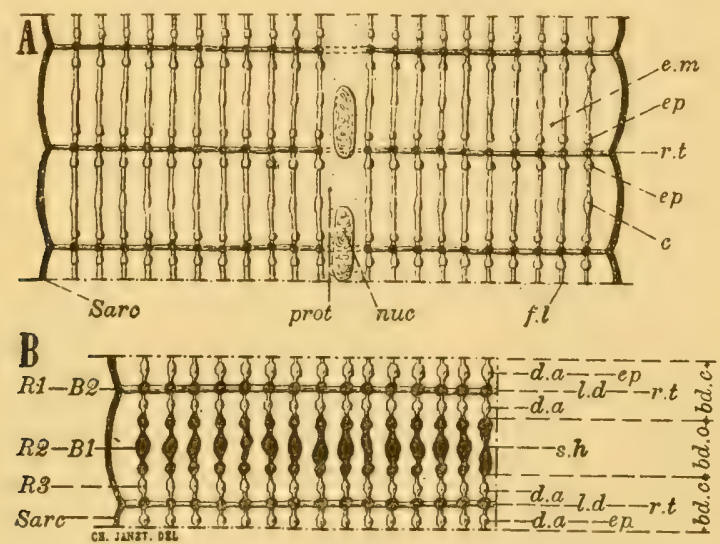

Fig. 100. - Schéma de la structure intime de la fibre musculaire d'un Insecte (Voir van Gehuchten): 1 , Tronson de fibre à l'état naturel : Sarc, sarcolemme; $f l$, filaments longitudinaux ; $r t$, risenu transversal produisant en coupe optique la ligne de Dobie $\left(l . d_{\text {. }}\right)$; ep, épaississements des filarnents longitudinaux, voisins du résenu transversal et correspondant ì ce que l'on appelle disques accessoires $(d a)$; $c$, épaississements exceptionnels de la partie movenne des trabécules longitudiniles]; em, enchylème; nuc, novaux multiples de la fibre musculaire; prot. protoplasma entourant le: noyaux; $B$, tronson après traitement par leaul chaude, l'alcool et l'hématoxyline : brlo, bande obscure: bilc, bande claire; sh, strie de Hansen, souvent plus foncce, parfois plus claire que les parties voisines; $R l, R 2, R 3$, réseaux de 1 er, de $2^{\text {e }}$ et de $3^{\text {a }}$ ordre de Retzius; $B 1, B 2$, reseaux de 1 er et de 2e ordre de Bremer.

Dans une troisième partie, je décris, au moyen de nombreuses préparations (Vespa, Camponotus, XYlocopa, Apis) la structure intime de la fibre musculaire striée. De même que van Gehuchten l'a reconnu chez d'autres Insectes, je constate que les disques alternativement sombres et clairs de la fibre 
vivante, ou alternativement peu colorés et fortement colorés des préparations, sont dus, dans le premier cas, ì un effet optique et, dans le second, à l'action coagulante des réactifs.

En r'éalité, ainsi que le démontrent les nombreuses préparations représentées par les fig. ior à ro5̆, la structure intime de la fibre musculaire striée des Hyménoptères peut être résumée comme suit :

Chaque fibre doit être considérée comme étant une cellule à nombreux noyaux. Le sarcolemme représente la membrane cellulaire; il forme un tube résistant et extrêmement élastique qui est gonflé par une substance de remplissage.

Cette substance de remplissage, semi-fluide, hyaline, homogène, riche en myosine, fortement biréfringente, remplit une fonction nutritive pour les filaments rayonnants et longitudinaux qui sont plongés dans sa masse et qui constituent la partie structurée de la fibre.
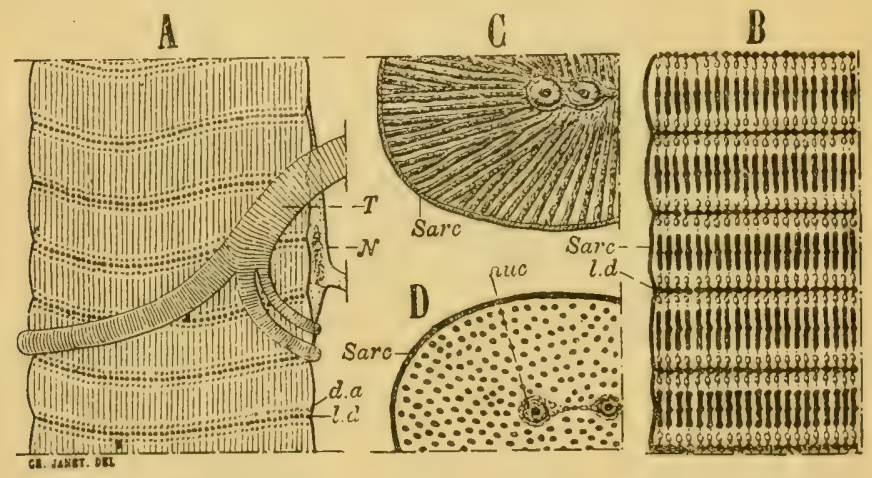

Fíg. 101. - Vespa crabro, onvière, fixét par lit cbaleur el laalcool quelques licures ilprès son

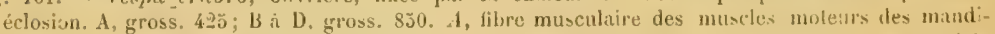
bules, tratéc pendant dix minules par la polasse à 1 p. c.; $B$, fibre du meme muscle, non traitée par la potasse, colorée à thémaloxyline; $C$, vue, à plat, diun disque, la mise au point étaut fitite au niveau dun etage de filaments ravonnants; $D$, vue, à plat, d'un discuc, la mise au point fitant faite an niveau des hatonnets.

Les filaments longitudinaux sont continus, disposés r’égulièrement les uns à côté des autres, parallèlement à l'axe de li fibre. Sous l'influence de l'excitation nerveuse, ils se contractent localement sur eux-mêmes, rapprochent les unes des 
autres les surfaces carrespondant aux lignes de Dobie et compriment la substance de remplissage qui gonlle latéralement le sarcolemme. Il en résulte une onde de contraction qui progresse en s'éloignant du point qui a r'eçu l'excitation et attire violemment ver's elle les filaments de la région qu'elle va atteindre.

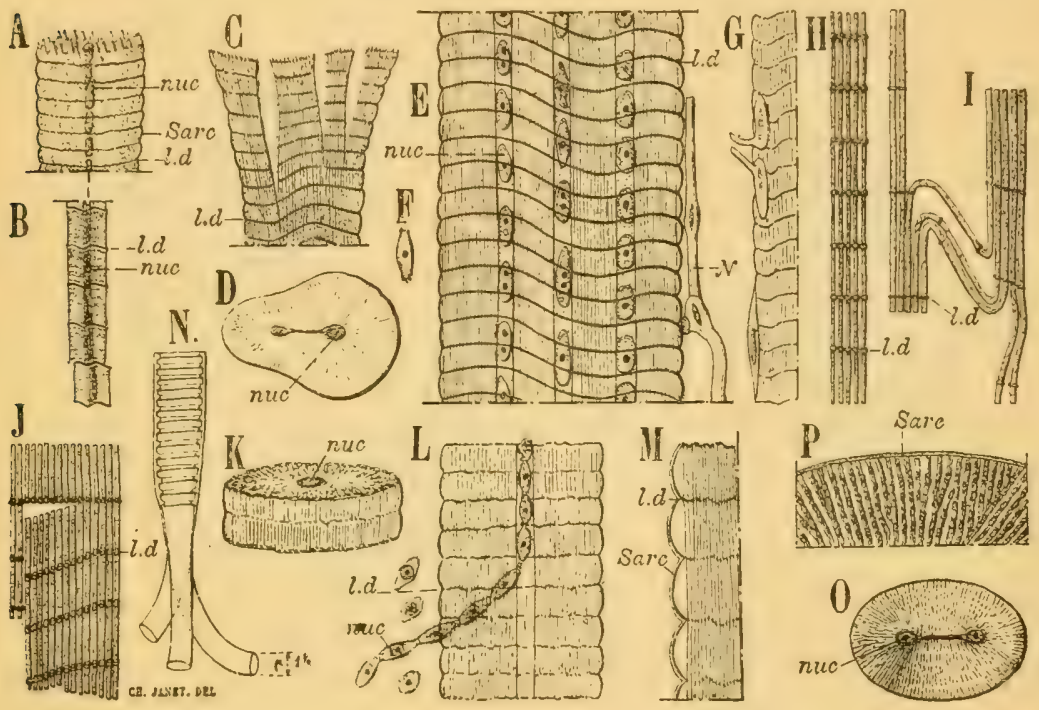

Fig. 102. - Vespa crabro, ouvrière, peu après son éclosion; fixation par la chaleur, durcissement par l'alcool, coloration par l'hématoxyline : I, N, I', gross. 1700 fois; H, J, M, gross. 8 ŏn fois ; les autres figures gross. 423 fois. $A$ à $C$, muscles moteurs du scape de l'antenne; $D$ à $P$, muscles moteurs de la 3 e cuisse; $A$ et $B$, les deux extrémilés, à des états de contraction bien ditférents, d'une mème fibre. D'un côté les stries transversales sont rapprochées, de l'autre elles sont très écartées; $C$, cassure écrasée d'un brin présentant un aspect fibreux par suite de la rupture des filments rayonnants et de la dissociation des filaments longitudinaux; $D$, disque musculaire, à deux files do noyaux, vu à plat; $E$, brin musculaire à trois files de noyaux; $F$, un noyau accompagné de protoplasma coagulé, sorti d'une cassure du brin musculaire précédent; $G$, terminaisons nerveuses, très rapprochées les unes des autres, sur un mẻme brin musculaire; $\boldsymbol{H}$, filaments longiludinaux régulièrement recouverts de substance coagulée, et formant, dans toute la massc cle la filore, des filaments continus; $I$, filaments fortement dissociés; $J$, filaments longitudinaux montrant le commencement dune des ruptares transversales qui isolent des disques; $h$, vte oblique d'un disque obtenu par dissociation, d'un brin ả section circulaire à une file axiale de noyaux. Ce fragment comprend trois étages de filaments rayonnants; $L$, brin musculaire à une file de noyaux. A la partie inférieure les noyaux sont sortis par une fente longitudinale de la tibre et sont restés reliés en châne; $\boldsymbol{M}$, bordure d'un brin musculaire dans lequel il y a un espace clatir assez large entre le sarcolemme et les bitonnets; $\boldsymbol{N}$, passage de la partie annelée des trachées aux capillaires à cuticule lisse; $\boldsymbol{O}$, disque elliptique provenant d'une fibre à deux files de noyaux et montrant un étage de filaments rayonnants; $P$, frugment très fortement grossi du bord dun thisque vu à plat. 
Les filaments rayonnants sont étagés suivant des surfaces régulièrement espacées (réseau transversal, van Gehuchten) dont la tranche, sur les fibres vues de côté, correspond à la ligne de Dobie. Ces filaments rayonnants vont s'attacher au sarcolemme et produisent sur lui une traction qui est antagoniste des pressions exercées par la substance de remplissage et qui se traduit fréquemment, sur la surface extérieure de la fibre,

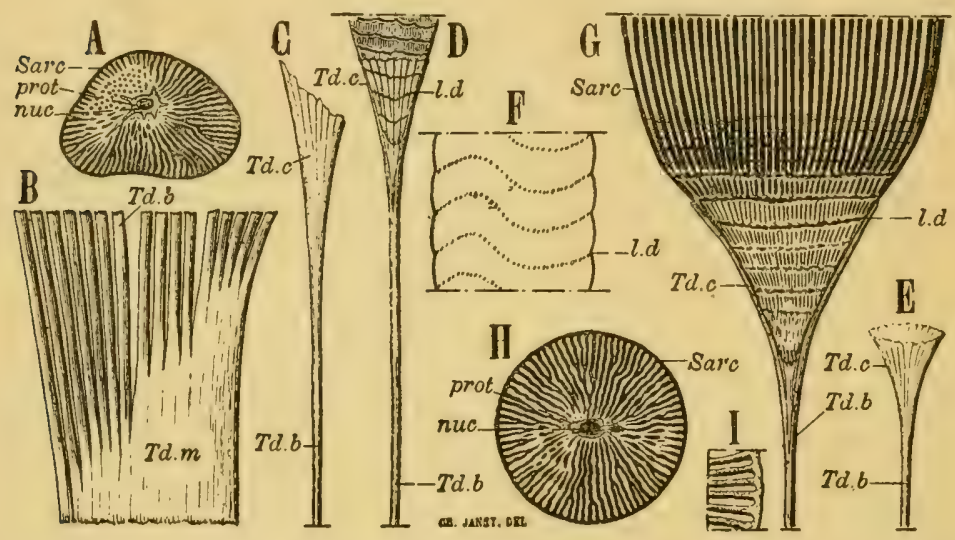

Fig. 103. - Cimponotus ligniperdus, ouvrièc à grosse tète, muscle adducteur des mandibules. Gross. 500: A, fibre fixée, in situ dans l'animal, par l'eau chaude et l'alcool. Un disque isolé, vu ì plat, montrant un réseau transversal et, en une place, des filaments longitudinaux vus en bout; $B$ ì $F$, muscle traité par la potasse a $1 \mathrm{p}$. c. pendant $10 \mathrm{~m}$; $B$, fragment du grand tendon; $C, D, E$, cornets terminaux des tendons des fibres; $F$, fragment de fibre ne laissant voir que son sarcolemme et les granulations des réseaux transversaux; $G \dot{r}$ à fibres traitées par l'eau chaude, l'alcool et I'hematoxyline, in situ dans J'animal; $G$, Onde de contraction au contact du comet terminal du tendon. Sauf nu voisinage immédiat de ce dernier, la striation transversale est devenue tout a fait invisible, tandis quion voit une striation longitudinale très netle; $/ 1$, Disque circulaire, vu à plat: 1 , fragment, plus grossi (Gross. 1000), de la Jordure d'un disque. Nuc, noyaux de la fibre; Tilm. tendon du muscle; Tdh, tendons des fibres; Tdc, cornets terminaux; Sare, sarcolemme; prot, protoplasma; $\mid \boldsymbol{l}$, ligne de Dobie.

par des sillons annulaires. Ces filaments rayonnants, formés d'une substance extrêmement élastique, relient entre eux et maintiennent les filaments longitudinaux. Ils leur transmettent l'excitation nerveuse et les ramènent à leur place lorsque, après s'être contractés au passage d'une onde, ils ont repris la longueur qui correspond à leur état de repos. 


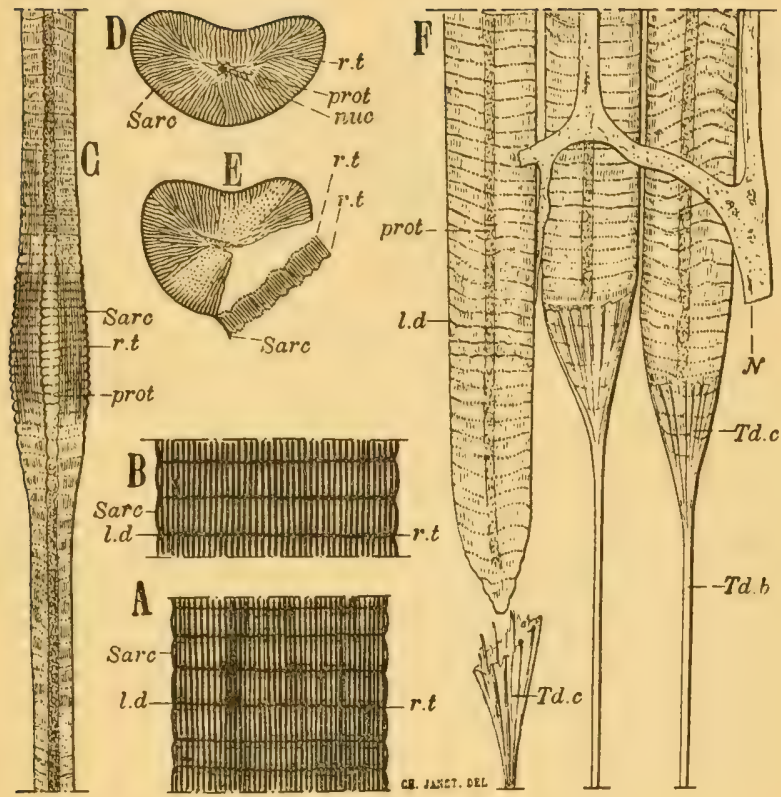

Fig. 104. - A et B, Yylocopa violacea, femelle, fixée par l'alcool. Gross. 500. Fragments de muscles montrant les filiments longitudinaux régulièrement épaissis par suite de la coagulation ; C, gross. 250. Apis mellifica, sur le point d'éclore, fixée par la chaleur et l'alcool, non colorée. Une fibre présentant une onde de contraction. Les noyaux de la fibre ne sont pas nettement distincts, mais la colonne protoplasmique dans laquelle ils sont logés et qui est dilatée au droit de l'onde, présente, là, un étranglement bien net au niveau de chaque étage de filaments rayonnants; $D$ ì $F$, Apis mellifica, àgée. Gross. 500. Muscle mandibulaire, traité in situ par l'eau chaude, l'alcool et l'hématoxyline; $D$, un disque vu ì plat; $E$, un disque dont une partie rompue se montre par la tranche et dans lequel, sur une bande diamétrale, les filaments longitudinaux Bont vus en bout; $F$, trois fibres dans le voisinage de leurs tendons. Liune d'elles est sortie de son cornet d attache; Srre, sarcolemme; $l d$, ligne de Dobie; $r t$, réseau transversil ; prot, colonno protoplasmique renfermant les noyaux; nuc, noyau; $T d b$, tendons de fibres; $T d l$, cornets terminaux; $N$, nerf musculaire. 


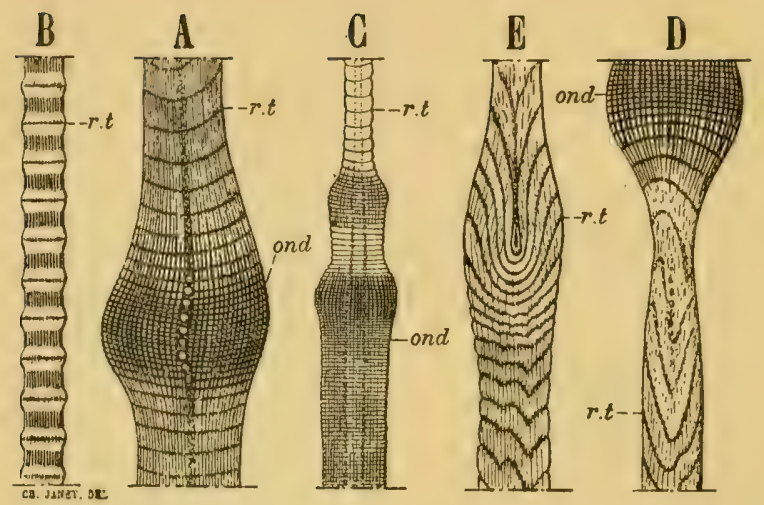

lïg. 103. - Vespa crabro, reine âgée, fixée à la fin de son agonie par l'eau chaude et l'alconl. Muscle mandibulaire. Fibres présentant, malgré la cessation de tout mouvenent apparent de lianimal, de nombreuses ondes de contraction; C gross. 125, les autres figures gross. 250. $A$, onde très courte ; $b$, une fibre extremement étirée par suite de l'existence, en d'autres points de son parcours, de longues ondes de contraction. Par suite de l'étirement, la fibre est cylindrique dans les zones obscures formées par les bâlonnets, et renflée dans les zones claires au milieu desquelles on voit le réseau transversal $r t ; C$, succession de deux ondes contiguës; $D$, une onde progressant de baut en bas et produisant un étirage extremement considérable de la partie vers laquelle elle s'avance; $E$, étirage, analogue à celui de la figure précédente, dans la région vers lacpuelle arrive une onde; rt, réseaux transversaux (Dohie's Linie); ond, ondes au niveau desquelles la fibre prend toujours un aspect de striation longitudinale qui pıut aller jusqu'à faire disparaitre loute apparence de striation transversale.

\section{8}

Les Fourmis. Conférence faite le 28 février 1896, à l'occasion de la Réunion générale annuelle de la Société Zoologique de France.

Cette conférence donne un résumé de l'état actuel de nos connaissances sur les Fourmis.

Elle contient sur les Poils d'acerochage des jeunes larves, sur l'Origine des nouvelles formilières, sur l'Appareil à venin, sur la réaction alcaline des nids, quelques faits nouveaux que je n'ai pas publiés ailleurs. 


\section{9}

\section{Sur les Rapports des Lépismides myrmécophiles avec les Fourmis.}

Cette Note débute par un examen sommaire des diverses catégories dans lesquelles on peut classer les rapports si variés des animaux myrmécophiles avec les Fourmis.

Les Lépismides sont depuis longtemps cités parmi les animaux myrmécophiles, mais la nature de leurs rapports avec les Fourmis n’a pu être éclaircie jusqu'ici.

Des observations faites dans mes appareils d'élevage mont permis de combler cette lacune.

Les conclusions de ces observations sont les suivantes :

$\mathrm{I}^{\circ}$ Les Lepismina polypoda peuvent bien réellement se passer des Fourmis lorsqu'ils ont à leur disposition une nourriture appropriée.

$2^{\circ}$ Ils sont tolérés dans les fourmilières pour cette boune raison que sachant, par leur agilité, échapper aux Fourmis, ces dernières renoncent généralement à les poursuivre.

3o Ils sont attirés dans les fourmilières par l'appàt du liquide nutritif que les Fourmis emmagasinent dans leur jabot.

$4^{\circ}$ Contrairement à ce qui a lieu dans les cas de myrmécoxénie, les Fourmis ne donnent pas, d'elles-mêmes, ce liqquide aux Lepismina, mais ces derniers savent profiter d'une circonstance favorable pour s'en emparer furtivement (mirmécoclepsie).

Sur le Lepismina polypoda Grassi et sur ses Rapports avec les Fourmis. 


\section{1}

Sur les Filets arqués des Antennes des Xylodiplosis.

Dans cette Note, je cherche à expliquer quel peut être le mode de formation de ces singuliers filets chitineux arqués, qui forment une série de boucles tout autour des antennes de certains Xylodiplosis. 




